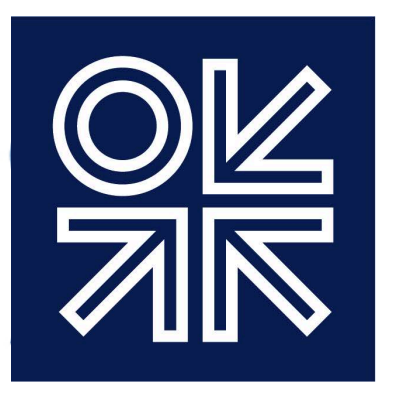

THE OXFORD INSTITUTE FOR ENERGY STUDIES

\title{
Gas Industry Reform and the Evolution of a Competitive Gas Market in Malaysia
}

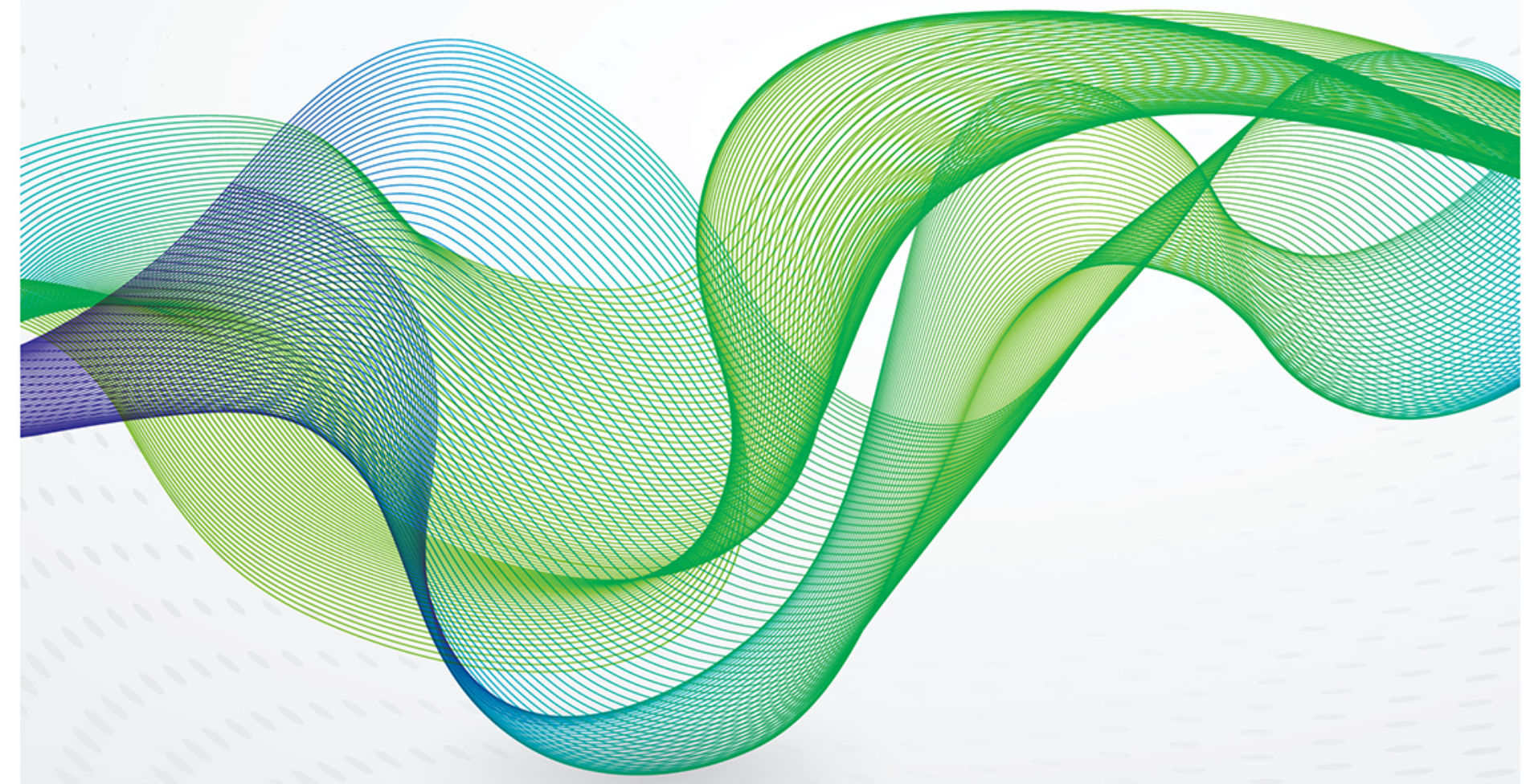


The contents of this paper are the authors' sole responsibility. They do not necessarily represent the views of the Oxford Institute for Energy Studies and the Institute of Energy Policy and Research (IEPRe) or any of their members.

\title{
Copyright $@ 2020$
}

Oxford Institute for Energy Studies (Registered Charity, No. 286084) \& the Institute of Energy Policy and Research (IEPRe) of Universiti Tenaga Nasional (UNITEN)

This publication may be reproduced in part for educational or non-profit purposes without special permission from the copyright holder, provided acknowledgment of the source is made. No use of this publication may be made for resale or for any other commercial purpose whatsoever without prior permission in writing from the Oxford Institute for Energy Studies and the Institute of Energy Policy and Research (IEPRe) of Universiti Tenaga Nasional (UNITEN).

\author{
ISBN 978-1-78467-157-0
}




\section{Acknowledgements}

This paper was written as part of the OIES-UNITEN Fellowship in Malaysian Energy Studies Programme, and the authors would like to thank Universiti Tenaga Nasional (UNITEN) for sponsoring the programme. The programme in collaboration between Oxford Institute of Energy Studies (OIES) and Institute of Energy Policy \& Research (IEPRe) of UNITEN for which this Study entitled "Gas Industry Reform and the Evolution of a Competitive Gas Market in Malaysia" is aimed at examining and evaluating the impact and anticipated time frame of increasing competition and development of spot LNG trade and pricing in the regional (ASEAN) and global gas market on the availability and price in Malaysia. The findings from the study would enable to assess the anticipated rate of Malaysian gas market liberalisation and the form of that liberalisation that shall enable decision strategies between participating in upstream gas development, as opposed to purchasing gas from producers.

The authors would like to thank all the contributors of the project team mentioned below including stakeholders for the unwavering support to complete this study.

The work also benefited greatly from valuable inputs obtained from the stakeholders and project team, hence the authors would also like to express their sincere appreciation and gratitude for their active participation including the invaluable views and remarks they contributed to help complete this study. All views and remaining errors are the responsibility of the authors.

We would like to express our heartfelt thanks to Prof. Dato' Ir. Dr. Kamal Nasharuddin Mustapha, Vice Chancellor, UNITEN, for being instrumental for inception of this study and being a very supportive and passionate patron of the OIES-UNITEN Fellowship in Malaysian Energy Studies Programme.

The authors would like to take the opportunity to express our gratitude to the following professionals and representatives from the related Malaysian Authorities, Government Agencies and Malaysian Industries of whom contributed to the success of this study:

\section{OIES}

Dr. Bassam Fattouh

Prof. Jonathan Stern

\section{UNITEN}

Prof. Dato' Dr. Siti Salbiah Mohamed Shariff (Advisor)

Prof. Ir. Dr. Kumaran Palanisamy (Managing Director, URND)

Dr. Siti Indati Mustapa @ Jaafar (Director, IEPRe)

Prof. Ir. Dr. Tuan Ab Rashid Tuan Abdullah

\section{Authorities, Government Agencies and Industries:}

Ministry of Energy, Science, Technology, Environment \& Climate Change (MESTECC).

Ministry of Economic Affairs (MEA).

Energy Commission (EC), Malaysia.

Performance Management \& Delivery Unit (PEMANDU).

Petrolium Nasional Berhad (PETRONAS).

Federation of Malaysian Manufacturers (FMM).

Petronas Gas Berhad (PGB).

Malaysian Gas Association (MGA).

Gas Malaysia Berhad (GMB). 
SHELL (M) Berhad.

SHELL Eastern Petroleum (Pte) Ltd, Singapore.

Pavilion Gas (Pte) Ltd, Singapore.

Diamond Gas International (Pte) Ltd., Singapore.

Malaysian Iron \& Steel Industry Federation (MISIF).

Malaysian Rubber Glove Manufacturers Association (MARGMA).

Xinyi Glass Holdings Limited.

Frosco (M) Sdn. Bhd.

Sime Darby Bhd.

N.U.R Power Sdn. Bhd.

Strategy and Regulatory Division, Tenaga Nasional Berhad.

TNB Fuel Services Sdn. Bhd.

Single Buyer.

UNITEN Research and Development Sdn. Bhd. (URND).

The Institution of Engineers, Malaysia. 


\section{Contents}

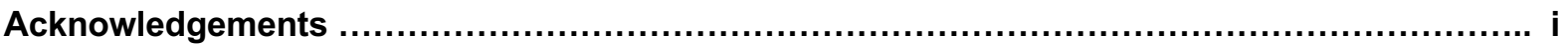

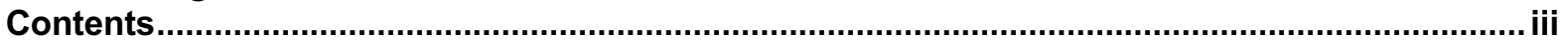

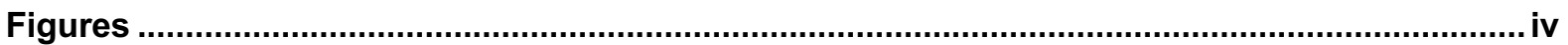

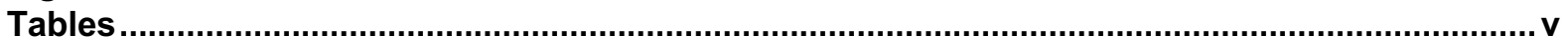

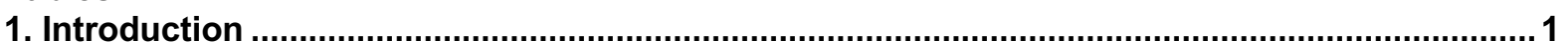

1.1 Background to petroleum industry development in Malaysia and the creation of a legal/regulatory

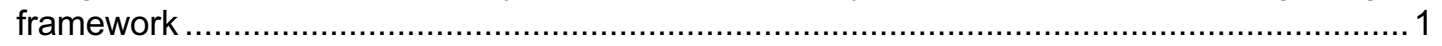

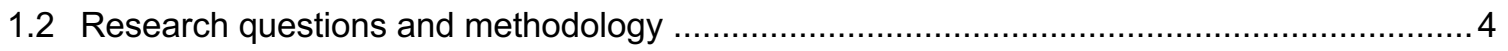

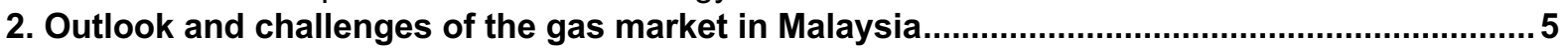

3. Current status of gas liberalisation in Malaysia............................................................... 10

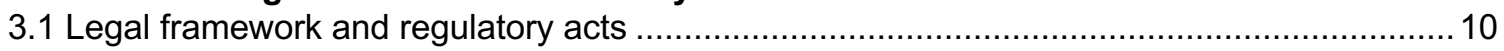

3.2 Institutional structure and regulation of the gas market.................................................... 12

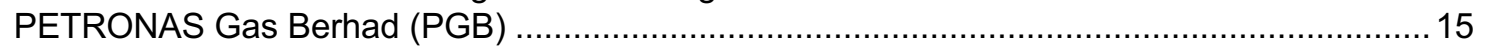

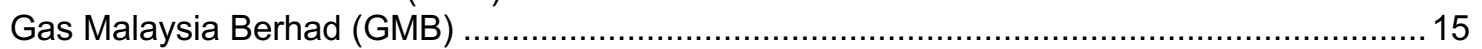

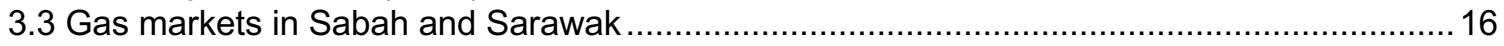

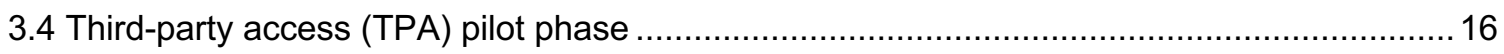

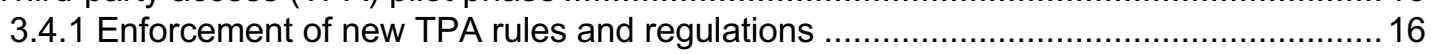

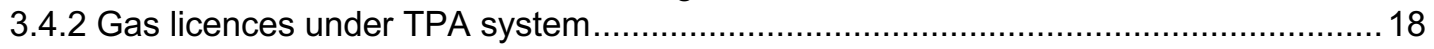

3.4.3 Regulated and unregulated gas prices ............................................................. 19

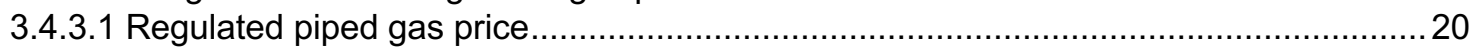

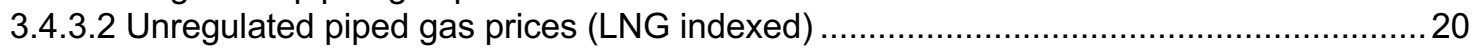

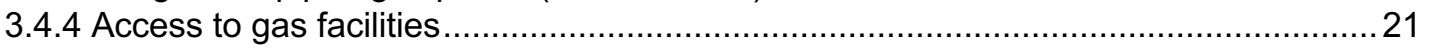

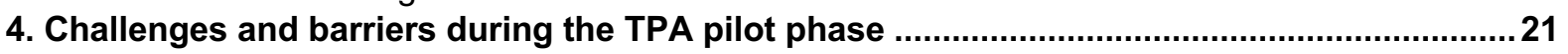

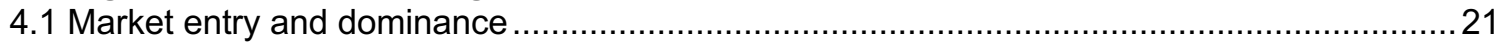

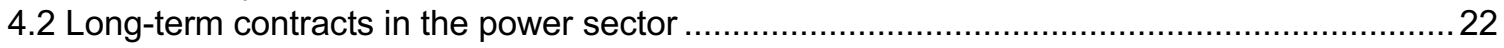

4.3 Continued barriers to third-party access to LNG terminals and transmission pipelines .........24

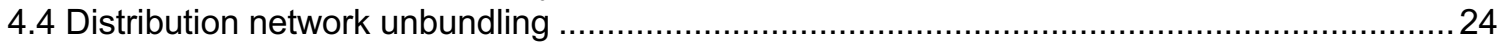

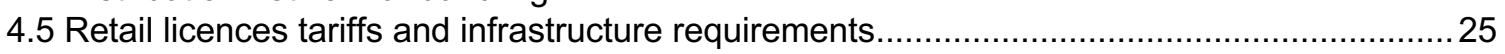

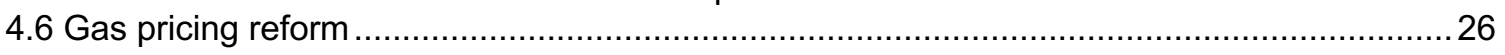

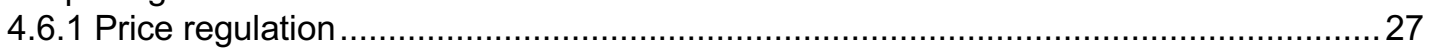

4.6.2 Stages of gas price harmonisation ................................................................. 28

5. The changing global LNG market and potential impact on ASEAN .......................................29

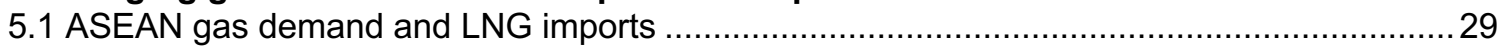

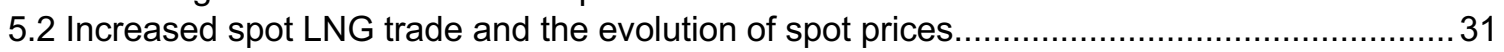

5.3 The potential impact of LNG spot trading and pricing on the Malaysian gas market .................33

6. Ways forward towards gas market liberalisation and competition in Malaysia.......................34

6.1 Increasing demand in the non-power and power markets and releasing gas from long-term

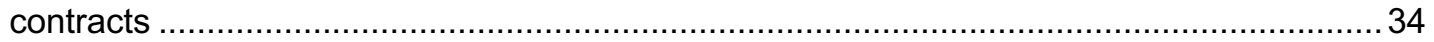

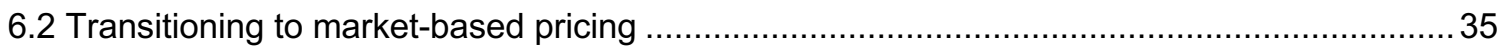

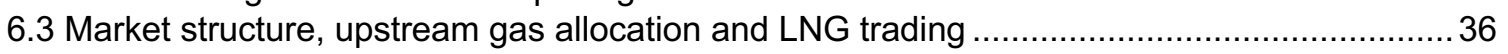

7. Obstacles to the promotion of competition in the gas market ................................................. 36

8. Conclusions: answers to research questions........................................................................... 39

8.1 Prospects for liberalisation and competition in the Peninsular Malaysia gas market ............. 39

8.1.1 Strategy for gas stakeholders in Malaysia ............................................40

8.2 The development of spot LNG trading and pricing and impact on the Malaysian and regional

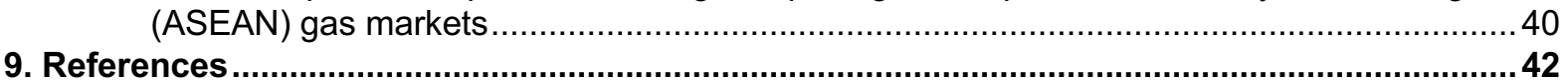

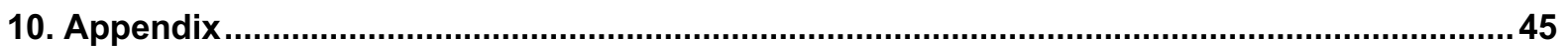

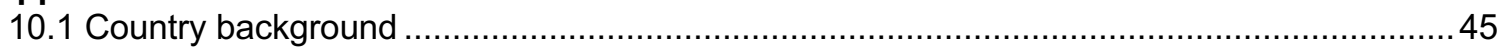

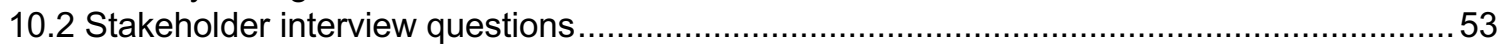

10.3 Definition of independent regulation in European Union .............................................. 55 


\section{Figures}

Map 1: Gas facilities and gas pipeline connectivity in Peninsular Malaysia and ASEAN..................... 4

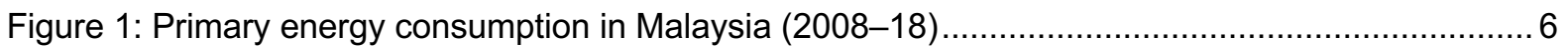

Figure 2: Primary energy consumption by fuel $(2018)$ in Malaysia ................................................ 6

Figure 3: Growth of gas production, consumption, exports and imports (1980-2018) in Malaysia ....... 7

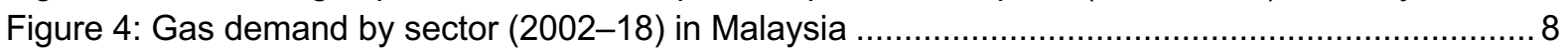

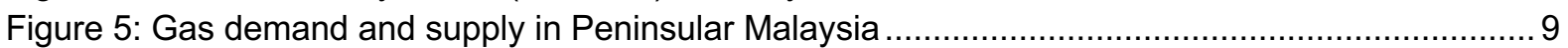

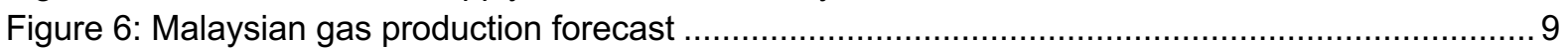

Figure 7: Steps to liberalisation, trading and establishing a liquid gas market.................................. 10

Figure 8: Changes in supply chain through the Gas Supply Act (Amendment) in $2016 \ldots \ldots \ldots \ldots \ldots \ldots \ldots . . . . . .11$

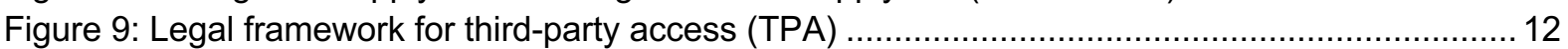

Figure 10: EC and other stakeholder mapping across the natural gas value chain ........................... 13

Figure 11: Industry players and licences under the TPA regulatory framework ............................... 14

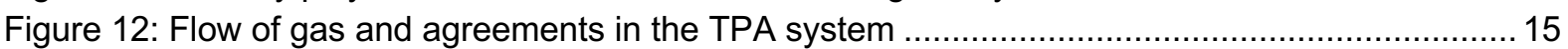

Figure 13: Summary of unbundled subsidiaries from the parent company - PETRONAS and Gas

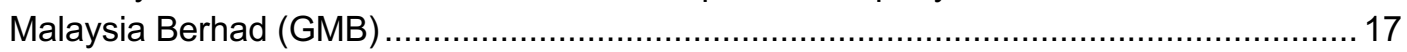

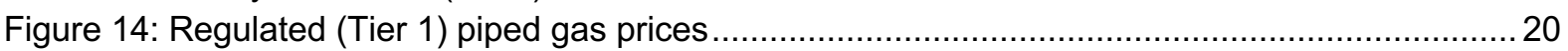

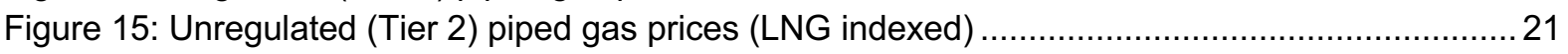

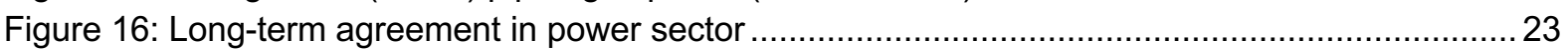

Figure 17: Unregulated and regulated gas price to power sector and GMB .................................2

Figure 18: Liquefaction projects that had taken a final investment decision by the end of $2018 \ldots \ldots \ldots .29$

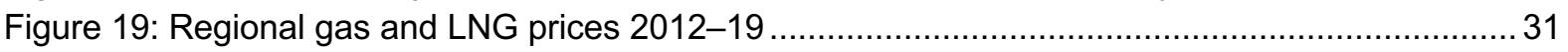

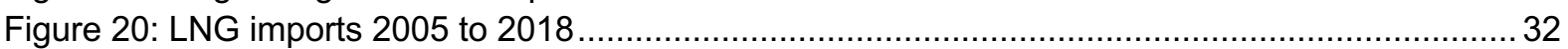

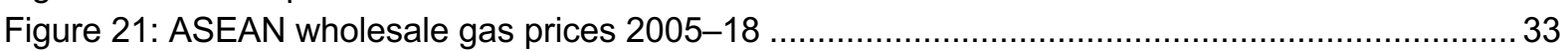

Figure 22: Map of Malaysia: Peninsular Malaysia, Sabah and Sarawak …..................................... 45

Figure 23: Summary of GDP, population and demand distributions .............................................. 46

Figure 24: Natural gas reserves in Peninsular Malaysia, Sabah and Sarawak .................................46

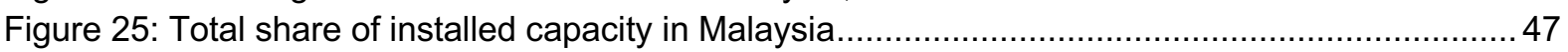

Figure 26: Production and consumption of gas in Malaysia (1980-2018) ........................................ 48

Figure 27: Gas demand growth by sector (1971-2018) in Malaysia............................................... 48

Figure 28: Scope of Gas Supply Act 1993 and Gas Supply (Amendment) Act 2016 ........................52 


\section{Tables}

Table 1: Published tariff for LNG terminals and transmission system in Peninsular Malaysia............. 17

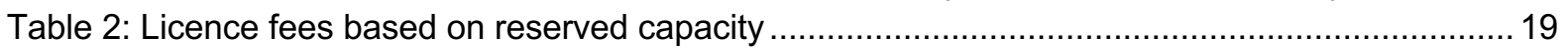

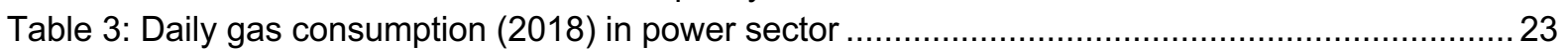

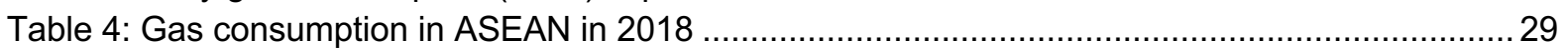

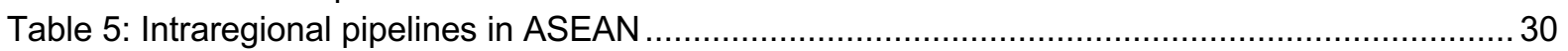

Table 6: Low and high projections of ASEAN LNG imports 2018-30 (Bcm) …............................. 30

Table 7: Final energy consumption by fuel in the manufacturing sector in 2016 (Mtoe)...................... 35

Table 8: Share of TNB, SESB, SEB and IPP installed capacity (MW) in Malaysia.............................47

Table 9: Power sector gas supply agreement (GSA) on gas volume ......................................... 49

Table 10: Average sales volume (2014-18) in non-power by Gas Malaysia Berhad (GMB).............. 49

Table 11: Average daily gas consumption over a year in the power sector ...................................50

Table 12: Regulated piped gas prices to power sector (TNB) and non-power (GMB) (2000-2019) ...51

Table 13: Conversion - natural gas (NG) and liquefied natural gas (LNG) units .............................56 


\section{Introduction}

This is the first of two papers which set out possible futures for the liberalisation and introduction of competition into the gas and electricity markets of Malaysia. This first paper focuses on the natural gas market. It is organised into seven sections: following an overview of the development of the oil and gas industry in Malaysia, Section 2 examines the outlook and challenges for the gas market. Section 3 then looks at the legal framework and status of gas liberalisation during the pilot phase of third party access (TPA), followed by Section 4 on the challenges and barriers of this pilot phase. Section 5 then describes the development of global and ASEAN LNG spot trade and their potential impact on the Malaysian gas market. Section 6 examines possible ways forward for gas market liberalisation and Section 7 highlights seven obstacles to the promotion of competition in the gas market. Section 8 draws some conclusions.

\subsection{Background to petroleum industry development in Malaysia and the creation of a legal/regulatory framework}

Hydrocarbons were first discovered in 1910 in Miri, Sarawak by Shell. The first oil well started with a production of 83 barrels per day (bbl/d), reaching a maximum of $15000 \mathrm{bbl} / \mathrm{d}$ in 1929. By the 1960s, exploration had increased significantly due to the discovery and development of four offshore fields in Sarawak. In 1968, the first concession was awarded to develop gas in offshore Peninsular Malaysia for supply to that market. In the 1970s, the prospects were further boosted by the discovery of offshore fields on the east coast of Peninsular Malaysia and Sabah.

\section{Petroleum Development Act 1974}

Before 1974, the oil and gas industry in Malaysia was governed by the Petroleum Mining Act 1966 (Act 95) and it adopted the concession system to explore and produce petroleum resources in return for royalties and taxes. Shell and Esso dominated upstream production, downstream refining and sales. Many other foreign companies such as Conoco, Mobil, Aquitaine, Oceanic and Teiseki were also given exploration licences by state governments through concession agreements.

The development of the oil industry as a significant activity in the country led to the enactment of the Petroleum Development Act in July 1974 and formation of the Petroleum Nasional Berhad (PETRONAS) in October 1974. This Act regulated the oil, gas and petrochemical industries and vested in PETRONAS the formulation of policies for effective control and development of onshore or offshore petroleum and related industries (MEA 1981).

'Petroleum Development Act 1974 is an Act to provide for exploration and exploitation of petroleum whether onshore or offshore by a Corporation in which will be vested the entire ownership in and the exclusive rights, powers, liberties and privileges in respect of the said petroleum, and to control the carrying on of downstream activities and development relating to petroleum and its products; to provide for the establishment of a Corporation under the Companies Act 1965 [Act 125] or under the law relating to the incorporation of companies and for the powers of that Corporation; and to provide for matters connected therewith or incidental thereto.'

Under this Act, ownership of and the exclusive rights, powers, liberties and privileges in respect of the said petroleum, and control of downstream activities and development relating to oil and its products, were vested in PETRONAS. PETRONAS is entitled to carry out the business of processing, refining of petroleum or manufacturing of petrochemical products from oil unless permission is given to any other entity by the government. All upstream activities such as exploration, development and production of resources, are carried out through production sharing contracts (PSCs) under the Petroleum Development Act 1974. In 1976, PETRONAS and the major companies operating in Malaysia signed production sharing agreements (PSAs), which determined the distribution of oil production between these parties to explore for and develop resources. To further develop the natural gas industry in Malaysia, PETRONAS carried out the Gas Masterplan Study in 1981, which created a long-term strategy and integrated planning for gas industry development in Malaysia, as well as recommending the development of Peninsular Gas Utilisation (PGU) pipeline network (MEA 1981; MGA 2017). 


\section{Petroleum Regulation Act 1974}

The establishment of the Petroleum Regulations (1974 further amended in 1975, 1981 and 1991) set out the regulation and licensing of upstream and downstream activities to different entities. Under this Act, PETRONAS is responsible for the planning, investment and regulation of all upstream activities. Meanwhile, the Ministry of International Trade and Industry (MITI) and the Ministry of Domestic Trade, Co-Operatives and Consumerism (MDTCC) regulate all downstream activities.

PETRONAS regulates and issues licences for upstream activities, which include:

- to commence or continue any business or service, onshore or offshore relating to the exploration, exploitation, winning and obtaining of petroleum and, in particular involving the supply and use of rigs, derricks, ocean tankers and barges;

- to commence or continue any business or service involving the supply of equipment and facilities and services required in connection with the exploration, exploitation, winning and obtaining of petroleum.

For downstream activities, MITI regulated licensing to commence or continue any business of processing or refining of petroleum or manufacture of petrochemical products from petroleum. MDTCC performed the same function in relation to marketing and distribution of petroleum or petrochemical products.

\section{Gas Supply Act 1993}

However, the regulatory system changed following the Gas Supply Act implementation in 1993 and the establishment of the Energy Commission (EC) in 2001 as the downstream regulator replacing MITI and MDTCC. The Gas Supply Act 1993 (gazetted on 4 February 1993) safeguards the interests of industrial, commercial and residential consumers who receive gas supply through pipelines.

'The Gas Supply Act 1993 is to provide the licencing of the supply of gas to consumers through pipelines and related matters, the supply of gas at reasonable prices, the control of gas supply pipelines, installations and appliances with respect to matters relating to safety of persons and for purposes connected therewith.'

With the implementation of this Act, the relevant sections in the Petroleum Development Act 1974 of the supply of gas through pipelines were amended (to avoid duplication of section 6(3A) of the Petroleum Development Act 1974) and all regulation related to supply of gas through pipelines came under the Gas Supply Regulations 1997 (which entered into force on 17 July 1997). These regulations outlined procedures for the issuance of licences for gas pipelines, gas installations, gas fitting and appliances used in pipelines or installations. The two categories of licences under these regulations were gas utility licences and private gas licences. The Department of Gas Supply was formed in 1993 under the Prime Minister's Department to regulate gas distribution. In 2001, this department was dissolved and the Gas Supply Act 1993 further amended to authorise the Energy Commission to regulate activities related to the supply of gas through pipelines.

Liberalisation of the gas market - the Gas Supply (Amendment) Act 2016

The Gas Supply Act 1993 [Act 501], which is referred to as the 'principal Act' in this Gas Supply (Amendment) Act, was amended by substituting the following:

'An Act to provide for the licensing of the import into regasification terminal, regasification, shipping, transportation, distribution, retail or use of gas in the supply of gas through pipelines and related matters, the supply of gas at reasonable prices, the control of gas supply pipelines, installations and appliances with respect to matters relating to safety of persons in the distribution, retail or use of gas and for purposes connected therewith.'

This Act (gazetted on 9 September 2016), which came into force on 16 January 2017, further expanded the regulatory role of the Energy Commission and implementation of third party access (TPA) in Peninsular Malaysia. The amended Act only applies to Peninsular Malaysia and Sabah and excludes the state of Sarawak: 
'The operation of the principal Act is deemed to be suspended for the state of Sarawak from 17 July 1997, and for that purpose it shall be treated as if an order has been made under subsection 1(2) of the principal Act...' (Clause 4A. (2))

The transformation of the gas industry is mainly focused in Peninsular Malaysia, and although the Gas Supply (Amendment) Act 2016 covers the state of Sabah, the focus of this research will be on the liberalisation of the natural gas industry in Peninsular Malaysia. ${ }^{1}$

Map 1 shows the Peninsular Malaysia regasification terminals, gas processing plants, Peninsular Gas Utilisation (PGU) pipelines, as well as gas production areas (Malaysia-Vietnam Commercial Arrangement Area (CAA), Malaysia-Thailand Joint Development Area (JDA) and West Natuna fields). The map also shows gas facilities and gas pipeline connectivity in ASEAN. 

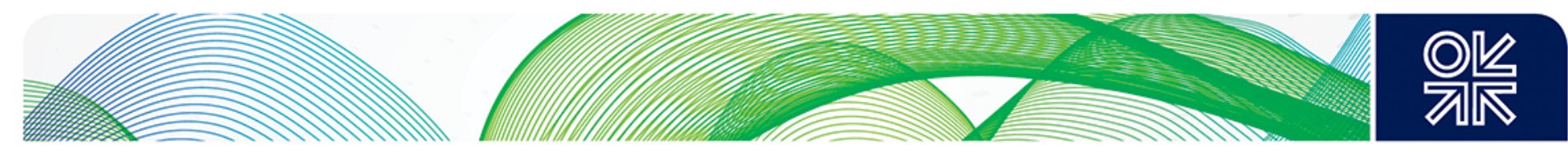

Map 1: Gas facilities and gas pipeline connectivity in Peninsular Malaysia and ASEAN

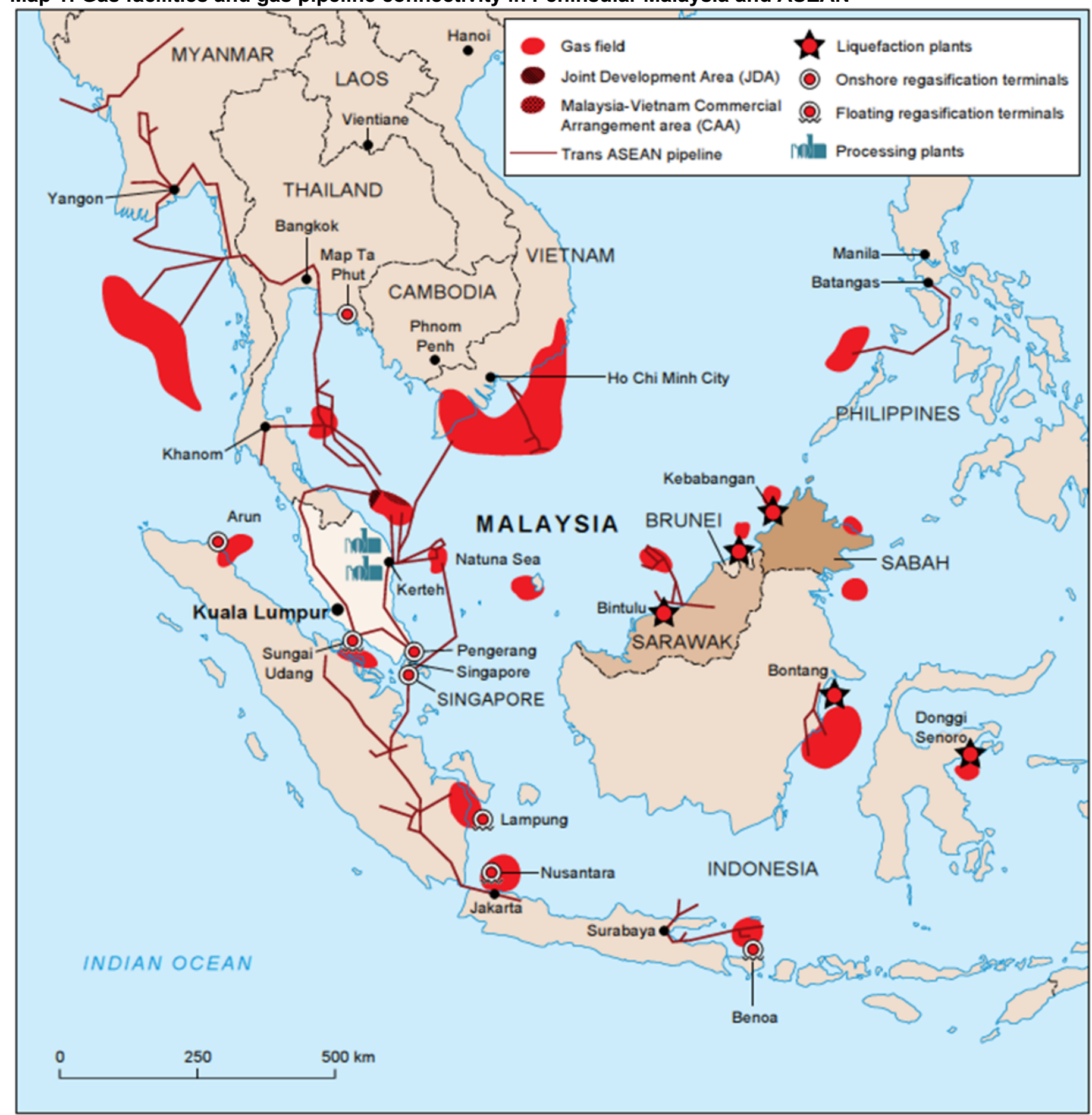

Source: OIES based on IGU (2019); PGB (2019); PGB (2016); PWC (2019); ASCOPE (2019)

\subsection{Research questions and methodology}

This study focuses on identifying and addressing the challenges in gas market liberalisation in Peninsular Malaysia. The scope of research is to examine gas market reform issues and design in Peninsular Malaysia through two specific research questions. It is envisaged that the research findings will contribute to gas industry reform that should result in: customers purchasing gas from different producers; producers competing for customers; and short-term gas trading and gas-to-gas competition. 
The two research questions which this paper aims to answer are:

I. How rapidly is the Peninsular Malaysia gas market likely to liberalise and what will the form of that liberalisation mean for any decision between participating in upstream gas development, as opposed to purchasing gas from producers or the international market?

II. Will increasing competition and the development of spot LNG trade and pricing in the regional (ASEAN) and global gas market have a significant impact on the availability and price for Malaysia, and if yes what is the likely time frame?

Two approaches have been applied to gather and analyse the data required to address the research questions.

\section{i. Secondary data collection}

Secondary data collection on the background and functioning of the country's energy system, historical energy supply and demand trends, government policies and objectives, energy institutions, gas market reform initiatives, gas and electricity tariffs/prices. Data has been collected from national publications, Malaysia Energy Information Hub (MEIH) database, the Energy Commission (EC) and Single Buyer websites.

\section{ii. Stakeholder Interviews}

Interviews with stakeholders (interview questions are attached in Appendix 10.2) were conducted on:

- the functions of the respective key energy players

- the existing role of the stakeholders

- gas and electricity market structures

- future objectives of the government to reform the gas and electricity markets.

The following stakeholders were interviewed:

1. Tenaga National Berhad (TNB)

2. Gas Malaysia Berhad (GMB)

3. PETRONAS Gas Berhad (PGB)

4. Ministry of Economic Affairs (MEA)

5. Malaysian Gas Association (MGA)

6. Petroliam Nasional Berhad (PETRONAS)

7. Energy Commission (EC)

8. Performance Management \& Delivery Unit (PEMANDU) Associates Sdn. Bhd.

9. TNB Single Buyer

10. Shell Eastern Petroleum (Pte) Ltd, Singapore

11. Pavilion Gas (Pte) Ltd, Singapore

12. Diamond Gas International (Pte) Ltd.

\section{Outlook and challenges of the gas market in Malaysia}

In 2018, total primary energy consumption in Malaysia was 99.3 Mtoe (BP 2019). Primary energy consumption has been increasing at an average growth rate of 2.5 per cent for 2008-18 (Figure 1). Oil and gas had the largest shares of primary energy consumption in 2018 , followed by coal, with other sources comprising less than 6 per cent (Figure 2). Natural gas accounted for 35.8 per cent of 
Malaysia's total primary energy supply met by domestic gas production and gas imports. As shown in Section 1 , the country developed the gas industry with the introduction of gas policies and establishment of the oil and .gas company, PETRONAS, to explore for oil and gas resources in the country.

Figure 1: Primary energy consumption in Malaysia (2008-18)

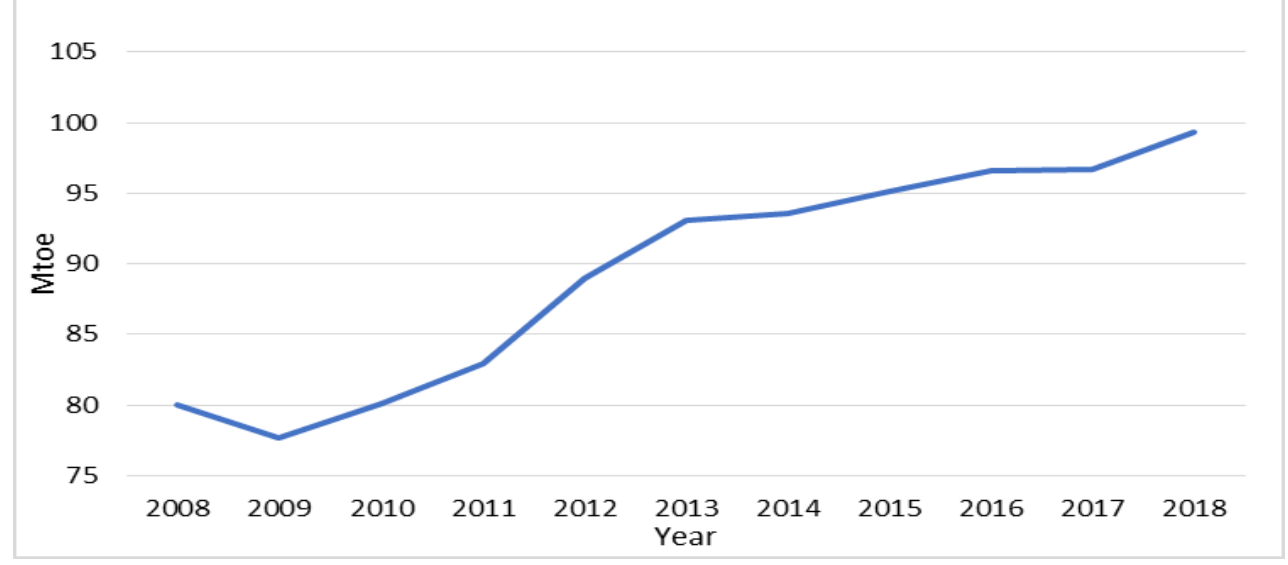

Source: BP (2019)

Figure 2: Primary energy consumption by fuel (2018) in Malaysia

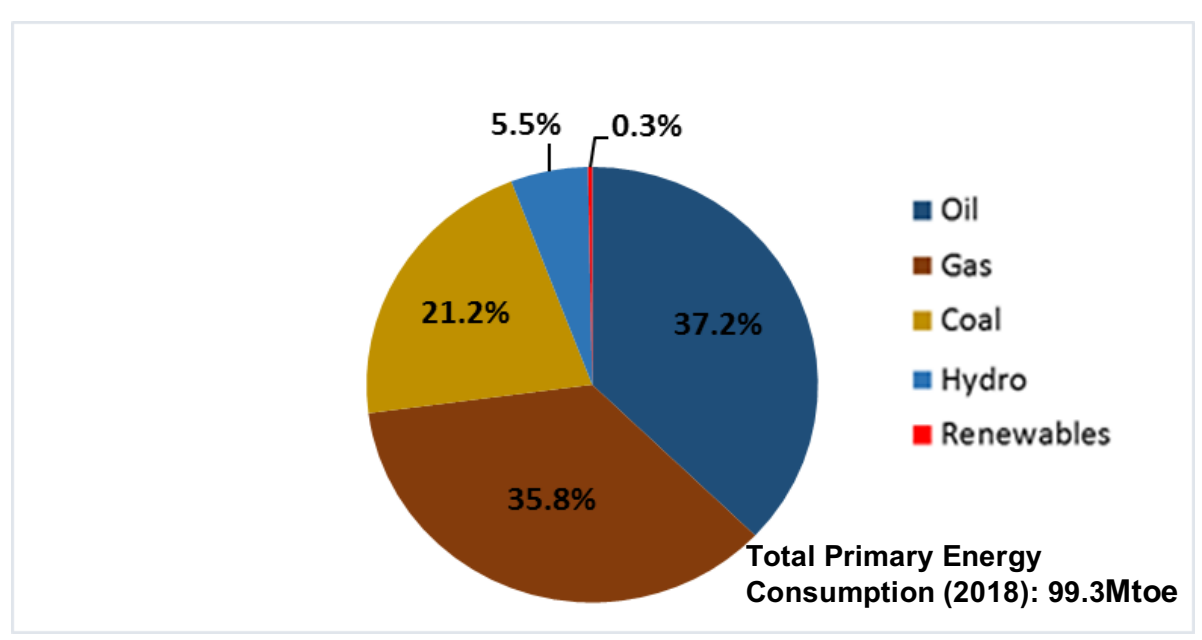

Source: BP (2019)

Gas reserves, supply, demand and imports

Total proved gas reserves in the ASEAN countries were about 7.5 trillion cubic meters in 2018; Malaysia had the second largest reserves at 2.4 trillion cubic meters (33 years of current production), only exceeded by Indonesia with 2.8 trillion cubic meters (BP 2019). Total gas production of Malaysia in 2018 was at $72.5 \mathrm{Bcm}$, of which $33 \mathrm{Bcm}$ was exported as LNG to (mainly) Japan and Korea. ${ }^{2}$ Gas demand was $41.3 \mathrm{Bcm}$ and the deficit of $1.8 \mathrm{Bcm}$ was filled by pipeline and LNG imports.

PETRONAS has been sourcing gas from the Malaysia-Vietnam Commercial Arrangement Area (CAA) since 2003 and the Malaysia-Thailand Joint Development Area (JDA) since 2005. As shown in Figure 3 , PETRONAS has also been importing gas through a pipeline from Indonesia since 2002. PETRONAS signed a contract for $45.28 \mathrm{Bcm}$ over 20 years from the Block B development in Indonesia's West Natuna field. Additional volumes are sourced from the JDA, CAA and imports from Indonesia to meet 
increased domestic demand and supplement the shortfall due to declining domestic production. Piped gas from CAA and imports from Indonesia's Natuna are processed at the PETRONAS Gas Berhad's gas processing plants (GPPs) together with domestic gas produced offshore Peninsular Malaysia (MGA 2017). There are also two LNG regasification terminals in Melaka and Pengerang; imports began in 2013 (for more details see Section 3.2). ${ }^{3}$

Figure 3: Growth of gas production, consumption, exports and imports (1980-2018) in Malaysia 100

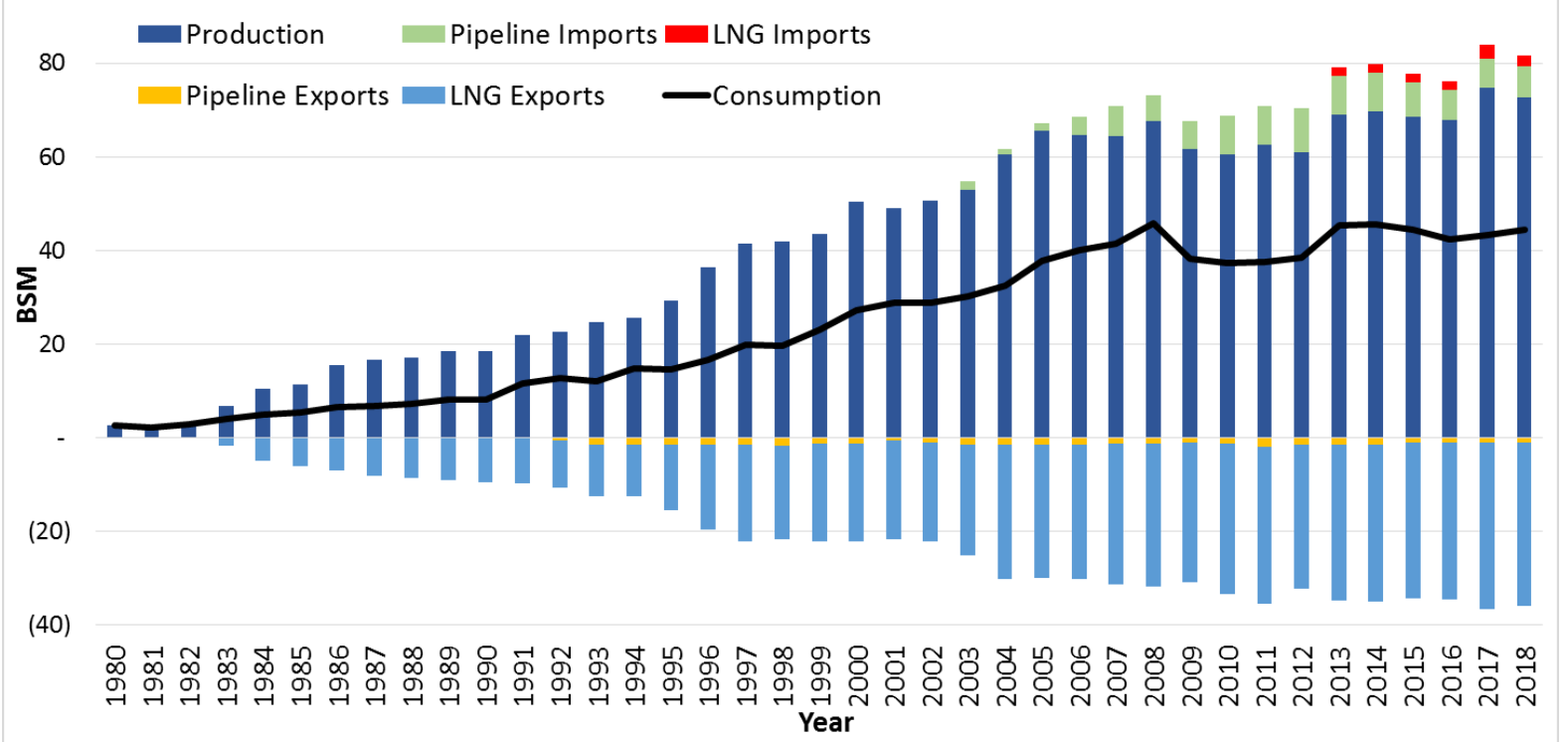

Source: OIES (2019)

Gas demand in Malaysia has been growing since the 1980s, mainly due to increasing gas consumption in the power sector and industry. Demand in Malaysia peaked in 2008 and declined in 2009 and remained low for four years, possibly due to the Asian financial crisis and gas curtailment in 2011. Curtailments of domestic gas supply to the power sector lasted for almost 50 days, which impacted power sector system security and reliability. As gas was the main generation source in 2011, a sufficient amount of gas was required to maintain the security and reliability of the system to meet the demand. The gas shortage caused a net loss to TNB's revenue and more importantly, raised the issue of fuel security in the power sector. The gas shortage was due to shutdowns of gas facilities due to gas facilities (Bekok C) on fire (TNB 2020). Furthermore, prolonged regulated pricing at low levels has increased industrial demand and resulted in market imbalance, inefficient use of resources and gas shortages (PETRONAS 2013b, see Section 3.4.3). Demand increased to 2008 levels post-2013 and has since been relatively stable, as shown in Figure 4. 
Figure 4: Gas demand by sector (2002-18) in Malaysia

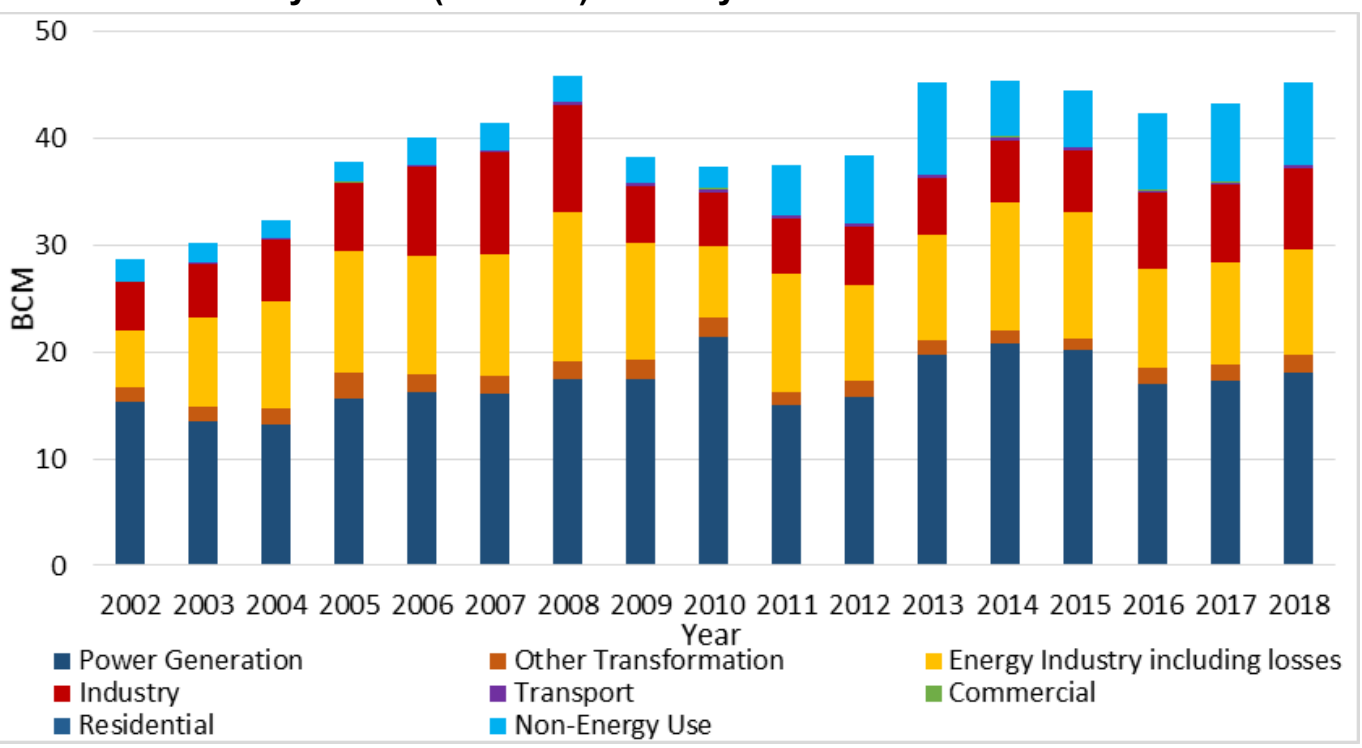

Source: OIES (2019)

\section{Note:}

Non-Energy Use - Use of products resulting from the transformation process for non-energy purpose (i.e. bitumen/lubricants, asphalt/greases) and use of energy products (such as natural gas) as Industry feedstocks Other Transformation -Transformation process from primary supply to secondary supply

Energy industry including losses - Refers to the quantity of gas flared, reinjected into the gas fields and use for production purpose; input of any energy product to convert it to one or more secondary products and losses of natural gas which occur outside and plants.

Peninsular Malaysia accounts for about 90 per cent of total Malaysian gas demand, and power is the most significant sector comprising nearly half of demand (Figure 4). ${ }^{4}$ By 2016, 84 per cent of gas power plants comprising $14.1 \mathrm{GW}$ total gas installed capacity were located in Peninsular Malaysia. Gas also served as feedstock to develop energy industry (e.g. petrochemicals). Gas is supplied via the Peninsular Gas Utilization (PGU) pipeline for district cooling and transportation (compressed natural gas was introduced in 1984 as alternative fuel for road vehicles in Peninsular Malaysia). Although many stakeholders say that the gas demand in Peninsular Malaysia has been growing in recent years, Figure 5 shows it to have been relatively stable post-2015. Domestic producing fields in Peninsular Malaysia are in decline (but not rapid decline, as shown in Figure 6) due to accelerated extraction and maturing of the fields. ${ }^{5}$

\footnotetext{
${ }^{4}$ Oil had been primarily consumed for electricity generation, but with the implementation of National Depletion Policy in 1980, the power sector gradually switched from oil to gas to phase out the oil power plants. The most recent switch from gas to coal for power generation was due to the competitive price of imported coal from Indonesia, Australia, Russia and South Africa. Coal consumption gradually increased with the commissioning of Manjung coal-fired power plant in 2003. Coal power plants are entirely dependent on imported coal and coal consumption is expected to increase to more than 30 million tonnes per annum in the next five years (EC 2017c).

${ }^{5}$ We have been unable to obtain detailed data on gas supply and demand in Peninsular Malaysia from official Malaysian statistics.
} 
Figure 5: Gas demand and supply in Peninsular Malaysia

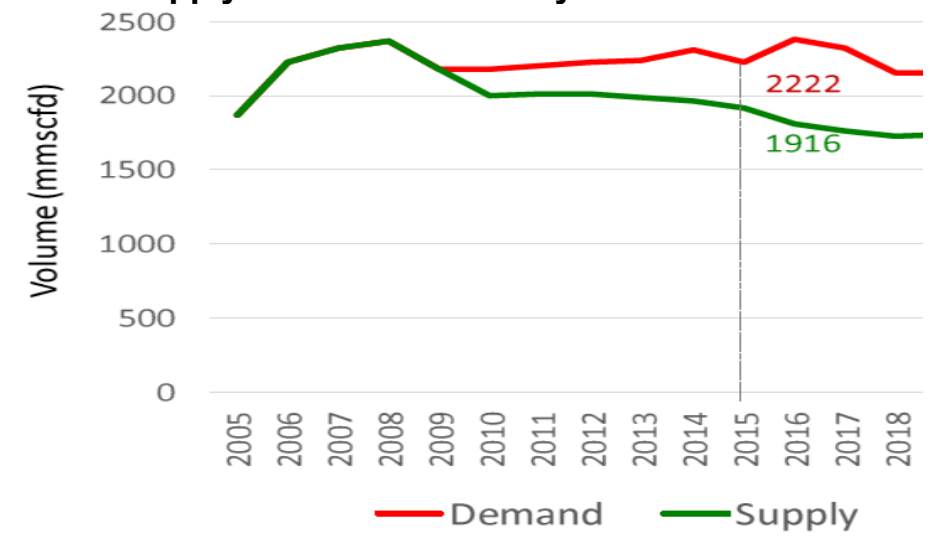

Source: EC (2017a)

By end 2009, gas demand reached a level which could no longer be satisfied by Peninsular Malaysia indigenous gas production. Gas fields in offshore Peninsular Malaysia provide fuel and feedstock for domestic consumption and the export market. Meanwhile, gas reserves in offshore Sabah and Sarawak are for domestic consumption ${ }^{6}$ and LNG export (PETRONAS 2013a). Total gas production in Sarawak is forecast to increase in future, with further development of offshore fields (Evans 2019). Meanwhile, gas production in Peninsular Malaysia and Sabah will decline further post-2021 (Figure 6). In Sabah, the continental shelf is limited, and production projections show continued decline to 2025. But Peninsular Malaysia's production is projected to decline much faster and new gas reserves will be technically and commercially challenging and costly to develop due to location, water depth and high $\mathrm{CO}_{2}$ content.

\section{Figure 6: Malaysian gas production forecast}

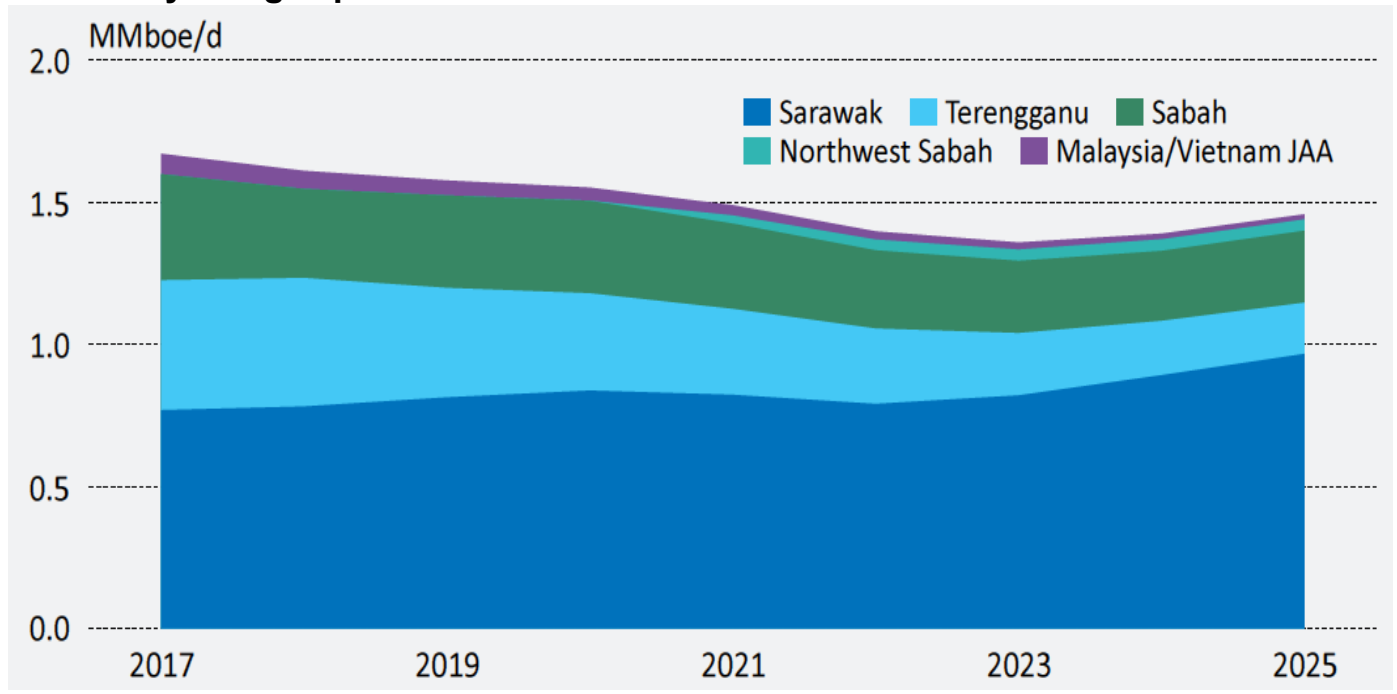

Source: Evans (2019)

\footnotetext{
${ }^{6}$ Gas demand in these two provinces accounted for about 10 per cent of the total Malaysian gas demand. See Section 3.3 for details on Sabah and Sarawak.
} 


\section{Current status of gas liberalisation in Malaysia}

\subsection{Legal framework and regulatory acts}

Gas market liberalisation is at an early stage in Malaysia. As shown in Section 2, falling indigenous gas production was progressively unable to satisfy domestic demand in Peninsular Malaysia, and it was hoped that liberalisation of the gas market would be a significant step to address this issue. Therefore, the government, via the New Energy Policy 2010, the 10th Malaysia Plan and the Economic Transformation Program, introduced the concept of the third-party access (TPA) system aimed at ensuring the security, reliability and sustainability of gas supply in Malaysia (EC 2016a).

The TPA system comprises three objectives:

i. to allow third parties to access infrastructure for the supply of gas to consumers

ii. to promote self-sustaining gas-to-gas competition

iii. to enable gas consumers to benefit from competitive prices, better services and enhanced sustainability.

Figure 7: Steps to liberalisation, trading and establishing a liquid gas market

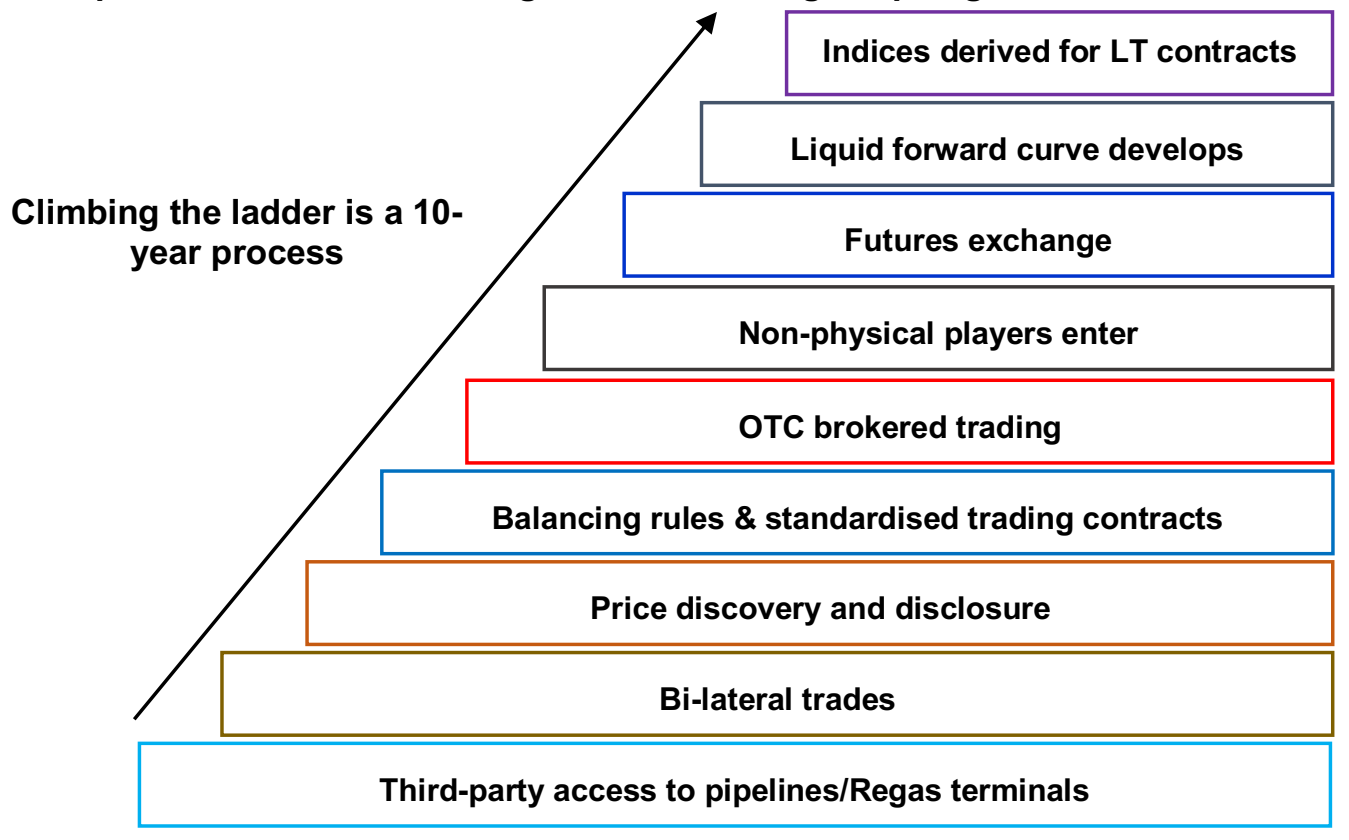

Where is the Malaysian gas market on this journey?

Source: Heather (2015)

The first step to achieving gas market liberalisation (Figure 7) is the implementation of TPA, allowing third parties to access gas infrastructure (Heather 2015). Accordingly, Malaysia's Gas Supply Act 1993 was amended in 2016 and came into effect on 16 January 2017, creating the legal framework for the TPA system. The TPA system allows multiple entities to utilise Malaysian gas infrastructure on a nondiscriminatory basis. Three types of gas facilities fall within the scope of the TPA system: regasification terminals, transmission and distribution pipelines. The TPA system was introduced to ensure security of supply, create a platform for healthy competition and provide room for growth of the Malaysian gas 
industry (EC 2018) ${ }^{7}$. The Energy Commission (EC) oversees the implementation, economic and technical regulation of TPA.

Figure 8: Changes in supply chain through the Gas Supply Act (Amendment) in 2016 Gas Supply Act (Amendment) 2016

\begin{tabular}{|c|c|c|c|c|c|}
\hline $\begin{array}{l}\text { Sourcing of Gas } \\
\text { (Production } \\
\text { /Import) }\end{array}$ & Regasification & Shipping & $\begin{array}{l}\text { Marketing } \\
\text { \& Sales }\end{array}$ & $\begin{array}{l}\text { Transportation } \\
\text { \& Distribution }\end{array}$ & Retail \\
\hline \multicolumn{6}{|l|}{ Details } \\
\hline $\begin{array}{l}\text { Define supply } \\
\text { portfolio } \\
\text { - Ownership } \\
\text { - Gas quality } \\
\text { - Long-term } \\
\text { versus short- } \\
\text { term } \\
\text { - Import LNG and } \\
\text { pass ownership } \\
\text { to shipper } \\
\text { Key Stakeholders }\end{array}$ & $\begin{array}{l}\text { - Regasification } \\
\text { services are offered } \\
\text { at Regasification } \\
\text { Terminal (RGT) Sg. } \\
\text { Udang, Melaka } \\
\text { - First come first serve } \\
\text { basis } \\
\text { - Energy Commission } \\
\text { (EC) regulates RGT } \\
\text { tariffs and guidelines }\end{array}$ & $\begin{array}{l}\text { - Owning and } \\
\text { supplying of the } \\
\text { gas } \\
\text { e }\end{array}$ & $\begin{array}{l}\text { - Contact fuel- } \\
\text { switching and } \\
\text { new industries } \\
\text { - Negotiate new } \\
\text { contracts }\end{array}$ & $\begin{array}{l}\text { - Transport via } \\
\text { transmission } \\
\text { pipeline and/or } \\
\text { distribution pipeline } \\
\text { - Ensure sufficient } \\
\text { pipeline capacities } \\
\text { - Energy Commission } \\
\text { (EC) regulates } \\
\text { transmission and } \\
\text { distribution tariffs }\end{array}$ & $\begin{array}{l}\text { - Identify customers } \\
\text { from commercial } \\
\text { and residential } \\
\text { e sectors } \\
\text { - Set retail price and } \\
\text { establish contracts }\end{array}$ \\
\hline $\begin{array}{l}\text { - PETRONAS } \\
\text { - Third Party }\end{array}$ & $\begin{array}{l}\text { - PETRONAS } \\
\text { - Federal agencies } \\
\text { - State authorities }\end{array}$ & $\begin{array}{l}\text { - PETRONAS } \\
\text { - Third Party }\end{array}$ & $\begin{array}{l}\text { - Malaysia Investment } \\
\text { Development } \\
\text { Authority (MIDA) } \\
\text { - PETRONAS } \\
\text { - Gas Malaysia Berhad } \\
\text { (GMB) } \\
\text { - Third Party }\end{array}$ & $\begin{array}{l}\text { - Petronas Gas } \\
\text { Berhad (PGB) } \\
\text { - Gas Malaysia } \\
\text { Berhad (GMB) } \\
\text { d }\end{array}$ & $\begin{array}{l}\text { - Gas Malaysia Berhad } \\
\text { (GMB) } \\
\text { - Third Party }\end{array}$ \\
\hline
\end{tabular}

Source: Lim and Kim (2019)

This system will allow market players, in addition to PETRONAS which is currently the sole gas supplier, to import and supply liquefied natural gas (LNG) using existing facilities. The amended legislation will create equal opportunities for gas importers and suppliers by issuing licences (see below, Figure 11) that will entitle holders to transport gas through the Peninsular Gas Utilisation (PGU) pipeline (EC 2016a). Figure 8 provides details of different parts of the gas value chain and stakeholders involved in each part under the amended Act.

Three inferences can be drawn from the experience of gas market liberalisation in other countries, which may also apply to Malaysia:

The existence of enabling legislation and regulation does not necessarily mean that the market will liberalise.

- $\quad$ Government and regulatory commitment to developing competition in the gas market is essential. In this case, for example, the role of PETRONAS as the dominant gas (and oil) company will need to be significantly reduced, favouring the entry of new companies into the gas market. Hence, the government response to 
the development of competition (or the lack of it) will be an essential indicator of the progress of the liberalisation programme.

- $\quad$ Creating all the steps to a competitive gas market (Figure 7) is a process which usually takes a decade and may take longer.

Figure 9: Legal framework for third-party access (TPA)

Gas Supply Act 1993 amendments are enablers to implement the third-party access system. Amendments are approved by Parliament.

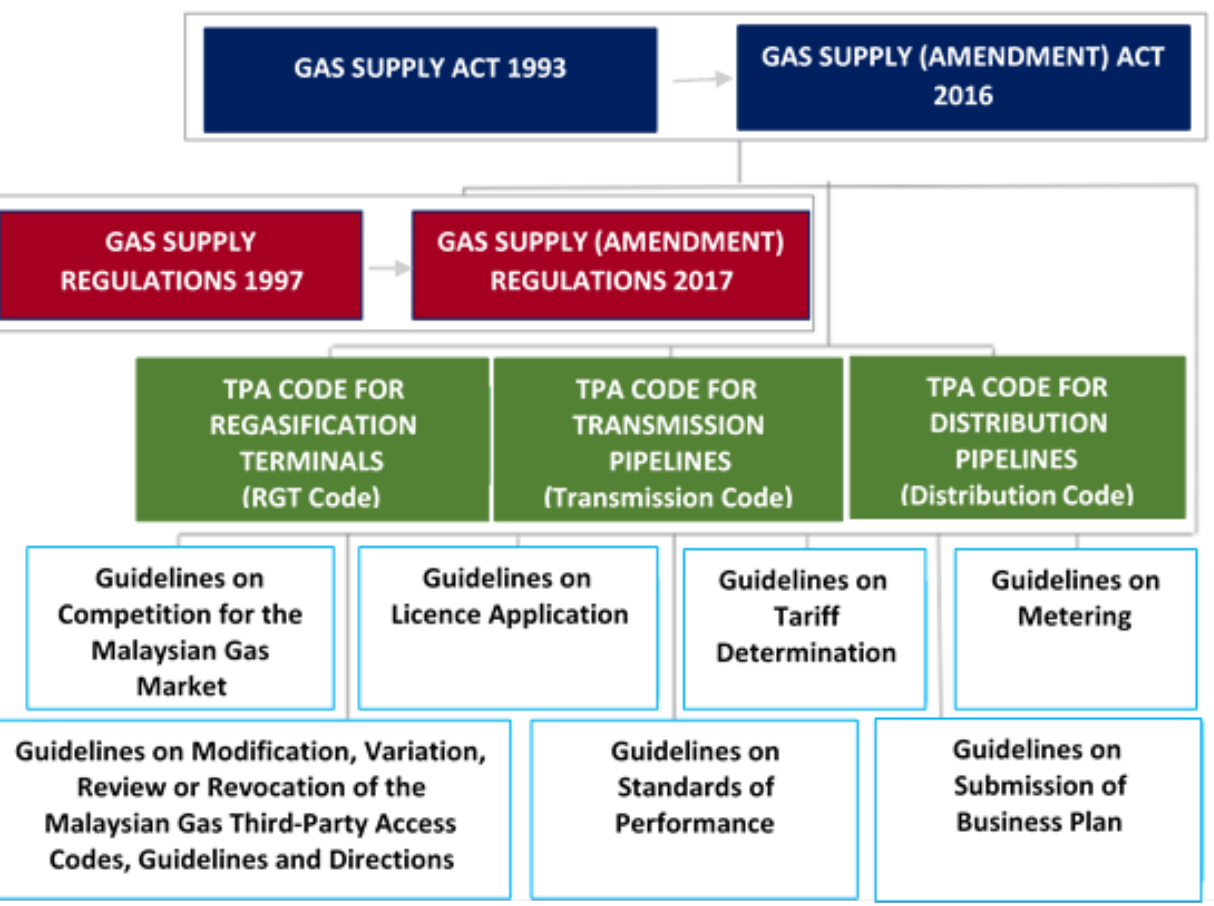

Gas Supply Regulations 1997 amendments prescribe regulatory requirements as provided for under the Act. Amendments are approved by the Minister.

Third-Party Access Codes prescribe principles of access by the owners, operators and users to gas facilities. Codes are approved by the Minister.

Guidelines are reference or explanatory documents that detail out technical, commercial or procedural requirements for the implementation of provisions under the Act and Regulations. Guidelines are approved by the Commission.

Source: EC (2016b); EC (2017a)

Despite the existence of the legal framework (Figure 9), the degree and pace of liberalisation and competition in the gas market will determine whether parties decide to continue to purchase gas from the incumbent, third parties or the international market, or decide to develop their own gas and vertically integrate through the value chain.

\subsection{Institutional structure and regulation of the gas market}

One of the significant changes under the Gas Supply Act (Amended) in 2016 is the scope and role of the downstream regulator. PETRONAS is the owner of onshore or offshore fields and is its own regulator for upstream oil and gas production under the Petroleum Development Act 1974 (discussed in Section 1). In 2001, the Energy Commission (EC) was established (by the Energy Commission Act of 2001) as a statutory body to regulate the electricity supply industry and piped gas supply industry in the Peninsula and Sabah. The EC's role is to ensure that electricity and piped gas to consumers are supplied securely, reliably, safely and at reasonable prices. The EC reports to the Ministry of Economic Affairs (MEA) ${ }^{8}$ for gas-related activities and reports to Ministry of Energy, Science, Technology, Environment \& Climate Change (MESTECC) ${ }^{9}$ for electricity-related activities. The role of the Commission has changed since $2001,{ }^{10}$ and it anticipates becoming an independent regulator (see

\footnotetext{
${ }^{8}$ MEA is previously known as the Economic Planning Unit (EPU).

${ }^{9}$ MESTECC is previously known as Ministry of Energy, Green Technology and Water (KeTTHA).

${ }^{10}$ See Figure 28 in Appendix for EC's scope under the Gas Supply Act 1993 and the amended Gas Supply Act 2016. The scope of the EC was to regulate the distribution level (approximately 500 million standard cubic feet per day (mmscf/d) of the distribution
} 
Section 7) in future. Figure 10 summarises the current role of the $E C$ across the natural gas value chain under the Gas Supply (Amended) Act 2016.

Figure 10: EC and other stakeholder mapping across the natural gas value chain

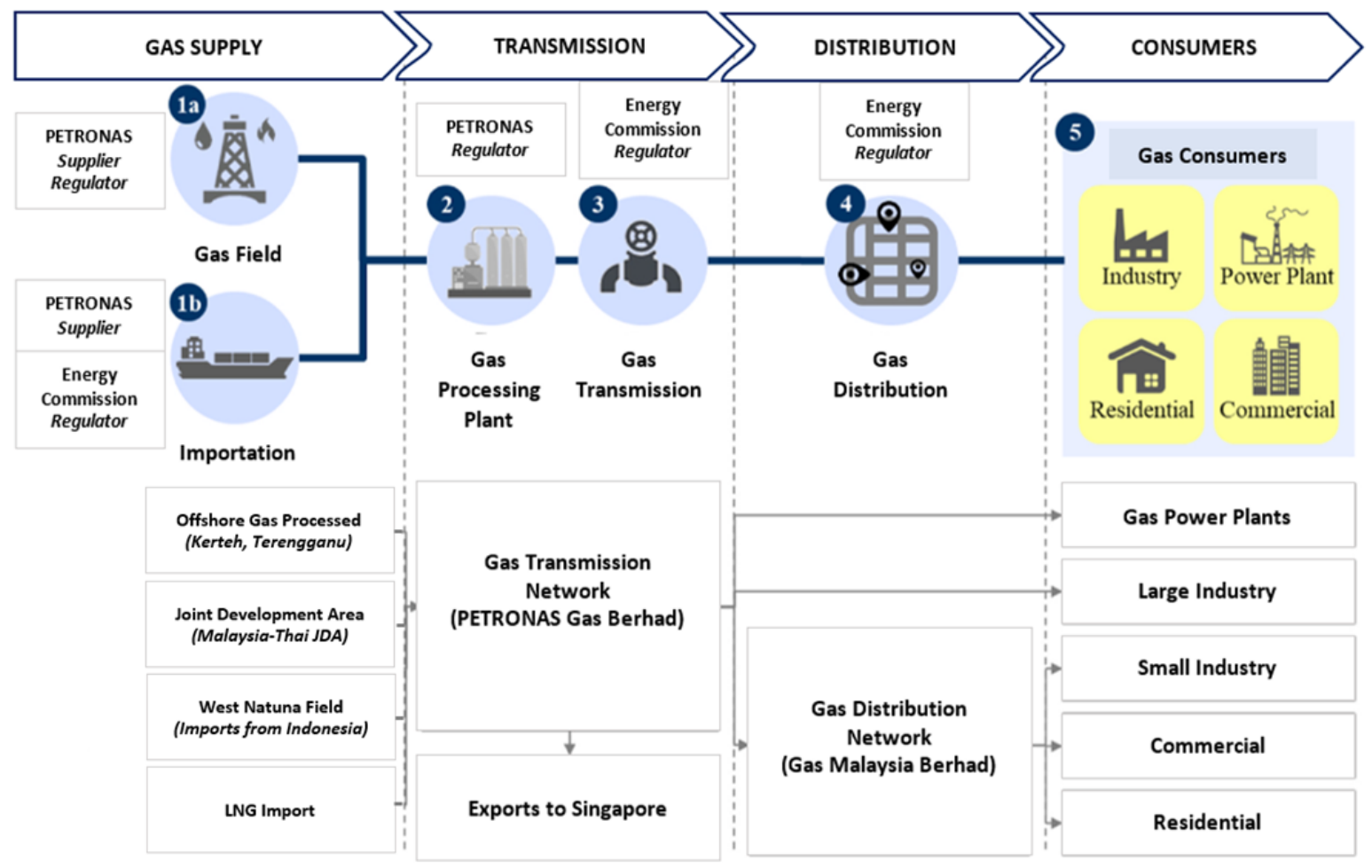

Source: Lim and Kim (2019)

In Peninsular Malaysia, there are two key categories of gas consumers: the power sector, TNB power plants and Independent Power Plants (IPPs); and the non-power sector, which is comprised of the distribution company Gas Malaysia Berhad (GMB), and large industry players such as PETRONAS Penapisan Melaka, PETRONAS Chemical Fertiliser Kedah, LOTTE Chemical Titan and White Horse Ceramic Industries. These industry players negotiate gas contracts directly with PETRONAS. PETRONAS supplies gas to GMB which then distributes to the smaller industries. Natural gas prices for these groups will be discussed in Section 3.4.3. 
Figure 11: Industry players and licences under the TPA regulatory framework

\begin{tabular}{|c|c|c|c|c|}
\hline $\begin{array}{l}\text { GAS } \\
\text { FACILITY }\end{array}$ & - Regasification terminal & - Transmission pipeline & - Distribution pipeline & - Network within buildings \\
\hline $\begin{array}{l}\text { GAS FACILITY } \\
\text { LICENCE TO } \\
\text { BE ISSUED }\end{array}$ & - Regasification licence & - Transmission licence & - Distribution licence & - Retail licence \\
\hline $\begin{array}{l}\text { GAS FACILITY } \\
\text { LICENSEE }\end{array}$ & $\begin{array}{l}\text { - RGT Sg. Udang Sdn. } \\
\text { Bhd. }\end{array}$ & - Petronas Gas Bhd. & $\begin{array}{l}\text { - Gas Malaysia Bhd } \\
\text { - Sabah Energy Corp. } \\
\text { Sdn. Bhd. }\end{array}$ & $\begin{array}{l}\text { - Shopping malls } \\
\text { - Apartment blocks }\end{array}$ \\
\hline $\begin{array}{l}\text { GAS FACILITY } \\
\text { USER }\end{array}$ & $\begin{array}{l}\text { - Shipping licence } \\
\text { (e.g. Petronas) }\end{array}$ & $\begin{array}{c}\text { - Shipping licence } \\
\text { (e.g. Petronas) }\end{array}$ & $\begin{array}{l}\text { - Shipping licence } \\
\text { (e.g. Gas Malaysia Bhd, } \\
\text { Sabah Energy Corp. } \\
\text { Sdn. Bhd) }\end{array}$ & - Retail licence \\
\hline END-USER & - & $\begin{array}{l}\text { - Power sector } \\
\text { - Large industry }\end{array}$ & $\begin{array}{l}\text { - Medium \& small } \\
\text { industry } \\
\text { - Private gas licence } \\
\text { (e.g. restaurant, hotel, } \\
\text { hospital) }\end{array}$ & $\begin{array}{l}\text { - Restaurant operator } \\
\text { - Household }\end{array}$ \\
\hline
\end{tabular}

Source: EC (2017a)

Note: Individual premises (e.g. restaurant, hotel or hospital) that are not connected to the network and use gas for their own consumption apply for gas private licensing.

The regulator $(E C)$ issues licences for seven types of activity under the TPA system. The licences are for:

1. import into a regasification terminal

2. regasification

3. shipping

4. transportation

5. distribution

6. retail

7. gas usage.

Three types of gas facilities are included under the TPA system, namely regasification terminals, transmission pipelines and distribution pipelines. PGB owns and operates regasification terminals and transmission pipelines, and GMB owns and operates the distribution pipelines. Figure 12 summarises the contractual agreements which determine the flows of gas in the TPA system. 
Figure 12: Flow of gas and agreements in the TPA system

\begin{tabular}{l} 
LNG IMPORTER \\
- Brings LNG into Malaysia and transfers \\
ownership of LNG to the SHIPPER at the \\
loading arm of the regasification terminal. \\
- Enters into gas supply agreement with \\
SHIPPER \\
\hline \hline SHIPPER (SUPPLIER) \\
- Supplies gas to GAS CONSUMERS through \\
gas facilities (regasification terminal, \\
transmission pipeline or transmission \\
pipeline) \\
- Enters into gas supply agreement with gas \\
consumers \\
- Enters into gas facility access arrangement \\
with GAS FACILITY OWNER \\
\hline \hline RETAILER \\
- Buys gas from SHIPPER via gas supply \\
agreements and supplies gas to GAS \\
CONSUMERS through retailer's pipe \\
network \\
- Enters into gas supply agreement with GAS \\
CONSUMERS \\
\hline
\end{tabular}

Source: EC (2017a)

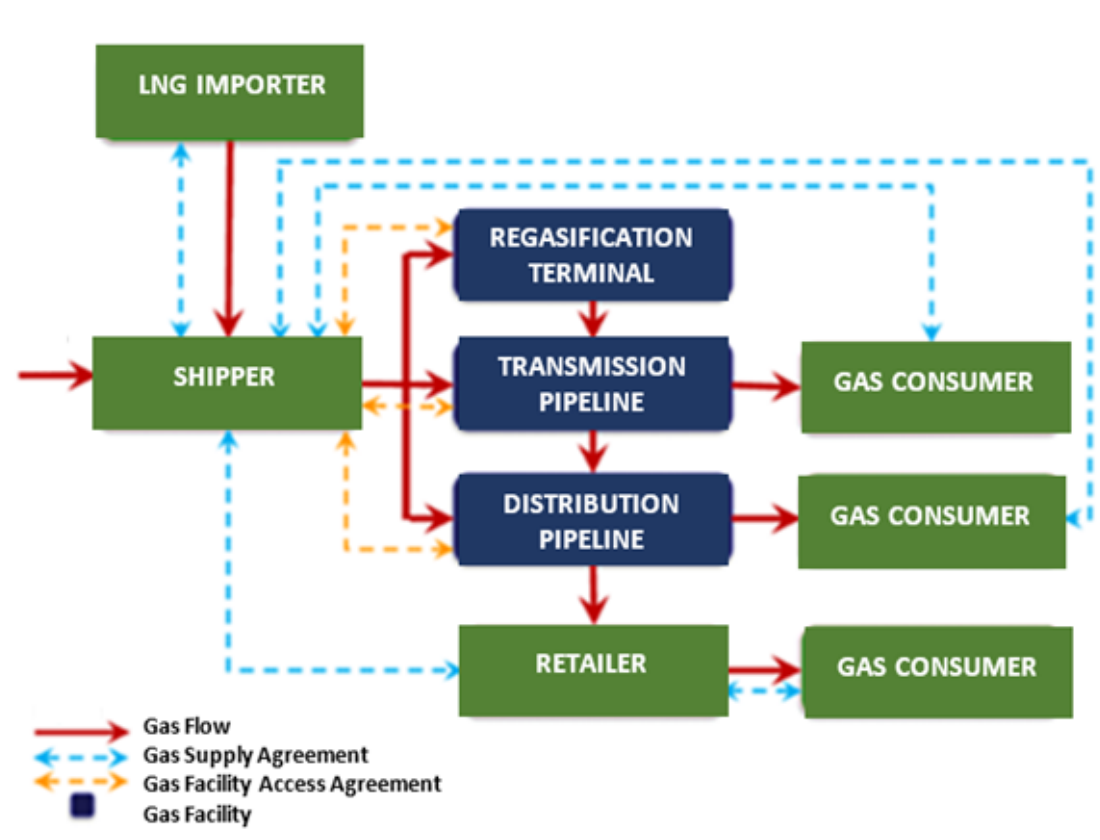

\section{PETRONAS Gas Berhad (PGB)}

The Malaysian Government initiated the liberalisation of the gas industry under the 10th Malaysian Plan and the New Energy Policy and introduced the TPA system. In line with TPA implementation, PGB ${ }^{11}$ is required to open up the available capacity of regasification terminals and pipelines for access by licensed third parties - see Map 1 for the location of these facilities. The EC approved and published the access arrangement documents for both facilities in 2019 for new market players to use the facilities under TPA.

\section{i. Regasification terminals}

There are two regasification terminals in Peninsular Malaysia owned by PGB. The offshore Liquefied Natural Gas (LNG) Regasification Terminal in Sungai Udang, Melaka (RGTSU) was commissioned in 2013 with a capacity of $530 \mathrm{mmscf} / \mathrm{d}$. The onshore LNG Regasification Terminal in Pengerang, Johor (RGTP) with a capacity of $490 \mathrm{mmscf} / \mathrm{d}$ began commercial operations in 2017 . The facility receives vessels carrying PETRONAS's LNG imported from around the world, stores and regasifies the LNG and injects gas into the PGU pipeline network for distribution to PETRONAS's customers. PGB collects a fee from PETRONAS based on capacity usage outlined in the 20-year Regasification Services Agreement (RSA).

\section{ii. Transmission pipelines}

The $2551 \mathrm{~km}$ of gas transmission pipelines with a capacity up to $3000 \mathrm{mmscf} / \mathrm{d}$ covering much of West Malaysia are known as the Peninsular Gas Utilisation (PGU) gas pipeline network. After processing, gas is transported to PETRONAS's customers in the power and non-power sectors.

\section{Gas Malaysia Berhad (GMB)}

GMB was established in 1992 to sell, market and distribute natural gas to industrial, commercial and residential customers in Peninsular Malaysia through the Natural Gas Distribution System (NGDS). 
PETRONAS sources the gas via PETRONAS Gas Berhad's PGU pipeline. The gas is supplied to GMB through the City Gate Stations and distributed throughout NGDS to end consumers. GMB is expected to unbundle into two different entities: GMD (Gas Malaysia Distribution) and GMES (Gas Malaysia Energy and Services). However, by the end of 2019, GMB had not yet unbundled - discussed in Section 4.4 .

\subsection{Gas markets in Sabah and Sarawak}

Although the Gas Supply (Amendment) Act 2016 included Sabah in the liberalisation process, Sabah and Sarawak have different gas market structures from Peninsular Malaysia, hence there are three different gas market structures in Malaysia. In Sabah, prices of natural gas are based on the Gas Sales and Purchase Agreement signed by the licensee Sabah Energy Corporation Sdn. Bhd. (SEC) ${ }^{12}$ and the users according to the Gas Supply Act 1993. Low gas demand in the non-power sectors means these are not attractive for new market entrants (there is no residential gas demand). Installed gas-fired capacity in Sabah is $1.2 \mathrm{GW}$ (about 8.5 per cent of total installed gas-fired capacity in Malaysia). The gas price to power is about RM $6.40 / \mathrm{mmbtu}$ (USD1.55/mmbtu at the 2019 exchange rate), which is expected to remain for the foreseeable future due to the difficult financial situation of the utility company, Sabah Electricity Sdn. Bhd (SESB). Anecdotally, the electricity theft rate is extremely high, with approximately one-third of Sabah electricity generation lost to theft. Furthermore, the continental shelf in Sabah is limited compared with Sarawak and Peninsular Malaysia, and the reserves could deplete soon (see Figure 6). Gas is also sold to the distribution company, SEC at the extremely low price of RM $2.70 / \mathrm{mmbtu}$. So, future high-cost production would not be feasible with current regulated electricity and gas prices to consumers. For all these reasons it is not feasible to introduce TPA in Sabah.

Sarawak is not part of the Gas Supply (Amendment) Act 2016 and is therefore not required and not likely to liberalise its gas market. The gas price to power in Sarawak is about RM 5.00/mmbtu (USD1.21/ $\mathrm{mmbtu}$ ), and consumers do not pay the full cost of monetising offshore gas. The subsidy is probably higher than Peninsular Malaysia, but it is uncertain whether prices will increase in future; there is limited information about subsidy reform in Sarawak. Furthermore, Sarawak and Sabah are at a much lower stage of development compared with Peninsular Malaysia ${ }^{13}$, and it is politically challenging to increase the gas prices in both states.

These are the reasons why TPA implementation is currently focused on Peninsular Malaysia. With the regulation and institutional structure in place, the TPA pilot phase began in January 2019.

\subsection{Third-party access (TPA) pilot phase}

The TPA pilot phase ran for a period of one year, January-December 2019. The objective of this pilot phase was to provide the opportunity for all parties - shippers, infrastructure owners, sellers and buyers of gas - to adopt and adapt to the key elements of the TPA system.

\subsubsection{Enforcement of new TPA rules and regulations}

For the last 30 years, the gas market operated as a vertically integrated system. The pilot phase provides a platform for any interested party to understand the TPA system, regulations and licensing requirements, as well as the rules and implementation of TPA. During this phase, existing industry players were given a one-year grace period to prepare, unbundle and apply for licences as required by the TPA system, while new industry participants are required to comply with the system immediately. The EC is facilitating the TPA implementation process so that existing and new gas market players understand the market structure, the operation of the market, and how these rules are being applied with the flexibility for new players to enter the gas market.

The EC has enforced corporate restructuring to prepare for TPA: the unbundling of PETRONAS into separate supplier and shipper entities - the establishment of PETRONAS Energy \& Gas Trading

\footnotetext{
${ }^{12}$ Sabah Energy Corporation Sdn. Bhd. (SEC) is licensed by the Energy Commission (EC) to distribute natural gas in Sabah and Labuan.

${ }^{13}$ See Figure 23 - GDP contribution of Sabah and Sarawak as compared to Peninsular Malaysia
} 
(PEGT) as the shipping licence holder, and PETRONAS as gas producer and supplier. Figure 13 provides a summary of unbundled subsidiaries from the respective parent company - PETRONAS and Gas Malaysia Berhad (GMB) to fulfil the TPA requirement in Peninsular Malaysia.

Figure 13: Summary of unbundled subsidiaries from the parent company - PETRONAS and Gas Malaysia Berhad (GMB)

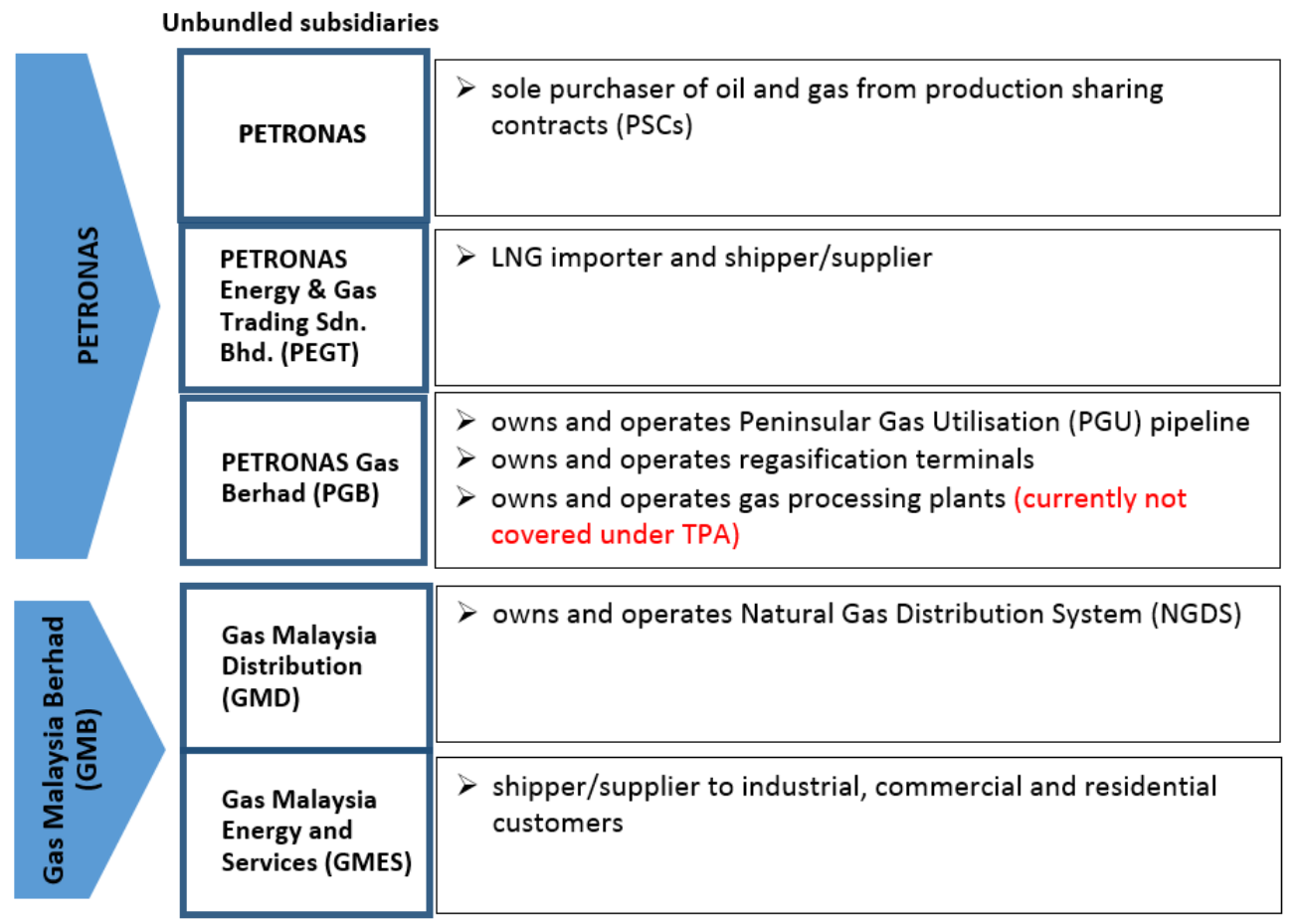

Note: As of December 2019, GMB has not yet unbundled to separate entities, GMD and GMES.

Under this new framework, PEGT is meant to buy gas from PETRONAS and ship gas to customers (for example, TNB and GMES) through the transmission network. However, at the end of 2019, this framework arrangement was not in place due to the existing long-term agreements with PETRONAS. Changes are expected to happen in the period 2020-22, subject to the revision of these agreements.

The EC has published the Access Arrangement documents and tariffs for regasification terminals and the transmission network. The distribution pipeline tariff is yet to be published as the GMB, which is the owner of the distribution network, is in the process of unbundling (discussed in Section 4.4). The published tariff for the utilisation of gas facilities for 1 January to 31 December 2019 is shown in Table 1.

Table 1: Published tariff for LNG terminals and transmission system in Peninsular Malaysia ${ }^{14}$

\begin{tabular}{lll}
\hline Regasification terminal (Pengerang Johor) & 1 Jan 2019-31 Dec 2019 & USD 0.637/mmbtu/day \\
\hline Regasification terminal (Sg. Udang Melaka) & 1 Jan 2019-31 Dec 2019 & RM 3.518/mmbtu/day \\
\hline Transmission pipeline (PETRONAS Gas Berhad) & 1 Jan 2019-31 Dec 2019 & RM 1.072/GJ/day \\
\hline
\end{tabular}

Source: EC (2019).

Since the Pengerang Johor regasification terminal investment was negotiated in US dollars (USD), this terminal is allowed to charge a USD-based tariff under the TPA system in order to ensure that the operator is not exposed to foreign exchange risk, which may lead to a tariff increase. The EC allows

${ }^{14}$ As of August 2019, currency exchange of USD to RM (Ringgit Malaysia): USD 1.00 = RM 4.13. 
Pengerang regasification terminal to charge its tolling tariff in USD currency to ensure that the terminal recovers its costs with a defined profit element.

\subsubsection{Gas licences under TPA system}

Under the Gas Supply (Amendment) Regulations 2017, seven types of activities require licences under the TPA system (Figure 12). The guidelines for the licence were designed to capture fundamental requirements, as the gas market is capital intensive in terms of infrastructure and commodity (EC 2016a). The guidelines incorporated some flexibility to encourage new entry to the gas market. However, consistent with licence requirements, a company with a licence for infrastructure assets cannot own the licence for supply and trading of gas. This requirement is to support the unbundling of existing companies, for example GMB, to address any potential conflict of interest. The licensing guidelines are also designed for this particular phase to encourage domestic participation and locally registered companies, due to lack of experience with gas market liberalisation and other concurrent issues, such as gas pricing. These guidelines and regulations may be revised to include more companies when the gas market in Malaysia stabilises.

Shown below are the licences issued by EC to companies that have applied to enter the gas market in 2019. These licences are still at a very early stage of implementation, and other organisations may still apply for licences as the TPA system unfolds.

i. Import Into Regasification Terminal Licence (7 licences issued)

- PETRONAS Energy \& Gas Trading Sdn. Bhd.

- TNB Fuel Services Sdn. Bhd

- Shell Malaysia Trading Sdn. Bhd

- Gaztech E\&S Sdn. Bhd

- B.B. Energy Malaysia Ltd.

- Petrolife Aero Sdn. Bhd.

- OCN Energy Resources Sdn. Bhd.

ii. Shipping Licence ${ }^{15}$ (6 licences issued)

- PETRONAS Energy \& Gas Trading Sdn. Bhd.

- TNB Fuel Services Sdn. Bhd.

- Shell Malaysia Trading Sdn. Bhd.

- Gaztech E\&S Sdn. Bhd.

- B.B. Energy Malaysia Ltd.

- Petrolife Aero Sdn. Bhd.

iii. Regasification Licence (2 licences issued)

- Pengerang LNG (Two) Sdn. Bhd.

- Regas Terminal (Sg. Udang) Sdn. Bhd.

iv. Transportation Licence (4 licences issued)

- PETRONAS Gas Berhad - Access Arrangement published in March 2019

- PRPC Utilities and Facilities Sdn. Bhd.

- PRPC Refinery and Cracker Sdn. Bhd.

- Trans Thai-Malaysia (Malaysia) Sdn. Bhd.

\footnotetext{
${ }^{15}$ Shipping licence includes the rights to ship gas to pipeline and to supply to end-users.
} 
v. Distribution Licence (2 licences issued)

- Sabah Energy Corporation Sdn. Bhd.

- Malaysia Airports (Sepang) Sdn. Bhd.

- Gas Malaysia Berhad (GMB) - as of December 2019, GMB does not have a licence as the company has not yet unbundled.

vi. Retail Licence (no licences issued as of December 2019)

vii. Private Gas Licence (no licences issued as of December 2019)

The fees for these licences are based on reserve capacity (outlined in the Third Schedule of the Gas Supply (Amendment) Regulations 2017) as shown in Table 2.

Table 2: Licence fees based on reserved capacity

\begin{tabular}{lc|}
\hline Type of licence & Fees (sen/mmbtu based on reserved capacity) \\
\hline Import into & 0.1 \\
regasification & \\
\hline Shipping & 0.1 \\
\hline Regasification & 0.5 \\
\hline Transportation & 0.5 \\
\hline Distribution & 1
\end{tabular}

Note: The last two categories of licence are for the end users based on the class of installation.

It is very unusual to base licence fees on capacity or throughput. Licence charges are usually a onetime or annual fee not a unit charge.

\subsubsection{Regulated and unregulated gas prices}

Before the Asian Financial Crisis of 1997-98, the gas price to downstream consumers (power and nonpower) was at a level intended to reflect PETRONAS's costs plus a profit. Piped gas prices were subsequently regulated in response to the financial crisis. The contract price for piped gas was USD $1.68 / \mathrm{mmbtu}$ in 1997, and this kept increasing in Malaysia Ringgits (RM), not because of cost increases but due to falling exchange rates during the financial crisis. A fixed gas price of RM 6.40/mmbtu for power sector was introduced in May 1997, and a regulated gas price of RM9.40/mmbtu was introduced in October 2002 to assist recovery in the industry sector which had been badly affected by the recession (EC 2017d). Thereafter, the government decided to extend regulated pricing to include the non-power sector.

Regulated gas pricing was supposed to be a temporary measure (for approximately three years) to stabilise the Malaysian economy. However, subsidies have remained due to political challenges faced by the government to revise prices in both sectors. Internationally traded Asian gas and LNG contract prices have been predominantly linked to crude oil prices, which meant that increases in oil prices during the 2000s and 2010s led to contract price increases. As gas prices remained regulated in Malaysia, there was a widening gap between PETRONAS's cost of production and imports and the regulated price which, according to PETRONAS, resulted in the latter having to subsidise the domestic market to an increasing extent. Lack of transparency in relation to PETRONAS's cost of supply makes the extent of any such subsidy impossible to judge. Reforms aimed at harmonising the current two-tier price level (see below) will certainly raise prices, but whether the eventual harmonised price level will be pegged to international LNG prices, or to some mix of the latter and domestic production costs, remains to be decided by regulators.

Gas prices in Peninsular Malaysia are determined based on a two-tier pricing model: the regulated piped gas price and the unregulated LNG gas price (also known as the discounted LNG market price). Gas is consumed by two categories of customers: power (TNB and IPP) and non-power (GMB). This 
two-tier gas pricing mechanism is an initiative introduced to liberalise prices and rationalise subsidy removal (EC 2017b). Regulation has resulted in PETRONAS selling gas at a low price, which negatively impacts the government's revenue collection through a lower annual contribution from PETRONAS. This issue becomes particularly serious during a period of lower global oil and gas prices which has been the case since 2016 (Lim and Kim 2019).

\subsubsection{Regulated piped gas price}

For the power sector, the wholesale gas price was capped at RM $28.7 / \mathrm{mmbtu}$ for volumes up to 1000 $\mathrm{mmscf} / \mathrm{d}$ as of October $2019^{16}$. For non-power sector volumes up to $300 \mathrm{mmscf} / \mathrm{d}$, the price is capped at RM 30.55/mmbtu. Figure 14 summarises regulated gas price trends since January 2014. In 2011, the government launched a subsidy rationalisation programme to increase the gas price by RM3.50/mmbtu every six months. This price increase was a challenge for the industry sector, which had to adapt to the increase in the gas price as well as the electricity tariff. Adjustments in the regulated gas price directly impact the electricity tariff (as electricity generation mainly depends on gas power plants during this phase). So the government decided to revise the regulated (Tier-1) gas pricing again and increase the price by RM1.50/mmbtu every six months effective in 2014. In December 2016, the government mandated that the price would increase by RM1.50/mmbtu every six months until a 'reference (wholesale) market price' was achieved reflecting the ex-Bintulu price (see below).

\section{Figure 14: Regulated (Tier 1) piped gas prices}

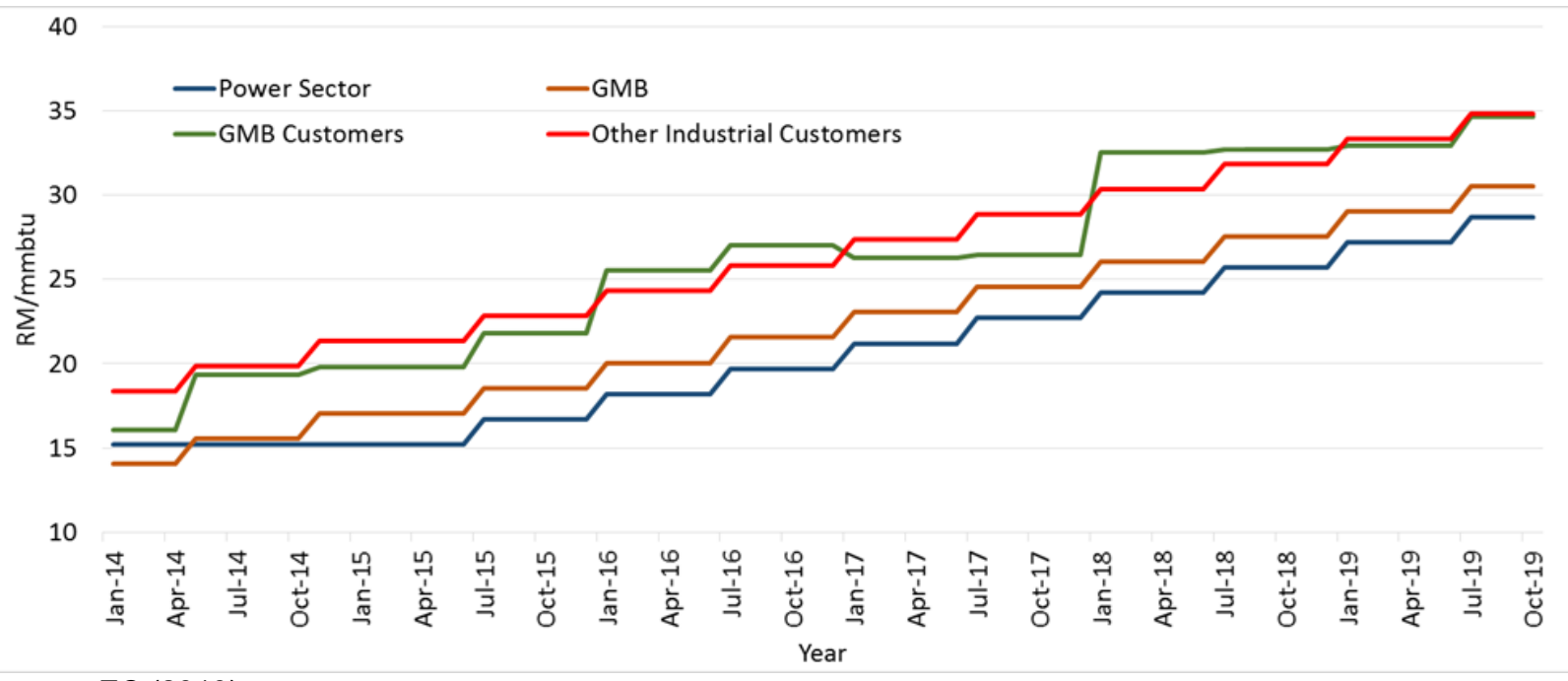

Source: EC (2019)

\subsubsection{Unregulated piped gas prices (LNG indexed)}

Any gas volumes consumed above $1000 \mathrm{mmscf} / \mathrm{d}$ (power) and $300 \mathrm{mmscf} / \mathrm{d}$ (non-power) are charged at the unregulated piped gas price. As of October 2019, the unregulated gas price for the power sector was about RM $31.7 / \mathrm{mmbtu}(\$ 7.69 / \mathrm{mmbtu})$ and RM $33.8 / \mathrm{mmbtu}(\$ 8.20 / \mathrm{mmbtu})$ for non-power. The unregulated (Tier-2) pricing formula includes costs of: production, shipping, regasification and transmission. Product cost in Tier-2 pricing is derived from the LNG Free On Board (FOB) Weighted Average Price (WAP) ex-Bintulu with a discount factor. The ex-Bintulu price is formulated based on a portfolio of PETRONAS's LNG buyers (see Section 4.6). The gas price is then differentiated by category with a discount of 15 per cent for the power sector and 10 per cent for the non-power sector (GMB) as shown in Figure 15.

\footnotetext{
${ }^{16}$ See Section 4.2 on how the long-term agreements in the power sector work. Single Buyer TNB aggregates gas to gas power plants under these long-term arrangements. In 2018, approximately about 47 per cent of daily gas consumption in the power sector was below this threshold (Table 3).
} 
Figure 15: Unregulated (Tier 2) piped gas prices (LNG indexed)

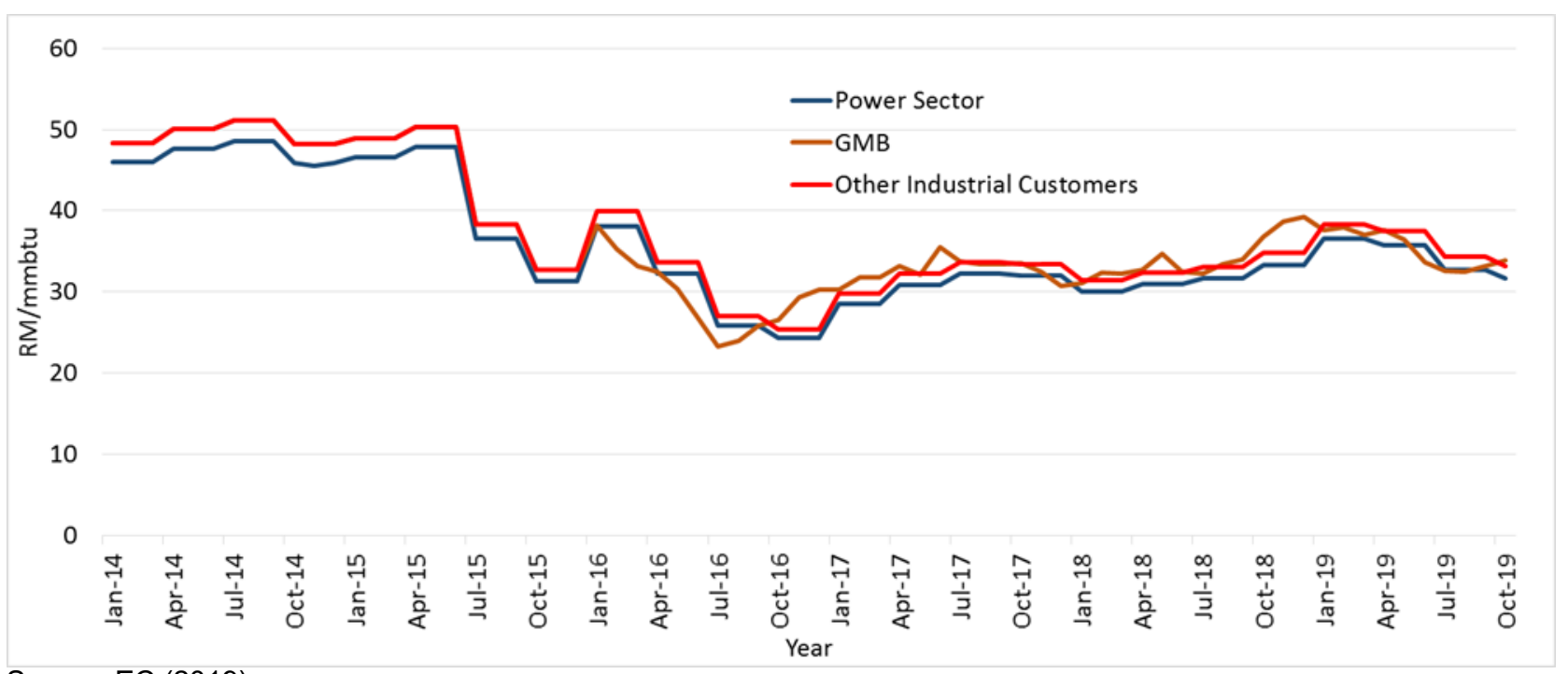

Source: EC (2019)

\subsubsection{Access to gas facilities}

Access arrangement (AA) documents and utilisation tariffs for the regasification terminals and the transmission network under the TPA system are approved by the regulator and published on the PGB website. PGB owns and operates these facilities. Access to these facilities is applied to all shippers on a non-discriminatory basis. Based on anecdotal evidence in 2019, infrastructure is only 73 per cent utilised, with the usage of the facility depending on gas demand. Based on AAs, TPA code and ST regulations, $\mathrm{PGB}$ analyses the historical use of the capacity by individual shippers over the previous six months in order to avoid capacity hoarding. If capacity is under-utilised (by more than a certain percentage), the shipper will be informed that part of its allocation could be transferred to new shippers under AA requirements. ${ }^{17}$ PETRONAS Gas Berhad (PGB) also owns processing plants that are not regulated under TPA, which means that markets players are not able to request access (see Section $6.3)$.

\section{Challenges and barriers during the TPA pilot phase}

Market entry for new players is still in the pilot phase. Towards the end of the pilot phase in 2019 , there had been no new entry into the gas sector despite insufficient domestic gas in Peninsular Malaysia. ${ }^{18}$ Negotiations between stakeholders had taken place, but no bilateral agreements had been achieved. Some stakeholders believe this was due to commercial issues. For example, there is no negotiation/communication on gas trading between customers and suppliers, and new players are waiting for opportunities to participate in the market when harmonisation of regulated and unregulated prices is achieved. Parties could refer to the EC for further clarification if technical problems in relation to TPA rules and regulation occurred during the pilot phase.

\subsection{Market entry and dominance}

PETRONAS has unbundled to meet the requirement of TPA with the establishment of PETRONAS Energy Gas Trading (PEGT) as LNG importer and shipper/supplier. PEGT is an independent company

\footnotetext{
${ }^{17}$ This is generally known as the 'use it or lose it' (UIOLI) principle.

${ }^{18}$ In October 2019, an LNG trial cargo arrived in Malaysia to test the TPA arrangement via the Regasification Terminal (RGT) in Sg. Udang, Melaka and Peninsular Gas Utilisation (PGU) gas pipeline network owned by PETRONAS Gas Bhd. The LNG gas was supplied by Shell Malaysia Trading Sdn Bhd (SMTSB) to TNB's power plants in Port Dickson, Negeri Sembilan and Connaught Bridge, Klang.
} 
but a subsidiary of PETRONAS. However, PETRONAS will have no control over PEGT decisions to purchase its LNG from PETRONAS LNG Company or from other suppliers. At the same time, PETRONAS is required to ensure that there is no discrimination between sales to PEGT and third parties ${ }^{19}$. The establishment of PEGT is to separate the role of a national oil and gas producing company (as outlined in the Petroleum Development Act 1974) from PEGT as a shipper/supplier. PETRONAS is also mindful that as a national oil company, there is a need to support TPA implementation, despite the fact that PEGT is a subsidiary of PETRONAS.

One of the possible reasons that the market structure has remained unchanged during the TPA pilot phase is because PETRONAS or PEGT (even after unbundling) supplied the entire domestic gas market. Under the new arrangements, TNB Single Buyer deals with PEGT for gas supply to the power sector, and Gas Malaysia Berhad (GMB) deals with PEGT for gas supply to the non-power sector. PEGT supplies domestic gas and LNG to power and non-power sectors with differences in gas pricing to Tier 1 and Tier 2 customers. But PEGT's costs of domestic gas and LNG are not transparent, which raises the possibility of price discrimination in the supply of gas to the existing market that may deter new entrants. Moreover, given the extent of long-term contracts (Section 4.2) there is also uncertainty about the volume of new demand that will be available for competition in the market.

Another dominance issue in the Malaysian gas market is the scope of regulators. Under the Petroleum Development Act 1974, PETRONAS is self-regulating. The Energy Commission (EC) is the downstream regulator under the Gas Supply (Amendment) Act 2016. Even if there is price discovery in the upstream gas market, EC's role is limited to downstream regulation and any upstream issues have to be referred to PETRONAS.

\subsection{Long-term contracts in the power sector}

Historically, PETRONAS is committed to supplying individual gas power plants at a subsidised price. To sustain the fuel security for the power sector, TNB and PETRONAS have an agreement that a certain quantity ${ }^{20}$ of gas will be supplied to TNB and IPPs for electricity generation, with the volume being much higher than for the non-power sector. Hence, a considerable volume is dedicated to the power sector under this agreement. ${ }^{21}$ TNB is required to forecast its gas requirements to PETRONAS a year in advance. PETRONAS as a national company operating in the national interest has also been reserving additional volumes in case power plants require gas beyond the TNB nominations. PETRONAS has also signed GSA with individual gas IPP plants. A GSA agreement is required in order to execute a PPA; TNB has PPAs with all power plants, including its own power plants. Under a PPA, power plants are required to stand by to generate electricity and TNB pays power plants the capacity and energy cost. GSA is in place to secure physical gas supply for the power plants. Under the GSA, plants pay regulated gas prices for all gas volume consumed; meanwhile GFA only handles the differences in regulated and unregulated gas prices. Individual power plants could sign a GSA contract with any gas supplier under a PPA. But PETRONAS has been the sole supplier, and all GSA contracts are with this company (as of 2019). Figure 16 illustrates the current arrangement and long-term contract between TNB, PETRONAS and gas power plants (TNB and IPPs).

\footnotetext{
${ }^{19}$ In Europe, these arrangements are generally referred to as 'legal unbundling'.

20 In 2003, PETRONAS had agreed to supply gas to the power sector with volumes limited to $1350 \mathrm{mmscf} / \mathrm{d}$. This volume limit was reduced to $924 \mathrm{mmscf} / \mathrm{d}$ due to curtailments of gas supply to the power sector in 2011. In 2012, the supply of gas was slightly increased to $1150 \mathrm{mmscf} / \mathrm{d}$ and reinstated again to $1350 \mathrm{mmscf} / \mathrm{d}$ by end-2013. No new gas power plant has been developed since 2003, but there has been a significant increase of coal-fired power plant from 3,670 MW in 2003 to 7,170 MW in 2011. (TNB 2012a, TNB 2012b).

${ }^{21}$ See Table 9 in Appendix, 'Gas supply agreement (GSA) on volume with individual power plants'.
} 
Figure 16: Long-term agreement in power sector

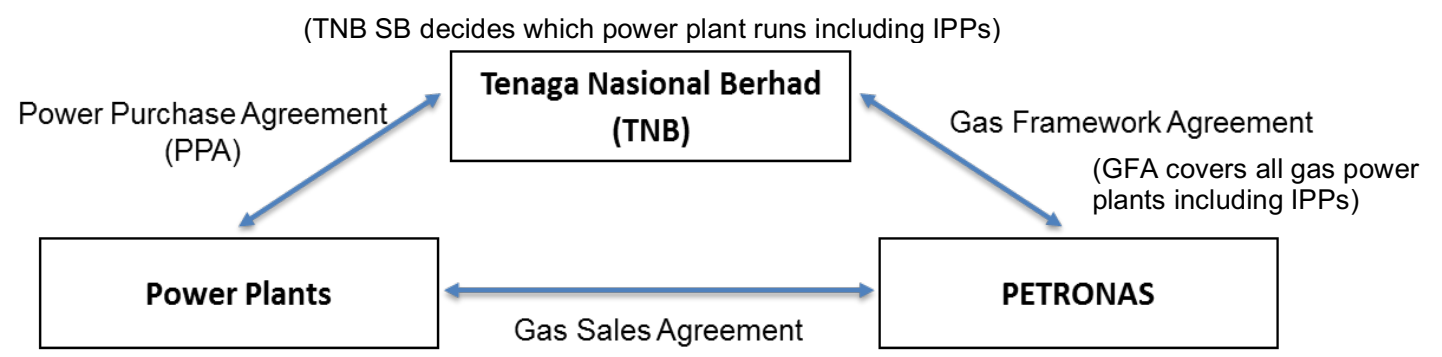

(GSA covers physical gas supply to all power plants including IPPs)

With the introduction of a subsidy rationalisation programme, questions were raised about who will pay the price for volumes above a threshold of $1000 \mathrm{mmscf} / \mathrm{d}$. IPPs are not willing to commit to a high gas price. However, when the regulated gas price reaches market parity, the power plants will pay for gas consumed at the market price directly to PEGT based on the power plants' GSA. There will not be an issue of IPPs not willing to pay a higher gas price, as all fuel costs will be entirely passed-through to customers under their PPAs. Removal of the gas subsidy also would directly impact the electricity tariff. The agreement with PETRONAS was revised under the GFA to manage the volume and pricing of gas to the power sector. Under the GFA, TNB Single Buyer determines the quantity of electricity to be generated and dispatched from each power producer (based on the PPAs), and hence determines the gas volume to be delivered to power producers to serve the grid.

The gas volume delivered is based on two-tier pricing, whereby volume below $1000 \mathrm{mmsfcd}$ is charged at the regulated gas price, with volumes above that level charged at the unregulated LNG-indexed price. In this case, power plants pay PEGT regulated gas prices for the gas consumption and TNB through TNB Single Buyer pays directly to PETRONAS the differential cost (Unregulated Price - Regulated Price) for gas consumed above $1000 \mathrm{mmscfd}$ (of both TNB and IPPs). Under this arrangement, PETRONAS is sole supplier of both domestic gas and LNG at different gas prices. Volumes are based on daily demand variations, for example, high power demand during high-temperature weather conditions. For instance, in 2018 there were 195 days when demand was above $1000 \mathrm{mmscf} / \mathrm{d}$, of which PETRONAS supplied $1000 \mathrm{mmscf} / \mathrm{d}$ at the regulated (price subject to subsidy rationalisation every six months), and any volume above $1000 \mathrm{mmscf} / \mathrm{d}$ supplied at the unregulated (quoted to TNB quarterly) price. Table 3 shows that demand was above $1000 \mathrm{mmscf} / \mathrm{d}$ for more than half the year, which means that the harmonisation of regulated and unregulated gas price may not significantly impact TNB's finances since any savings derived will be passed-through as ICPT rebate and conversely any additional costs will be passed- through as ICPT surcharge in consumers' electricity bill.

Table 3: Daily gas consumption (2018) in power sector

\begin{tabular}{lc}
\hline Volume (mmscf/d) & No. of Days \\
\hline above 1200 & 46 \\
\hline above $1000-1200$ & 149 \\
\hline above $800-1000$ & 135 \\
\hline above $600-800$ & 34 \\
\hline above $500-600$ & 1 \\
\hline
\end{tabular}

Source: TNB (2019)

However, as PETRONAS allocates all upstream gas production, unregulated volumes could be entirely from lower-cost domestic gas production (rather than higher-cost LNG). Therefore, the long-term agreement is a barrier for TPA implementation. The length of the GFA between TNB and PETRONAS 
is unknown. The expiry of GSAs between power plants and PETRONAS starts in $2020^{22}$. Under a $\mathrm{GSA}^{23}$, an individual power plant can seek gas from a new player. Once an agreement expires, individual power plants could (using the TPA system) negotiate a lower price ${ }^{24}$ than the price under the gas sales agreement. With the GFA, under which TNB Single Buyer manages the gas volume to power plants and decides which plants are to be dispatched, there are no incentives for power plants to search for new supplies.

Furthermore, the Imbalance Cost Pass-Through (ICPT) mechanism in the power sector aims to reflect fuel cost and generator cost variations, and any additional costs will be passed through to consumers. For example, due to higher fuel and generation cost in January-June 2018, the additional cost RM698.2 million or $1.35 \mathrm{sen} / \mathrm{kWh}$ ICPT surcharge was passed through to customers (SB 2019). ${ }^{25}$ In this case, IPPs were not affected by these changes in fuel and generation cost and the prices they pay for gas under the PPA model. Therefore, with the implementation of the ICPT mechanism, there are no incentives for them to search for new suppliers.

\subsection{Continued barriers to third-party access to LNG terminals and transmission pipelines}

PETRONAS Gas Berhad (PGB) operates and maintains LNG terminals and transmission pipelines. In March 2019, PGB published the Access Arrangements for LNG terminals and PGU, along with the tolling tariff for the utilisation of gas facilities (Table 1).

However, there could be a possibility that there will be insufficient pipeline capacity available for new players as the entire volume could be booked. TNB is required to submit a forecast for gas consumption for power a year in advance. Because of the GFA agreement with PETRONAS, all potential capacity could be booked for the entire year in advance. Even in a scenario where TNB does not submit a gas forecast which is equal to available capacity, PETRONAS still has to book capacity based on the total of GSAs for the entire year, which may mean that insufficient capacity remains available for new players. As mentioned above, to ensure optimal transmission capacity booking, PGB analyses the historical capacity usage of a shipper and, if underused, this allocation will be given to new shippers under the 'use it or lose it' provisions of the access arrangements (AAs). But there is uncertainty about how efficiently this mechanism will operate and potential shippers will be uncertain about guarantees of available capacity of transmission pipelines.

Concerns have been also expressed that there could be a possible barrier as PGB is the operator of gas pipelines as well as the owner of processing and regasification facilities. Unbundling of these facilities has not yet taken place and there are no plans to unbundle and provide access to processing plants. Until this situation is clarified, there may be conflicts of interest in providing these services and achieving a fully competitive market.

\subsection{Distribution network unbundling}

GMB is involved in the distribution, shipping and sale of gas to industry, residential and commercial consumers. GMB was established in 1992 with 18 per cent owned by PETRONAS, and a majority share owned by MMC Corporation Berhad. By 2019, the shareholders of GMB were MMC Corporation Berhad (30.9 per cent), Tokyo Gas-Mitsui (18.5 per cent), PETRONAS Gas Berhad (14.8 per cent) and Public (35.8 per cent). GMB needs to unbundle and to establish separate shipping and sales, and distribution entities. As an incumbent distribution company, GMB applied for licences in January 2018 and, at the

\footnotetext{
22 Two power plants expire in 2020 , followed by two more in 2022 . The rest of the power plants to expire after 2023 with the last one expiring in 2044 under the GSA.

${ }^{23}$ Existing or new power plants which signed a GSA agreement after May 2013 will have to pay the unregulated gas price but can negotiate directly with other suppliers. Although the GSA prices are based on the Tier 2 gas pricing, the contract also recognises that as long as there is Tier 1 gas pricing, the power plants would still pay PEGT the Tier 1 pricing.

${ }^{24}$ See section 4.6 on new suppliers' concerns about gas pricing and discounts on unregulated gas prices to the power sector

${ }^{25}$ The ICPT surcharge was only applied to non-domestic customers, and domestic customers were not affected as they were subsidised by the Electricity Industry Fund (KWIE).
} 
same time, requested time to transfer its assets and to unbundle its existing contracts with end consumers. Although GMB has applied for licences, the licences cannot be issued until unbundling is completed. In 2019, unbundling of GMB had not yet happened.

The distribution tariff at regulated prices agreed with customers (as of 2019) was still bundled and included the cost of gas + transmission + distribution. There are some challenges in terms of asset transfer (administrative hurdles) and unbundling of existing contracts - especially GMB's current contract with PETRONAS. Once unbundled, GMB will have two subsidiaries: GMD (Gas Malaysia Distribution) which will hold a distribution licence and GMES (Gas Malaysia Energy and Services) which will hold a shipping licence. The network assets that currently belong to GMB need to be transferred to GMD (Figure 13).

There are some changes in the contractual landscape in Peninsular Malaysia with changes in existing, and the emergence of new, parties/players under the TPA system. GMES has to sign new arrangements with PEGT, with the latter buying gas from upstream and selling to GMES which then sells to customers. Therefore, GMES has to pay PEGT according to the following formula:

Cost of gas purchased + regasification tariff $(R G T)^{26}+$ transmission tariff (to PGB) + distribution tariff (to GMD)

For TPA to operate effectively, AA documents and tolling tariffs are needed for third parties to evaluate the costs and risks involved in using the infrastructure before approaching any consumers. GMB submitted the first draft of the AAs for distribution in December 2017 and a revised version in 2018 (after the licence application). The AAs for transmission and RGTs were prepared and published first in March 2019. At the time of writing (December 2019), the AAs and tariffs for distribution had not yet been published but were expected soon.

\subsection{Retail licences tariffs and infrastructure requirements}

Seven different activities require licences under TPA: LNG import to regasification terminals, shipping, regasification, transportation, distribution, retail and private gas (discussed in Section 3.4.2). Interested parties can obtain licences from the EC for all activities except for retail licenses tariffs and infrastructure requirements that are not yet in place. In Peninsular Malaysia, owners of multiple occupation premises, such as shopping malls, own the internal pipelines within their buildings. Any tenant (e.g. food outlet) within such buildings currently has a contract with GMB. GMB coordinates and supplies gas to these customers despite not owning the internal gas pipelines.

This situation will change under TPA, and GMB will only be allowed to supply up to the distribution meter at the entry to the building. Building owners will have to apply for retail licences, which will give them the option to buy gas from PETRONAS Energy \& Gas Trading (PEGT), Gas Malaysia Energy and Services (GMES) or any other potential supplier and create a retail tariff which needs approval from the Energy Commission (EC) in order to sell gas to each of the tenants within the building. A retail licence is also required for internal pipelines supplying residential apartments. The issues/challenges involved with retail licencing are:

- Additional infrastructure is needed, e.g. meters that can register daily demand or nomination for each unit within these buildings. For example, GMES would supply gas as far as the meter at the entry to a specific building. The building owner will then have to install a daily meter for each individual tenant within a mall or an apartment block.

- The building owners, e.g. shopping malls or residential apartments, are not in the gas business and unsure about retail licence application and billing their tenants. The building owner is uncertain about the process of becoming a retail licence holder and many are not willing to become licence holders because of the complexity of the process. For example, a shopping mall owner has to buy gas from PEGT or GMES, and create a retail tariff (comprising gas cost

\footnotetext{
${ }^{26} \mathrm{Gas}$ supplied to GMB is charged at the regulated gas price up to $300 \mathrm{mmscf} / \mathrm{d}$. Any volume above this threshold is charged at the unregulated gas price and in this case, the RGT tolling tariff is applicable.
} 
purchased from PEGT/GMES + transportation cost through the internal pipeline + metering + margin) for each tenant. Another example is the apartment buildings in Putrajaya where pipelines are ready, but GMB is not able to sell gas to individual apartments. There is a similar problem for owners of small hotels which are uncertain about applying for a retail licence without which they will be unable to consume gas.

These problems need to be resolved. This class of customer needs time to understand the system, apply for a retail licence and obtain approval for their charges from the Energy Commission (EC). Building owners have to purchase gas from the shipper, and create retail tariffs which include all the different elements for delivery to their customers. It is an extremely complex system which may not be workable.

\subsection{Gas pricing reform}

Gas pricing is one of the main challenges to the implementation of TPA in Peninsular Malaysia. Piped gas prices have been kept artificially low by the government and have distorted the gas market. As long as there is a price difference between piped gas and LNG, with continued regulation of piped gas prices, entry into the gas market will not be attractive to new players. Gas prices in Peninsular Malaysia are determined based on a two-tier pricing model - regulated piped and unregulated LNG - (discussed in Section 3.4.3) with the aim being to harmonise these prices. However, in October 2019, unregulated (LNG indexed) prices were still above regulated prices (Figure 17). ${ }^{27}$ Harmonisation of these prices will also depend on the movement of international LNG prices, which are linked to crude oil prices (the LNG ex-Bintulu price is heavily dependent on the Japanese Customs-Cleared (JCC) Oil Import Price and consequently on crude oil prices). These LNG prices are differentiated with a discount of 15 per cent for the power sector and 10 per cent for the non-power sector (GMB), and price harmonisation will happen sooner in a period of low crude oil prices. Hypothetically, assuming that international oil prices remain around $\$ 60 / \mathrm{bbl}$ up to the end of 2019 , then price harmonisation is foreseen to happen in early 2020 (subject to RM1.50 per MMBtu increase of a regulated price the next six months and the Q4 2019 of LNG price quoted to TNB and GMB). 
Figure 17: Unregulated and regulated gas price to power sector and GMB
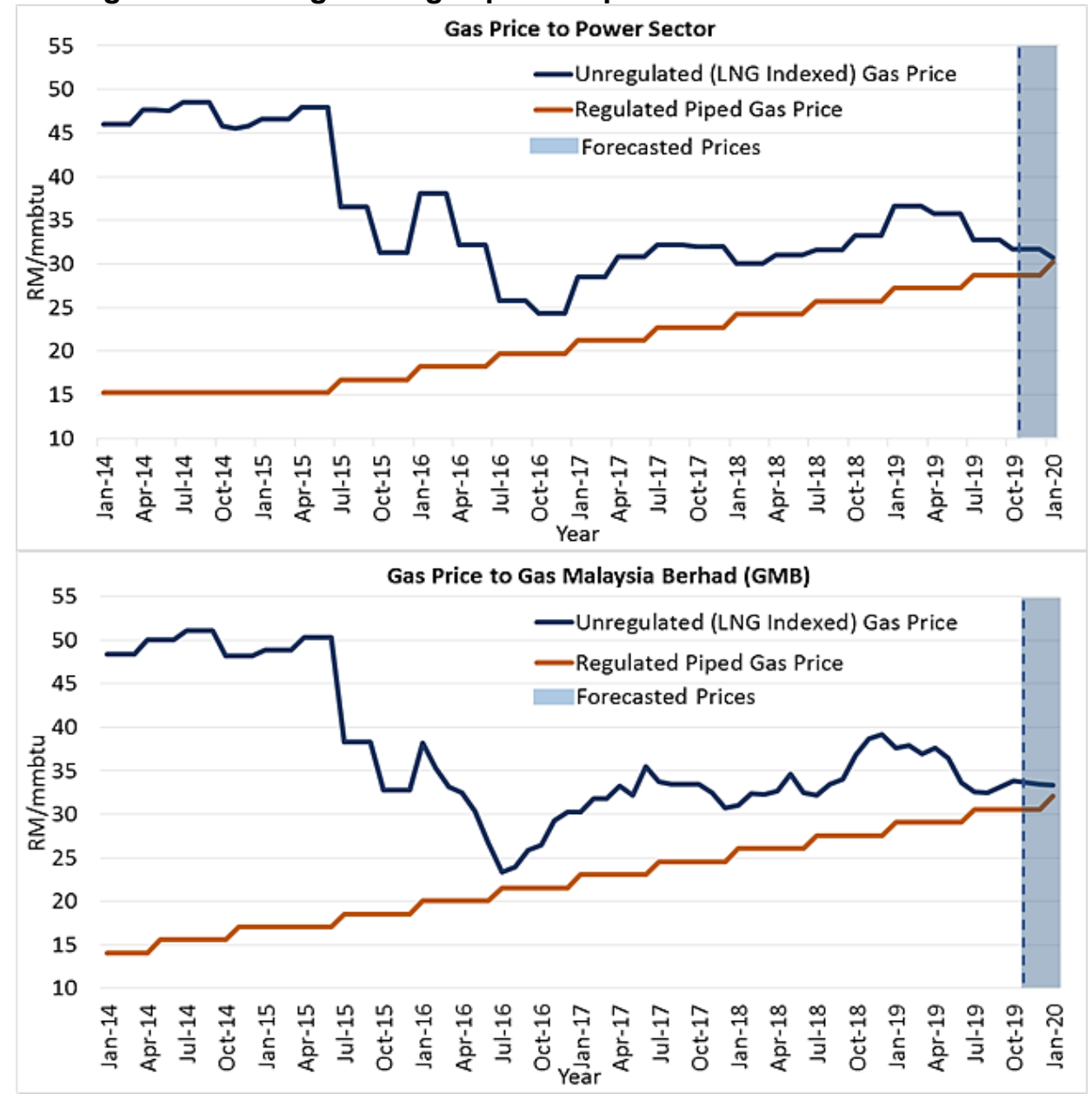

Source: EC (2019)

\subsubsection{Price regulation}

Regulated (Tier 1) prices of wholesale gas supplied to the non-power sector and power sector will increase by RM1.50 per MMBtu every six months until parity with unregulated prices is achieved. Unregulated (Tier 2) prices are derived from the LNG Free on Board (FOB) Weighted Average Price (WAP) ex-Bintulu with a 15 per cent discount for the power sector and a 10 per cent discount for the non-power sector. The objective of these discount rates is to narrow the gap between the unregulated and regulated prices. The formula for the LNG FOB WAP ex-Bintulu price is based on a portfolio of prices which PETRONAS charges to its LNG buyers. The logic behind the ex-Bintulu price was that, if Petronas did not have to deliver this gas to the domestic market, it could export more LNG.

In the power sector, the 15 per cent discount rate is negotiated between the incumbent and utility company based on LNG FOB WAP ex-Bintulu marker ${ }^{28}$. The pricing formula that is used to derive the reference market price for power sector as outlined in the Gas Framework Agreement (2017) and Lim and $\operatorname{Kim}(2019)$ is as follows:

\footnotetext{
${ }^{28}$ It is not clear how these discount rates are decided. These discount rates are arbitrary and not transparent, and the market price that is negotiated is unclear.
} 

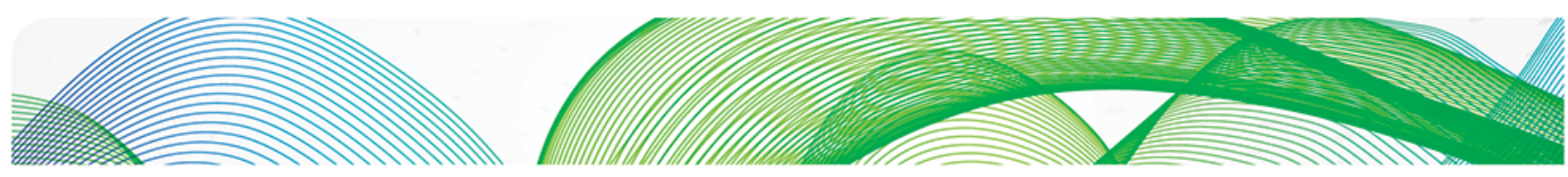

Reference market price for power sector $=$ Product cost + Delivery cost

whereby

Production cost $=$ LNG FOB WAP ex-Bintulu price $\times 15 \%$ discount

Delivery cost $=$ Shipping cost + Regasification cost + Transmission cost

This formula is used to determine price harmonisation of regulated and unregulated gas price in power sector. The LNG FOB WAP ex-Bintulu marker will be used until price harmonisation is achieved. There are two logical ways to reflect LNG-based market prices:

1. The LNG FOB WAP ex-Bintulu price + shipping cost + regasification cost + transportation (a distance-related element for delivery to power plants) cost; or

2. PETRONAS's weighted average price for its LNG imports + regasification cost + transportation cost.

The regasification and transportation cost should be the same for both of the pricing methods. The difference between these methods is the ex-Bintulu price + shipping cost compared with the weighted average price for LNG imports, and either of these methods could be a starting point for LNG-based market prices. In the future, all shippers and buyers need to get to a market price based on pipeline gas and LNG. Then, shippers and buyers will be able to negotiate gas prices based on other possible international markers, such as the Japan-Korea marker (JKM) which is increasingly being used for short-term trading in Asia (see section 6.2).

However, potential shippers are uncertain about the following issues which could present barriers to new players:

1. Transparency of the different elements that make up the LNG FOB WAP ex-Bintulu marker. This marker is based on the average price of PETRONAS's long-term oil-indexed contract exports to Korea, Japan, and imports from Australia, which may be an advantage to PETRONAS. A different marker is needed that reflects the gas supply-demand situation in Malaysia which would reflect the weighted average cost (WACOG) of domestic production, pipeline imports and LNG imports (see below).

2. Although there is a possibility to negotiate the discount rate, potential shippers are unsure of the prices based on the ex-Bintulu marker due to lack of price transparency and PETRONAS's dominance of LNG exports and imports.

3. New players are concerned that they will not be able to compete with those being supplied by PETRONAS because of these discounts.

\subsubsection{Stages of gas price harmonisation}

\section{i. Stage 1: Progressive harmonisation of power and non-power prices}

The harmonisation of gas prices to power (regulated and unregulated) and non-power prices (regulated and unregulated) is (as of 2019) being implemented and expected to be completed within one to three years. Currently, bilateral negotiation is encouraged between the customers and new market entrants. Once there is a single gas price for power and non-power customers, the regulator(s) will need to define a methodology for calculating a market price set by supply and demand fundamentals removing the need for bilateral negotiations.

\section{ii. Stage 2: Harmonised pricing for a unified gas market}

In the opinion of some stakeholders, following the achievement of a single price for both power and non-power customers, a discounted rate along the lines of reference market price formula could be negotiated equally in both sectors. However, in a competitive market the practice of discounts will need to be replaced by market pricing based on costs and competitive forces.

The first stage of harmonisation is currently being implemented and regulated by the government. In the opinion of some stakeholders, the second stage of gas price harmonisation should create a single price for all users. 


\section{The changing global LNG market and potential impact on ASEAN}

Over the past decade, LNG has changed from being a niche business with a relatively small number of players operating rigid long-term contracts, to a globalising market with rapidly increasing volumes of trade and numbers of participants. These trends will continue over the next decade, with large numbers of new liquefaction projects taking final investment decisions in 2019-20 and new players coming into the market due to technological advancements, particularly floating storage and regasification terminals (FSRUs). Figure 18 shows that projects that had taken final investment decisions by the end of 2018 will increase global LNG supply by $100 \mathrm{Bcm}$ over the next decade, but that anticipated demand (the import line in Figure 18) meant that by 2025 there could once again be a shortage. By September 2019, projects totalling another $80 \mathrm{Bcm}$ had taken investment decisions which could mean that any shortage of supply over demand will be delayed for several years beyond 2025. Additional LNG export projects, particularly in the US, Mozambique and Qatar, seem set to take FID during 2020, and this could further extend the period of supply surplus and hence lower LNG prices.

Figure 18: Liquefaction projects that had taken a final investment decision by the end of 2018

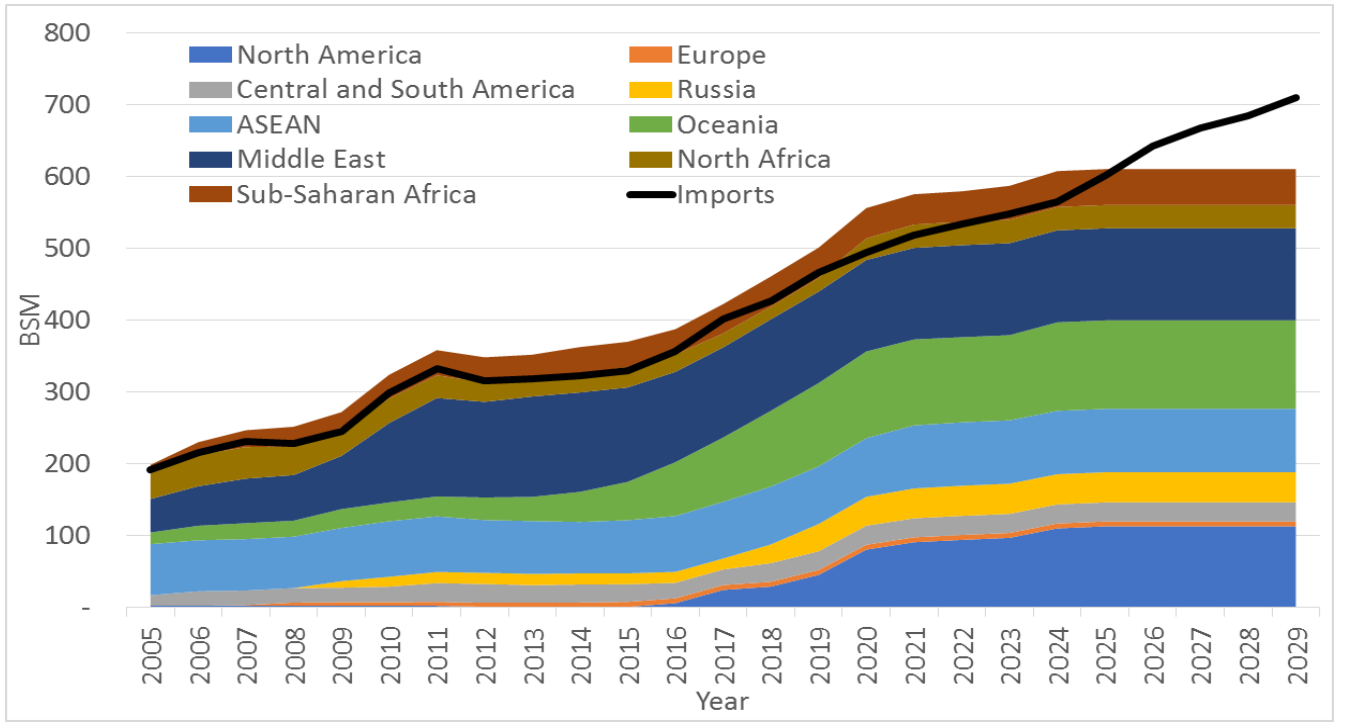

Source: Fulwood (2019)

\subsection{ASEAN gas demand and LNG imports}

ASEAN gas consumption is significant but, as Table 4 shows, highly concentrated in Thailand, Malaysia and Indonesia. Two-thirds of ASEAN's gas reserves are located in Indonesia and Malaysia, the traditional LNG exporters in the region (along with Brunei). Production in the region totalled $223 \mathrm{Bcm}$ in 2018, but is declining in most countries and it is projected that by around the middle of the 2020s the region will no longer be a net gas exporter (5th ASEAN Energy Outlook).

Table 4: Gas consumption in ASEAN in 2018

\begin{tabular}{lc}
\hline Country & Demand $(\mathbf{B c m})$ \\
\hline Thailand & 49.9 \\
\hline Malaysia & 41.3 \\
\hline Indonesia & 39.0 \\
\hline Singapore & 12.3 \\
\hline Vietnam & 9.6 \\
\hline Philippines & 4.1 \\
\hline
\end{tabular}

Source: BP (2019)

Note: Data on gas consumption in Brunei and Myanmar are not published, but a total for 'other Asia Pacific' of 12.0 $\mathrm{Bcm}$ is reported in the source, and there is no gas demand in Cambodia and Laos. 
LNG imports are increasing despite constraints on economic viability and limited pipeline connectivity due to regional geography. Nevertheless, pipelines connect many of the ASEAN countries (Table 5) and although capacities are small, these could be increased to facilitate trading depending on the availability of gas and LNG in different countries.

Table 5: Intraregional pipelines in ASEAN

\begin{tabular}{|c|c|c|c|}
\hline Intraregional & Pipeline & Operational (year) & Capacity (Bcm/yr) \\
\hline \multirow[t]{2}{*}{ Myanmar-Thailand } & Yadana-Export Pipeline & 1998 & 5.4 \\
\hline & Yetagun-Export Pipeline & 2000 & 2.0 \\
\hline Thailand-Vietnam & PM3-Ca Mau Pipeline & 2007 & 2.0 \\
\hline Thailand-Malaysia & $\begin{array}{l}\text { Trans-Thailand-Malaysia gas Pipeline } \\
\text { (TTM) }\end{array}$ & 2005 & 7.7 \\
\hline Malaysia-Singapore & $\begin{array}{l}\text { Peninsular Gas Utilisation Pipeline } \\
\text { System (PGU) }\end{array}$ & $1991 \& 2007$ & 2.6 \\
\hline \multirow[t]{2}{*}{ Indonesia-Singapore } & West-Natuna Transportation & 2001 & 3.4 \\
\hline & Grissik-Singapore Pipeline & 2003 & 3.6 \\
\hline
\end{tabular}

Source: IEA (2013)

There is significant uncertainty about the development of LNG demand to match the increasing supply. Although there is likely to be a decline in Japanese imports, and modest growth in the other established LNG markets of South Korea and Taiwan, there will be very substantial increases elsewhere in Asia, particularly in China and south Asia (India, Pakistan and Bangladesh). Table 6 shows a projection of LNG imports by ASEAN countries for the period up to 2030, which suggests these will increase from less than $14 \mathrm{Bcm}$ in 2018 to $73-96 \mathrm{Bcm}$ in 2030 . All countries are projected to significantly increase their imports and Vietnam and Philippines will become new LNG importers.

Table 6: Low and high projections of ASEAN LNG imports 2018-30 (Bcm)

\begin{tabular}{lccc}
\hline & $\mathbf{2 0 1 8}$ & \multicolumn{2}{c}{$\mathbf{2 0 3 0}$} \\
\hline & & Low & High \\
Indonesia & 3.8 & 14.2 & 19.3 \\
Malaysia & 1.9 & 8.3 & 14.9 \\
Thailand & 5.6 & 22.5 & 25.9 \\
Singapore & 2.4 & 17.8 & 22.4 \\
Vietnam & 0 & 8.3 & 10.2 \\
Philippines & 0 & 1.7 & 3.0 \\
Total & 13.7 & 72.8 & 95.7 \\
\hline
\end{tabular}

Source: Rogers (2016)

Even if only the lower figure is reached, this would be an increase of nearly $60 \mathrm{Bcm}$ of LNG imports by 2030 compared with 2018. The current global LNG surplus and a low price environment will be beneficial for LNG and gas demand throughout ASEAN. Figure 19 shows that in mid-2019, spot prices in both Europe (TTF) and Asia (ANEA) were at record low levels and much lower than long-term Asian LNG (JCC) prices. However, as Figure 19 shows, for much of this period spot prices since 2012 have been at much higher levels and therefore the 2019 price level should not necessarily be assumed to continue. 
Figure 19: Regional gas and LNG prices 2012-19

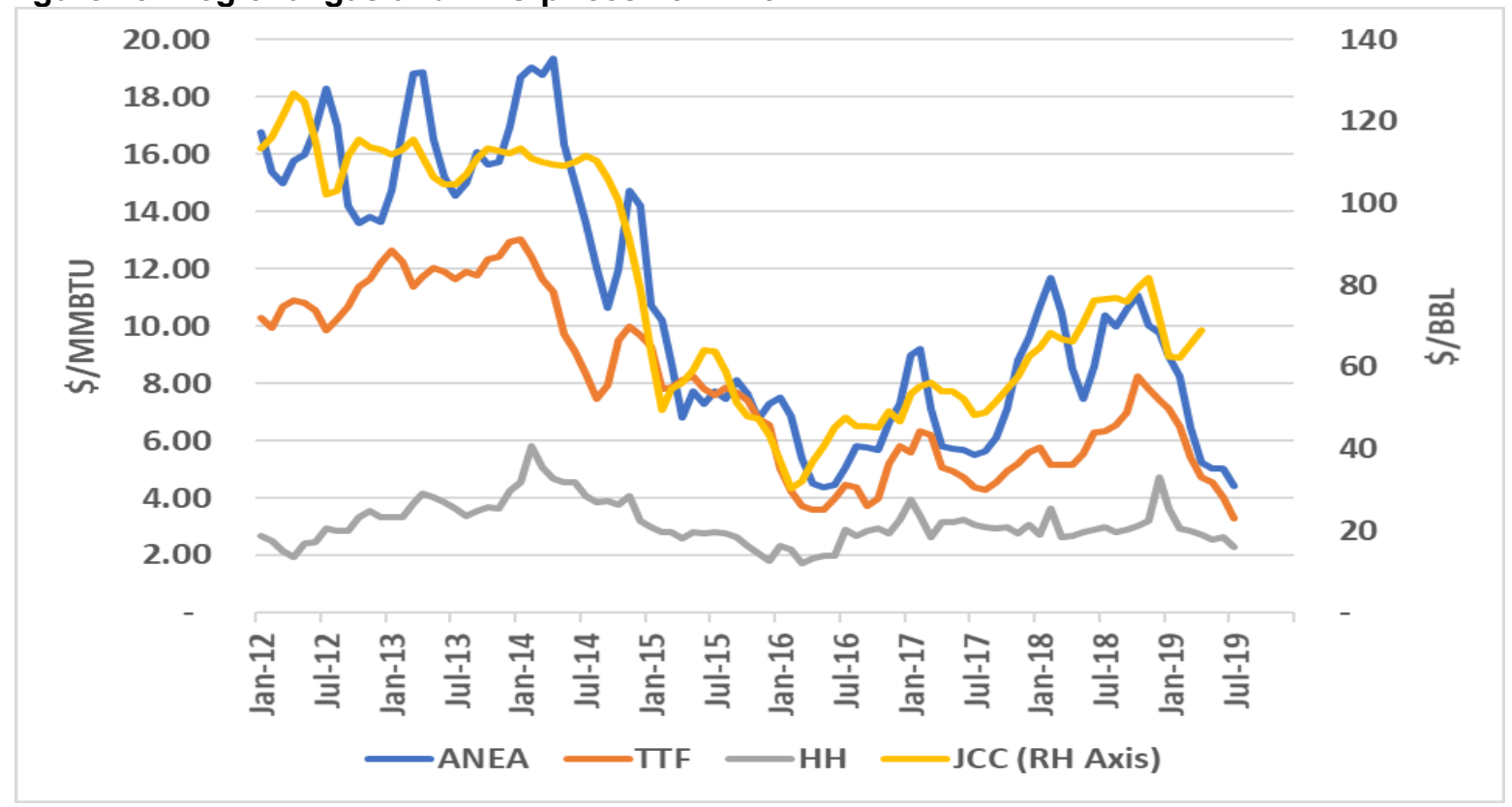

Source: Fulwood (2019)

\subsection{Increased spot LNG trade and the evolution of spot prices}

Spot and short-term LNG trade has grown significantly over the past decade and accounted for about 30 per cent of global LNG trade in 2018 (spot LNG rose almost seven percentage points) as in Figure 20. Global LNG trade is still dominated by oil-linked pricing (OPE), but spot trade at market prices is changing the picture. Gas on gas competition accounted for more than 50 per cent of LNG imports into Europe in 2018 as compared to 33 per cent in 2017. Gas on gas competition share can be divided into LNG going into traded markets (countries with liquid traded markets, e.g. Northwest Europe) and spot LNG (generally contracts under a year). Significant increases in global LNG supply - at least $150 \mathrm{Bcm}$ and probably closer to $200 \mathrm{Bcm}$ - over the next decade (in Figure 18) will increase spot trade considerably. By 2020 there will be about 15-18 LNG cargos on the water every day. In 2018, out of $135.1 \mathrm{Bcm}$ of spot and short-term global LNG imports, about $98.4 \mathrm{Bcm}$ of LNG was imported by Asian countries (GIIGNL 2019). ${ }^{29}$ ASEAN countries ${ }^{30}$ imported only $2.52 \mathrm{Bcm}$ of these cargos and 'real trading' has yet to happen in this region. Virtually all the gas imports and exports within ASEAN are currently based on long-term contracts to ensure security of supplies for importers and markets for exporters.

\footnotetext{
${ }^{29}$ Note: According to GIIGNL, spot and short-term imports are defined as volumes delivered under contracts with a duration of four years or less.

${ }^{30}$ Malaysia $(0.1 \mathrm{Bcm})$, Singapore $(0.35 \mathrm{Bcm})$, Thailand $(0.88 \mathrm{Bcm})$ and Indonesia $(1.19 \mathrm{Bcm})$
} 
Figure 20: LNG imports 2005 to 2018

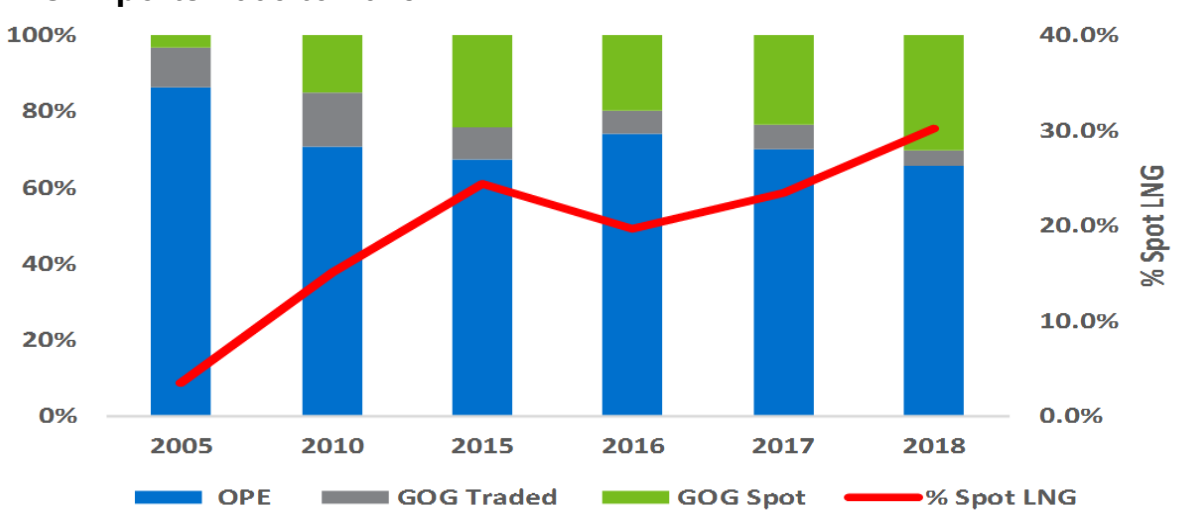

Source: IGU (2019a)

But the global surplus of LNG forced spot prices down towards (and even below) $\$ 4 / \mathrm{mmbtu}$ for some periods in 2019, and this price level should encourage new players to seek access to LNG terminals and pipelines, creating competition and price transparency. If spot LNG prices remain around this level, they will be competitive in ASEAN gas markets (Figure 21). Existing pipeline connectivity and regasification terminals within ASEAN should allow countries to access LNG at more competitive prices and create significant opportunities for trade. If liberalisation of the gas market and new market entry through TPA is successful, prices will increasingly reflect a regional LNG price marker.

Within ASEAN, Singapore is the most liberalised market with own gas price marker, the SGX LNG Index Group (Sling) was launched in 2015 by Singapore Exchange (SGX) and Energy Market Company (EMC). Financial markets in Singapore are well-developed and more than 40 LNG traders have offices in the country. However, the Singapore proved too small a market with insufficient liquidity to support a price index marker and, in July 2019, SGX announced that it was discontinuing the Sling index due to lack of trades. ${ }^{31}$ Over the same period, the Japan-Korea marker (JKM) has become increasingly dominant in the spot and short-term Asian LNG market (Bennett, 2019).

JKM has become the dominant Asian LNG price marker because Japan and Korea have traditionally been the biggest LNG markets, and because Platts is one of world's main energy price reporting agencies has created a marker with a credible and transparent methodology which has been rapidly embraced by those wishing to trade short term LNG in the Pacific. None of the other LNG price markers have seen such huge growth in volume and liquidity and it seems unlikely that JKM will be challenged until and unless a major price discovery hub is created in Asia, which at present is mostly likely in China.

${ }^{31} \mathrm{https}: / / \mathrm{www} . \mathrm{emcsg} . \mathrm{com} / \mathrm{sling}$ Sling indices will be discontinued in October 2019. 
Figure 21: ASEAN wholesale gas prices 2005-18

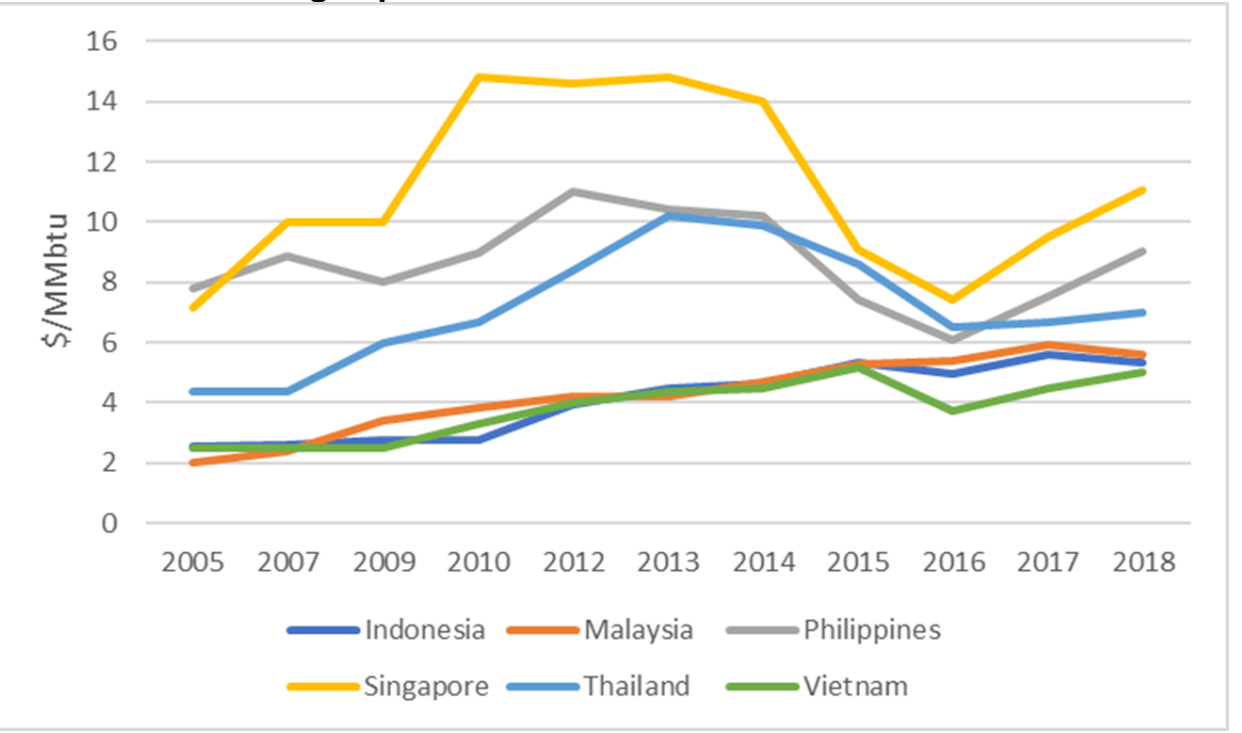

Source: IGU (2019a)

\subsection{The potential impact of LNG spot trading and pricing on the Malaysian gas market}

In Malaysia, all consumers are buying gas from a dominant gas supplier which controls the whole supply chain. PETRONAS's LNG FOB WAP ex-Bintulu marker is used to set unregulated gas prices in Malaysia. But potential shippers are uncertain about the transparency of this marker which is based on long-term LNG export contracts with Japanese and Korean customers. Anecdotal evidence suggests there are times where the marker trendline is sometimes below and sometimes above oil-linked LNG prices depending on the formulae in PETRONAS's contracts with its buyers. ${ }^{32}$ LNG traders are not comfortable with the ex-Bintulu marker since it is not used in the global market. The biggest challenge is how to develop transparent prices that reflect the realities of both the Malaysian (and perhaps the wider ASEAN) gas market and the global LNG market. In the late 2010s, short- and medium-term LNG contracts are being signed linked to different mixtures of: crude oil (Brent), Henry Hub (US), NBP and TTF (Europe), and JLC (Japan). Some contracts also have a share of JKM as short-term LNG trading begins to play a bigger role across the region.

Regional spot and short-term LNG trading will have an impact on the Malaysian gas market if price liberalisation and third-party access are successful, because it will encourage new and existing players to participate in the value chain. At present, the market is dominated by a long-term agreement and long-term contracts with PETRONAS. Only the incumbent has access to domestic gas, and the price it charges to the power sector removes the incentive for market players to look for alternative suppliers. But this may change if the opening of the gas market results in other parties gaining access to spot LNG cargos.

Pipeline connectivity between Malaysia, Singapore, Indonesia and Thailand (Table 5) could provide more significant opportunities for trading of both gas and LNG within the region, which would create price convergence between the major ASEAN markets. An independent regulator with oversight and powers across the gas value chain could accelerate these developments. 


\section{Ways forward towards gas market liberalisation and competition in Malaysia}

Previous sections described some of the important barriers to the participation of new players in the TPA pilot phase. These will need to be removed in order to make progress towards a liberalised and competitive market. This section highlights some initiatives which could be taken to break down these barriers.

\subsection{Increasing demand in the non-power and power markets and releasing gas from long-term contracts}

There are some possibilities for creating new gas demand in both power and non-power sectors. Gas prices have gradually increased since 2014 following the subsidy phase-out programme. To mitigate the impact of increasing gas prices in the power sector, initiatives were taken to switch from gas to coal, which is much cheaper. This decision was taken to offset the impact of gas prices on electricity tariffs, and the priority given to affordability of electricity. ${ }^{33}$ Following this switch to coal, the government intended to decarbonise and diversify the fuel mix in the power sector by introducing a target of 20 per cent renewables in the electricity generation mix by 2025 . With increasing renewables integrated into the system, gas-fired power plants could be a back-up system that can be ramped-up during peak demand periods; and also, when intermittent renewables (e.g. solar) are not producing. Therefore, a combination of gas and renewables can provide a competitive advantage in the power system. Cogeneration plants to promote energy efficiency in the power sector may also create new demand if gas is available at a competitive price.

With the implementation of decarbonisation strategies and clean air regulation in 2018, there are also possibilities for industries to consume more gas in the non-power sector. LNG bunkering for marine vessels is another initiative to create demand in new sectors, with an option to develop one of the regasification terminals as a regional LNG bunkering hub. Another possibility would be to truck LNG to customers in remote areas. Remote small and medium-sized industries are still consuming oil, and LNG trucking could encourage switching to a cleaner fuel. It takes almost two years to build pipelines to supply gas to remote areas and is also very costly (although the government is currently considering expanding gas pipelines to remote areas to create new demand), making LNG trucking a potentially attractive option. ${ }^{34}$

An important obstacle to competition in the non-power sector (described in Section 4) is that gas consumption in 2018 was $513 \mathrm{mmscf} / \mathrm{d}$, and is unlikely to expand substantially unless new sectors can be opened up to gas. ${ }^{35}$ The volume at the regulated gas price is $300 \mathrm{mmscf} / \mathrm{d}$, with unregulated prices for daily gas consumption above that volume. Energy-intensive industries are using less gas, but although there is strong growth from small industries using gas as an alternative to diesel (which is more expensive), at present the non-power volume is not big enough to attract new suppliers.

Other consumers of gas in Peninsular Malaysia are large industries, e.g. petrochemical companies, which are owned by, and would only purchase gas from, PETRONAS. Hence, at present there is too little volume available to attract new players and create competition.

The way forward is to revise the long-term GFA to unlock some of the gas volumes ${ }^{36}$ and allow these to be purchased by other parties on short-term contracts. This would create liquidity and space for new

\footnotetext{
${ }^{33}$ Moreover, an increase in coal generation was also due to depleting domestic gas resource and incapacity to import the LNG to meet the demand. The heavy reliance on gas caused a significant impact on the power sector during the prolonged gas curtailment event in 2011. This issue will also be addressed in electricity research.

${ }^{34}$ According to Natural Gas World (October 2019), PETRONAS has launched an LNG trucking business to cater to off-grid customers in Peninsular Malaysia, and commercial operations are expected to start in the second half of 2020. Transport of LNG via trucks could be the model to facilitate gas conversions for industries. LNG sourced from the Pengerang regasification terminal will be transported via trucks to off-grid customers located away from the main pipeline, as well as to small-scale customers. ${ }^{35}$ See Table 10 in Appendix: Average sales volume in non-power by GMB.

${ }^{36}$ The GFA agreement was initiated in 2017 to comply with government requirements on two-tier pricing and to ensure that IPPs could manage the fluctuation of gas prices (IPPs pay PETRONAS the regulated gas price). The threshold of $1000 \mathrm{mmscf} / \mathrm{d}$ was introduced to price gas based on the demand and not on the source of gas (PETRONAS could be selling either domestic gas or
} 
market entry (similar 'release gas' programmes have been used particularly in European countries to promote competition, see Section 7). Initiatives could also be taken to create a greater degree of flexibility of supply and demand in existing contracts. If some space in the market can be established by these initiatives, demand for long-term and short-term volumes, taking into account seasonality, could be identified.

\subsection{Transitioning to market-based pricing}

Towards the end of 2016, the LNG-based unregulated price gradually decreased, coming close to convergence with the regulated gas price of the power sector (Figure 17). However, this opportunity to kick-start competition was overlooked by the government when spot prices were low, and some large customers were anticipating TPA being introduced. PETRONAS was also advocating policymakers to encourage customers to buy spot LNG and start trading. Some customers came close to securing deals, but spot prices then increased to a level which meant that imports were not commercially feasible as the market environment was still influenced by regulated prices. However, as noted above, low price levels during 2019-20 present a new opportunity to import spot LNG.

As of October 2019, gas prices are based on the two-tier pricing model for power and non-power (Section 3.4.3). If the Tier-1 volume threshold in the power and non-power sectors under long-term contracts can be revised downwards to create greater flexibility, then volumes sold at Tier-2 prices would rise, creating greater business opportunities. This will depend on how new players see these opportunities as prices of regulated and non-regulated gas reach parity, possibly early in 2020 . Participation of new players could provide new sources of supply and gas price discovery. New shippers taking even a small market share could lead to price discovery, which would create the possibility of restructuring tariffs for transmission and distribution. Price convergence will create a wholesale price reference and, although there are different stakeholder views, there is a high probability this will be achieved in 2020, and certainly not longer than two years beyond that date.

Price increases will impact high value-added industry which mainly depends on gas. Gas accounts for 37 per cent of final energy consumption in the manufacturing sector (Table 7). This sector includes iron and steel as well as food, beverages and tobacco.

Table 7: Final energy consumption by fuel in the manufacturing sector in 2016 (Mtoe)

\begin{tabular}{lllllllll}
\hline Gas & Petrol & Diesel & Fuel Oil & LPG & Kerosene & Coal & Electricity & Total \\
\hline 4.642 & 0.099 & 1.290 & 0.477 & 0.124 & 0.002 & 1.690 & 4.220 & 12.544 \\
\hline
\end{tabular}

Source: NEB (2016)

When the subsidy rationalisation programme was introduced in 2014, industry was given a five-year period to prepare and adapt to the new pricing arrangements. This period gave industries time to study how to move up the value chain to take advantage of liberalisation and improve their understanding, access to technology and ability to forecast their future requirements. Incentives may be needed to encourage fuel switching (e.g. from oil to gas) and create new demand in the industry sector. There is a possibility that industries could form a consortium to buy LNG from a new supplier, but this also involves organisation, investment and risk. There is also concern about household affordability when the true cost of supply is passed through to customers.

LNG - or a mixture of the two - to IPPs and TNB). The threshold will be critical if the consumption is above $1000 \mathrm{mmscf} / \mathrm{d}$ for many days in a year. For example, in 2018 daily consumption was above this threshold for 53 per cent of days. Some changes are anticipated once price harmonisation is achieved, and the IPPs long-term contracts based on PPAs expire. For example, new pricing formulae may be introduced in the power sector by EC and IPPs without PPAs possibly be participating in short-term bidding through New Enhanced Dispatch Arrangement (NEDA) platform as merchant plants. These issues will be addressed in the second part of this research focusing on electricity in Peninsular Malaysia including the possibility to renegotiate the GFA the GSA to allow more flexibility in terms of gas purchase from PEGT or to implement a minimum gas offtake from PEGT before a competitive market can be established. 
Increased regional LNG trading or larger volumes of imported LNG could create a scenario similar to Europe whereby various pricing mechanisms co-exist but spot prices dominate. ${ }^{37}$ Although the LNG export marker created by the incumbent currently dominates, new market players would trade using other LNG market indicators. At a higher oil price, PEGT sales based on ex-Bintulu pricing would be less competitive than another player using JKM or European hub price markers (see Figure 18). Significant short-term LNG traded in Peninsular Malaysia, or in the ASEAN region as a whole, could provide a market-based substitute for the ex-Bintulu marker. In the opinion of some stakeholders, JLC (Japan average LNG import price) could be a possible price benchmark to reflect the cost of marginal supply in the region. But since JLC is an average price for all LNG imported into Japan, a far preferable benchmark would be one which represents a national (Malaysian), or regional (ASEAN or Pacific Basin LNG) market price.

\subsection{Market structure, upstream gas allocation and LNG trading}

PETRONAS has long-term contracts with Production Agreement Contractors (PACs) which are international oil and gas companies) to buy all domestic production, hence none of these contractors are able to sell gas directly into the market. In principle under TPA, when these upstream contracts with PETRONAS expire, contractors could decide not to sell their share of the gas to PETRONAS. Another alternative would be to require PETRONAS to release some of the gas from these long-term contracts, prior to their expiry to allow (or force) the PACs to sell directly to the market. Such 'release gas' programmes have been carried out in other markets to kick-start the development of gas-to-gas competition (see Section 7).

However, contractors would still need access to processing plants, which are not regulated under the current TPA system, and by the time their long-term contracts expire the existing low-cost gas fields in offshore Peninsular Malaysia will have depleted and new fields seem likely to be significantly higher cost. Without access to processing, PACs would have to consider the financial feasibility of building new gas processing plant and offshore pipeline facilities, which would involve very significant additional costs and would probably only be worthwhile if major new reserves are discovered or for substantial additional imports of (unprocessed) pipeline gas. Peninsular offshore is a relatively mature basin but offshore Sarawak may offer new production opportunities, combined with the possibility of imports of pipeline gas from new fields in neighbouring countries. For example, Indonesia's Natuna D Alpha project could build a pipeline to sell gas directly to the Peninsular market.

Even if new domestic or imported pipeline gas is insufficient to meet demand, supply competition in Peninsular Malaysia may be achieved through imports of LNG. Peninsular Malaysia LNG imports started in 2013 as domestic production became insufficient to meet demand and rose to around 1.8 $\mathrm{Bcm}$ in 2018 through the two terminals described in Section 3.2. As noted in Section 5, there has been little LNG trading activity in the ASEAN region. But due to low spot prices, an LNG trial cargo arrived in Malaysia, supplied by Shell Malaysia Trading Sdn Bhd (SMTSB) in October 2019 to TNB's Tuanku Jaafar Power Station in Port Dickson and TNB Connaught Bridge Power Station in Klang (The Star 2019). The purpose of this LNG trial cargo was to test the TPA arrangement via the Regasification Terminal (RGT) in Sg. Udang, Melaka and Peninsular Gas Utilisation (PGU) gas pipeline network owned by PETRONAS Gas Bhd.

\section{Obstacles to the promotion of competition in the gas market}

In addition to the fact that not all of the legal and regulatory framework for liberalisation and third-party access in the Peninsular Malaysia gas market was in place as of December 2019 (GMB is in the process of unbundling, and AAs for distribution network are not yet published), this study has identified

\footnotetext{
${ }^{37}$ This depends on the region of Europe under consideration. In Northwest Europe, 96 per cent of wholesale prices are sold on the basis of gas to gas competition, compared with 44 per cent in Mediterranean Europe. IGU (2019a) pp.44-47.
} 
significant obstacles which will need to be removed or resolved before a competitive market can be established.

The different categories of obstacles are: contracts, pricing, transparency, market entry and regulation. Sections 3-6 have noted a great number of these obstacles and we do not repeat all of them here. In our judgement, and the judgement of the stakeholders (see the list at Section 1.2) interviewed in the course of the study, the most important steps which will need to be taken to promote competition in the gas market are the following:

- Revising the terms of the long-term upstream production contracts to release a portion of existing production which could then be sold by producing companies directly into the market.

In a monopoly market, the dominant player produces or buys all the gas and sells all the gas. Release gas programmes were implemented in many European countries to create liquidity and to ensure availability of gas for new players. ${ }^{38}$ The regulator requires that the dominant player either releases gas from long-term contracts, or does not purchase all of the gas which becomes available from new sources of supply, so that gas is available for new entrants to buy and sell. In Malaysia, there could be a requirement to release gas from production agreement contracts (PACs) and for IOCs to sell a share of this released production to buyers other than PETRONAS or its subsidiaries. Another possibility is for PETRONAS to sell a certain volume of gas annually for several years to new players until the latter are able to purchase gas directly from other sources.

The next question would be at what price this gas should be released and how that price should be indexed. This scenario would also require calculation of a weighted average cost of domestic gas. The regulator will need to derive a weighted average cost of gas (WACOG) using information provided by PETRONAS about its domestic production and import costs. While the different elements of the WACOG do not need to be publicly disclosed, the regulator must have access to sufficient confidential information to make an informed judgement on gas costs.

At the same time, the TPA system will need to be extended to existing processing plants or require PETRONAS to release gas at the outlet of the plants. Based on the current PAC arrangements, all gas is sold to, and processed by, Petronas. PETRONAS owns the processing facilities and since it is very costly to build these facilities, access is crucial to allow for the possibility of imported or new domestic gas to be developed independent of PETRONAS. Extending the TPA system to include processing plants is particularly important if a portion of existing production is to be released, as new entrants will need to have access to processed gas. ${ }^{39}$

- Ensuring that the EC becomes a fully independent regulator to promote price discovery and fair competition throughout the gas value chain.

Currently, the regulator reports to MESTECC and MEA on all issues related to the energy market in Malaysia. An 'independent' regulator means that civil servants and ministers are not permitted to directly dictate or influence regulatory decisions (e.g. on tariffs or access conditions) which have been taken on the basis of economic principles and calculations. ${ }^{40}$

\footnotetext{
${ }^{38}$ The first release gas programme was initiated in the UK in 1992. Subsequent programmes were carried out in: Spain, Austria, Germany, Denmark, France, Italy and Greece. The European Federation of Energy Traders (EFET) issued guidance on gas and capacity release programmes, including when a programme is needed, the terms required in a programme; and a historical account of some programmes. EFET (2003).

${ }^{39}$ Access to processing can be complicated because facilities are very often designed to process hydrocarbons from specific fields and may not be adaptable to process those from other sources. There are some examples from the UK of disputes over access to processing facilities - see https://www.ogauthority.co.uk/regulatory-framework/disputes-and-sanctions/

${ }^{40}$ Many countries still use government departments to regulate their energy industries. In the European Union, after more than a decade of liberalisation measures, the Second Gas Directive mandated the creation of specialised independent regulators for the domestic gas market (but not for the award of exploration and production licences which remain under government control), but this process took several years. For details of developments in individual European countries see Haase (2009), pp. 239-40
} 
Legislation was developed in the European Union (EU) to define the role and independence of national energy regulators and to guarantee the independence of the regulatory authority. The legislative must ensure that the regulatory authority exercises its powers impartially and transparently. The regulator must be able to make decisions about all relevant regulatory issues if the internal market in natural gas is to function fully independent of government or private interests. ${ }^{41}$

The remit of the EC needs to be extended to oversight of the upstream activities, and powers to require PETRONAS to provide sufficiently detailed information about its operations to enable the EC to develop a weighted average cost of gas (WACOG) for domestic production and imports). Powers to award exploration and production licences would remain with government departments. ${ }^{42}$

- The existing framework of regulated and unregulated prices for power and non-power sectors with discounts must be replaced first with regulated prices defined by independent regulation and based on a WACOG, and eventually with unregulated transparent market (supply/demand) prices.

Several steps will be needed to replace the ex-Bintulu marker with a market price that reflects gas supply/demand balance in Peninsular Malaysia (and eventually the ASEAN region), which in turn will depend on the powers of the regulator to make changes to the gas market:

1. The ex-Bintulu marker price, however calculated, does not reflect the gas supply/demand balance in Malaysia. The first step to creating a supply/demand price is for the regulator to assess the weighted average cost of domestic gas production and LNG imports for Peninsular Malaysia. This can then become the new 'regulated price' for gas.

2. The second step is to liberalise the market and bring in new entrants to supply gas, either released by PETRONAS, or purchased from domestic producers or through imports.

3. The third step is that when competition develops in the Peninsular gas market, and the TPA system is fully established, regulated pricing can be replaced by market prices established by gas-to-gas competition. ${ }^{43}$ This is likely to reflect some combination of the cost of new domestic gas supply and regional LNG prices. To the extent that Peninsular Malaysia becomes more import-dependent (i.e. that domestic gas production declines and imports increase), LNG import prices such as the Japan-Korea marker (JKM spot price) and the Japan JLC price (an average price of LNG imports into Japan) may become increasingly relevant.

4. The final step might see the creation of a Malaysian or ASEAN gas hub, with a transparent spot price reflecting a combination of gas production and LNG imports in the region; this will depend on liberalisation of gas markets in other ASEAN countries.

- Certainty, transparency and non-discrimination in capacity booking of facilities, in particular regasification terminals and transmission pipelines will be essential for new market entry. Potential players must be able to book long- and short-term capacity on a firm basis.

\footnotetext{
${ }^{41}$ See Appendix 10.3 on the legislative definition of fully independent regulator in EU.

${ }^{42}$ An example within the ASEAN region: In 2002, Indonesia changed its regulatory system and established an upstream oil and gas regulator, transferring all Pertamina's rights and obligations arising from existing cooperation contracts to the new upstream regulator, SKK Migas. (Pertamina is a state-owned oil and gas enterprise which previously governed with its own upstream law.) SKK Migas controls upstream activities and manages oil and gas contractors on behalf of the government through joint cooperation contracts. Meanwhile, BPH Migas regulates downstream activities. Although the government oversees SKK Migas, i.e. it is not an independent regulator, the changing of the regulatory system in Indonesia is an example of creating an upstream regulator independent of the incumbent national company which could liaise with the EC.

${ }^{43}$ The regulator can decide to maintain regulated pricing for limited customer groups, e.g. residential or small commercial customers.
} 
The regulator has a major role in regulating capacity in these facilities. PGB owns the transmission pipelines and regasification terminals and must produce statistics on capacity availability in the transmission system, and berthing slot availability in the LNG terminals. PETRONAS's long-term contracts must be taken into account when allocating this capacity, i.e. PETRONAS must be allocated sufficient transmission and berthing slot capacity to honour its contracts, but this must not exclude new entrants. The regulator must ensure that any excess transmission capacity is available to new entrants. If requests for capacity exceed availability, an auction of available capacity can be conducted. The EU Capacity Allocation Network code allows for capacity to be auctioned for 15 years ahead in annual tranches, but up to 20 per cent of capacity must be reserved for short-term bookings. ${ }^{44}$ Similarly for LNG regasification berthing slots, the regulator must ensure that unused slots are made available to the market ahead of time. Should unused slots remain unavailable to the market, the regulator could limit the number of slots that players can reserve on a long-term basis and introduce shorter-term auctions. ${ }^{45}$

There is also a possibility of cross-subsidy of these facilities by dominant players. The dominant players have all the information and could set the rules to benefit themselves. Therefore, there is a need for regulators to impose requirements for disclosure of information, management of capacity constraints and rules for non-discrimination. In the case of gas for the power sector, the current requirement to book capacity one year in advance is an issue which must be examined by the regulator.

- Gas release will require revising, and eventually abolishing, the gas framework agreement and other long-term gas sales agreements in the power and non-power sectors to unlock the volumes which can then kickstart competition.

- When gas is available at a competitive price this may create gas demand in new sectors, although it is not guaranteed this will be the case, it will require the market price to be cheaper than other fuels (diesel, coal or renewable electricity).

\section{Conclusions: answers to research questions}

These conclusions are divided into two parts to address the gas market reform issues and design in Peninsular Malaysia. Section 8.1 focuses on the prospects for liberalisation and competition in the Peninsular Malaysia gas market. Section 8.2 looks at the development of ASEAN spot LNG trading and its impact on Malaysia.

\subsection{Prospects for liberalisation and competition in the Peninsular Malaysia gas market}

Research question 1. How rapidly is the Peninsular Malaysia gas market likely to liberalise, and what will the form of that liberalisation mean for any decision between participating in upstream gas development, as opposed to purchasing gas from producers?

The regulatory framework for the liberalised gas market in Peninsular Malaysia is not yet complete in relation to licence conditions and distribution tariffs. Towards the end of the TPA pilot phase an LNG trial cargo supplied by Shell Malaysia arrived in October, to test the TPA system for regasification terminals. However, the price paid for this cargo was not disclosed and the market is still monopolised with little transparency of contracts, costs or prices, which creates substantial barriers to entry. It is very early in the liberalisation experiment but these barriers will need to be addressed before self-sustaining competition can be expected to develop in the gas market.

\footnotetext{
${ }^{44}$ In Europe, a number of different mechanisms were adopted over the years, but the details of current arrangements are set out in the Capacity Allocation Management Network code. For details see Yafimava (2018).

${ }^{45}$ European LNG terminals have different detailed mechanisms for use it or lose it. See CEER (2019) and Yafimava (2020).
} 
How rapidly the Peninsular Malaysia gas market is likely to liberalise will depend on several factors:

- price harmonisation expected early in 2020 or within three years from that date;

- gas release from long-term upstream and midstream agreements to promote competition;

- price discovery in the gas market and new players trading gas and LNG, taking market share from the incumbent.

Any decision to participate in new upstream domestic or international gas development, as opposed to purchasing gas from producers or LNG suppliers, will depend on:

- the need for long-term security of supply, which will be different from the ability to access spot or short-term supply, for example from the LNG market where availability may be cyclical or seasonal and subject to global price competition.

- The fact that Peninsular Malaysia production is falling (see Figure 6), and the development of new deep-sea and high $\mathrm{CO}_{2}$ fields may be greater and more complicated, with potentially higher costs, than importing LNG.

\subsubsection{Strategy for gas stakeholders in Malaysia}

To conclude, the barriers to competition and new entry identified during the TPA pilot phase, and how these barriers will be tackled, will drive the pace of gas market liberalisation in Peninsular Malaysia.

Pricing is one of the main barriers and overcoming this barrier should create opportunities for new players to participate. However, once price harmonisation has been achieved (sometime between January 2020 and 2023), if there are still no changes in the market structure, then long-term agreements may need to be revised to release upstream and downstream gas volumes in order to create a platform for competition. If this does not happen, the current market structure could remain unchanged, even if price harmonisation and a level playing field for market participants is achieved on paper. Should this be the case, it will then be for the government and regulator(s) to decide whether this is acceptable, or whether greater efforts need to be made to ensure that gas market competition develops. It will therefore take until at least mid-2020 and possibly until 2023 before it is clear whether liberalisation and competition in the Peninsular Malaysia gas market has advanced beyond the first three steps in Figure 7: TPA, bi-lateral trades and price discovery and disclosure.

For these reasons, it may be too early to make decisions between participating in upstream development, as opposed to purchasing gas once competition occurs and the liberalisation of Malaysian gas market process advances to step 4 in Figure 7. An important factor will be the speed of production decline in Peninsular Malaysia and how new supply will be developed to meet demand. Should competition fail to develop over the next 1-4 years, the government will need to decide whether to make more strenuous efforts to encourage new entry, or accept that competition has failed and that PETRONAS will remain the dominant player in the Malaysian gas market. In the latter case, participating in upstream development will certainly be worth considering.

Hence, there will be no clarity on the strategy until it is clear that liberalisation is going to happen and how quickly the liberalisation process is going to take place. In this case, the strategy for the stakeholders remain unclear.

\subsection{The development of spot LNG trading and pricing and impact on the Malaysian and regional (ASEAN) gas markets}

Research question 2: Will increasing competition and the development of spot LNG trade and pricing in the regional (ASEAN) and global gas market have a significant impact on the availability and price for Malaysia, and if yes, what is the likely time frame?

- Malaysian LNG imports started back in 2013 due to declining domestic gas production in Peninsular Malaysia and in 2018 were about $1.8 \mathrm{Bcm}$. 
- The current global LNG surplus which forced Asian spot prices towards (and in some periods below) $\$ 4 / \mathrm{mmbtu}$ in 2019 will be positive for Malaysia and ASEAN, creating more gas supply options and helping to promote liberalisation and competition - new market entry in the region. But it should not be assumed that such low LNG prices will be permanent.

- Of 135.1 Bcm spot and short-term global LNG trade in 2018, $98.4 \mathrm{Bcm}$ was imported by Asian countries, although only $2.52 \mathrm{Bcm}$ by ASEAN countries (Malaysia, Singapore, Thailand and Indonesia).

- Liberalisation (and new market entry through TPA) means that prices should increasingly reflect gas supply/demand conditions in Malaysia as well as international LNG price benchmarks, rather than oil-linked prices. This will require:

- a break with the previous regulated/unregulated discount to ex-Bintulu price regime.

- reducing the dominance of PETRONAS (and its unbundled subsidiaries) in the gas value chain and increasing the market share of new entrants.

- Increased pipeline connectivity and numbers of LNG receiving terminals in ASEAN will allow member countries to access LNG at more competitive prices and provide greater opportunities to trade. But this will depend on the extent to which other ASEAN countries move towards gas market liberalisation and competitive gas markets.

To conclude, the development of spot LNG trade and pricing in the regional (ASEAN) and global gas market are likely to have a significant impact on the availability and price of gas in Peninsular Malaysia. But in the opinion of the stakeholders who were interviewed this could take at least five years and probably longer. The degree of impact and duration will depend on:

- The time required to reach harmonisation between domestic regulated and unregulated prices.

- The continued use of the ex-Bintulu marker for pricing, with price discounts by the incumbent to power (15 per cent LNG price discount) and non-power (10 per cent LNG price discount). If the ex-Bintulu price remains significantly above spot and short-term LNG import prices, customers will become increasingly interested in accessing spot LNG cargos.

- The time required for effective liberalisation and third-party access to regasification terminals and pipelines to be created.

- The extent to which the gas market continues to be dominated by incumbents and long-term gas contracts with non-transparent and non-market related prices for the power and non-power sectors, which may lock out new entrants and restrict short-term trading. 


\section{References}

ASCOPE (2019). 'Trans ASEAN Gas Pipeline Project (TAGP)', ASEAN Council on Petroleum, January 2019 (online). Available at: http://www.ascope.org/Projects/Detail/1060

Bennett, G. (2019). 'LNG trading liquidity and hedging', Oxford Energy Forum, 119. OIES.

BP (2019). BP Statistical Review of World Energy 2019 (68 $8^{\text {th }}$ Edition).

BNM (2017). 'Bank Negara Malaysia Annual Report 2017', Malaysia, Bank Negara Malaysia.

Petroleum Development Act 1974 (online). Available at:

http://www.agc.gov.my/agcportal/uploads/files/Publications/LOM/EN/Act\%20144\%20-

\%20Petroleum\%20Development\%20Act\%201974.pdf

CEER (2019). 'How to Foster LNG Market in Europe', Council of European Energy Regulators, Liquefied Natural Gas Work Stream of Gas Working Group, Ref: C18-LNG-37-03, 24 July 2019.

DOSM (2017). 'Population Statistics', Department of Statistics, Malaysia (online). Available at: https://www.dosm.gov.my/v1/uploads/files/3 Time\%20Series/Malaysia Time Series 2016/22 Pendu duk.pdf . [Accessed 25 August 2019]

EC (2016a). 'Gas Supply Industry Liberalisation: Paving the way to accessibility', Energy Malaysia Volume 8, Energy Commission Malaysia (online). Available at:

https://www.st.gov.my/ms/contents/publications/energyMalaysia/Energy $\% 20$ Malaysia\%20Volume\%20 8.pdf

EC (2016b). Peninsular Malaysia: Piped Gas Distribution Industry Outlook, Energy Commission (online). Available at:

https://www.st.gov.my/ms/contents/publications/outlook/Peninsular\%20Malaysia\%20Piped\%20Gas\% 20Distribution\%20Industry\%200utlook\%202016.pdf

EC (2017a). 'Gas Supply Act Amendments and Third-Party Access', $6^{\text {th }}$ Malaysia-Republic of Korea Energy Cooperation Workshop. Energy Commission.

EC (2017b). 'Gas Tariff', Energy Commission (online). Available at:

https://www.st.gov.my/ms/contents/presentations/2017/gas 1107/03-

\%20Penetapan\%20Tarif\%20Gas.pdf

EC (2017c). Peninsular Malaysia Electricity Supply Outlook 2017, Energy Commission (online).

Available at:

https://www.st.gov.my/en/contents/publications/outlook/Peninsular\%20Malaysia\%20Electricity\%20Su pply\%200utlook\%202017.pdf

EC (2017d). Malaysia Energy Statistics Handbook 2017, Energy Commission (online). Available at: https://www.st.gov.my/contents/files/download/116/Malaysia Energy Statistics Handbook 2017.pdf

EC (2018). Third-Party Access System (TPA): Why is the TPA system introduced?, Energy

Commission (online). Available at: https://www.st.gov.my/web/faqs/listing/1

EC (2019). Third-Party Access System (TPA): Tariff for the utilisation of gas facilities for 1st January to 31 December 2019. Energy Commission (online). Available at:

https://www.st.gov.my/web/industry/details/3/4

EFET (2003). 'Implementation of Gas Release Programme for European Gas Market Development', https://efet.org/Files/Documents/Internal\%20Energy\%20Market/23\%20June\%202003\%20Gas\%20rel ease $\% 20-\% 20$ final $\% 20$ version $\% 20 \% 20(1)$.pdf 
Evans, D. (2019). 'Shell pushing ahead in Malaysian deepwater', Natural Gas Insight, Vol 1/No.2/30 May 2019.

Fulwood, M. (2019). 'LNG supply/demand balances, 2018-2025: Is there a problem?', OIES Forum: LNG in transition: from uncertainty to uncertainty, Issue 119/September 2019.

https://www.oxfordenergy.org/wpcms/wp-content/uploads/2019/09/OEF-119.pdf

Gas Supply Act 1993, Laws of Malaysia (online). Available at:

https://resourcegovernance.org/sites/default/files/Gas\%20Supply\%20Act\%201993.pdf

Gas Supply (Amendment) Act 2016, Laws of Malaysia (online). Available at:

https://policy.asiapacificenergy.org/sites/default/files/Gas\%20Supply\%20\%28Amendment $\% 29 \% 20$ Act \%202016\%20\%5BAct \%20A1515\%5D.pdf

GIIGNL (2019). GIIGNL Annual Report: The LNG industry (online). Available at:

https://giignl.org/sites/default/files/PUBLIC AREA/Publications/giignl annual report 2019compressed.pdf

GMB (2018). Annual Report 2018: Embracing Challenges and Standing Tall (online). Available at: https://www.gasmalaysia.com/images/download/annual-report/Gas Malaysia_AR2018min compressed compressed reduce.pdf

Haase, N. (2009). European Gas Market Liberalisation: competition versus security of supply? Energy Delta Institute/Castel International.

Heather, P (2015). 'The Evolution of European Traded Gas Hubs', OIES Paper NG 104, Oxford Institute for Energy Studies, December 2015. Available at: https://www.oxfordenergy.org/wpcms/wpcontent/uploads/2016/02/NG-104.pdf

IEA (2013). Developing a Natural Gas Trading Hub in Asia: Obstacles and Opportunities (online). Available at: https://www.iea.org/publications/freepublications/publication/asiangashub final web.pdf

IGU (2019). 'IGU World LNG report - 2019 Edition' (online). Available at:

https://www.igu.org/sites/default/files/node-news item-

field file/IGU\%20Annual\%20Report\%202019 23\%20loresfinal.pdf

IGU (2019a). 'Wholesale Gas Price Survey 2018', May 2019.

Lim, Z. W., and Kim. L. G (2019). 'Natural gas industry transformation in Peninsular Malaysia: The journey towards a liberalised market', Energy Policy 128: 197-211.

MEA (1981). Fourth Malaysia Plan 1981-1985 (online), Malaysia: Ministry of Economic Affairs. Available at: https://www.mea.gov.my/en/rmk/fourth-malaysia-plan-1981-1985

MGA (2017). Malaysia: Natural Gas Industry Annual Review 2017 Edition (online), Malaysia:

Malaysian Gas Association. Available at: https://malaysiangas.com/wp-

content/uploads/2019/03/Natural Gas Industry Review-2017.pdf

Natural Gas World (2019). PETRONAS Launches LNG Trucking Business.

https://www.naturalgasworld.com/PETRONAS-LAUNCHES-LNG-TRUCKING-BUSINESS-

73902?UTM MEDIUM=EMAIL\&UTM CAMPAIGN=DAILY\%20NATURAL\%20GAS\%20WORLD\%20-

\%20LATEST\%20NEWS\&UTM CONTENT=DAILY\%20NATURAL\%20GAS\%20WORLD\%20-

\%20LATEST\%20NEWS+CID 42FDA315FD3346EDE474AE4C1D710A60\&UTM SOURCE=CAMPA IGN\%20MONITOR\&UTM TERM=PETRONAS\%20LAUNCHES\%20LNG\%20TRUCKING\%20BUSIN $\underline{E S S}$

NEB (2016). National Energy Balance 2016, Energy Commission Malaysia. 
Oh, T. H., S. Y. Pang and S. C. Chua (2010). 'Energy policy and alternative energy in Malaysia: Issues and challenges for sustainable growth', Renewable and Sustainable Energy Reviews 14(4): 1241-52.

OIES (2019). Statistical data from OIES Gas model Database.

PEMANDU (2011). Economic Transformation Programme (ETP) Roadmap. Performance Management and Delivery Unit (PEMANDU). [online]. Available at: https://policy.asiapacificenergy.org/sites/default/files/ETP.pdf

PETRONAS (2013a). 'Monetising Gas Resources for National Development: Malaysia's Experience', Abidjan, Cote d'Ivoire (online). Available at: http://members.igu.org/old/IGU\%20Events/other-iguevents/joint-gas-training-seminar-abidjan-cote-d2019ivoire/day-1-1600-mahmood-malaysiasexperience.pdf

PETRONAS (2013b). Peninsular Malaysia Gas Supply and its Challenges. Malaysia (online). Available at: https://www.st.gov.my/ms/contents/presentations/tariff/2 Petronas Cabaran\%20pembekalan\%20bah an\%20api\%20gas,\%20LNG\%20dan\%20arang\%20batu\%20kepada\%20sektor\%20penjanaan.pdf

PGB (2019). Regasification Facilities.

https://www.petronasgas.com/OurBusiness/Pages/Regasification.aspx

PGB (2016). PETRONAS Gas Annual Report. Available at: https://www.petronasgas.com/IR/Documents/Annual\%20Reports/PetGasFullReport2016.pdf

PWC (2019). Indonesian Oil \& Gas Concessions and Major Infrastructure Map, July 2019 (online). Available at: https://www.pwc.com/id/en/energy-utilities-mining/assets/oil-and-gas/oil-gas-map2019.pdf

Rahman Mohamed, A. and K. T. Lee (2006). ‘Energy for sustainable development in Malaysia: Energy policy and alternative energy.' Energy Policy 34(15): 2388-2397.

Rogers, H. V. (2016). 'Asian LNG demand: Key drivers and outlook', OIES Paper: NG 106.

SB (2019). Generation Tariff, Single Buyer Website: https://www.singlebuyer.com.my/about.php?id=3

The Star (2019). Newspaper Article: 'TNB in deal with Shell to buy cheaper gas' (online). Available at: https://www.thestar.com.my/business/business-news/2019/10/03/tnb-in-deal-with-shell-to-buycheaper-gas\#ODQjXQocGS1gy53w.99

TNB (2012-19). Analyst Briefing Presentation (2012-19) (online]). Available at: https://www.tnb.com.my/suppliers-investors-media-relations/financial-info

TNB (2012a). 'Presentation: Overview on the Energy Resources in Malaysia', Forum on Nuclear Energy as an option for Malaysia, United Nations Association Malaysia. Tenaga National Berhad, Malaysia.

TNB (2012b). 'Presentation: Future Technology Options for Malaysian Power', Tenaga National Berhad, Malaysia.

TNB (2020). TNB comments and feedback. Received: January 2020.

WB (2019). World Bank classifications: World Bank Country and Lending Groups. (online). Available at: https://datahelpdesk.worldbank.org/knowledgebase/articles/906519

Yafimava, K. (2018). 'Building New Transportation Infrastructure in the EU - what are the rules of the game?', OIES Paper NG 134.

Yafimava, K. (2020). 'Finding a Home for Global LNG in Europe: understanding the complexity of access rules for EU import terminals', OIES Paper NG 157. 


\section{Appendix}

\subsection{Country background}

Malaysia, classified as an upper-middle income economy (WB 2019), is divided into three main regions: Peninsular Malaysia, Sabah and Sarawak. Sarawak and Sabah are located on the island of Borneo and are separated from Peninsular Malaysia by approximately $640 \mathrm{~km}$ of the South China Sea. In 2017, GDP growth was 4.6 per cent. Most of Malaysia's economic activity has been concentrated in Peninsular Malaysia, driven mainly by the services and manufacturing sectors whose contribution to GDP has been substantial in recent years (BNM 2017).

\section{Figure 22: Map of Malaysia: Peninsular Malaysia, Sabah and Sarawak}

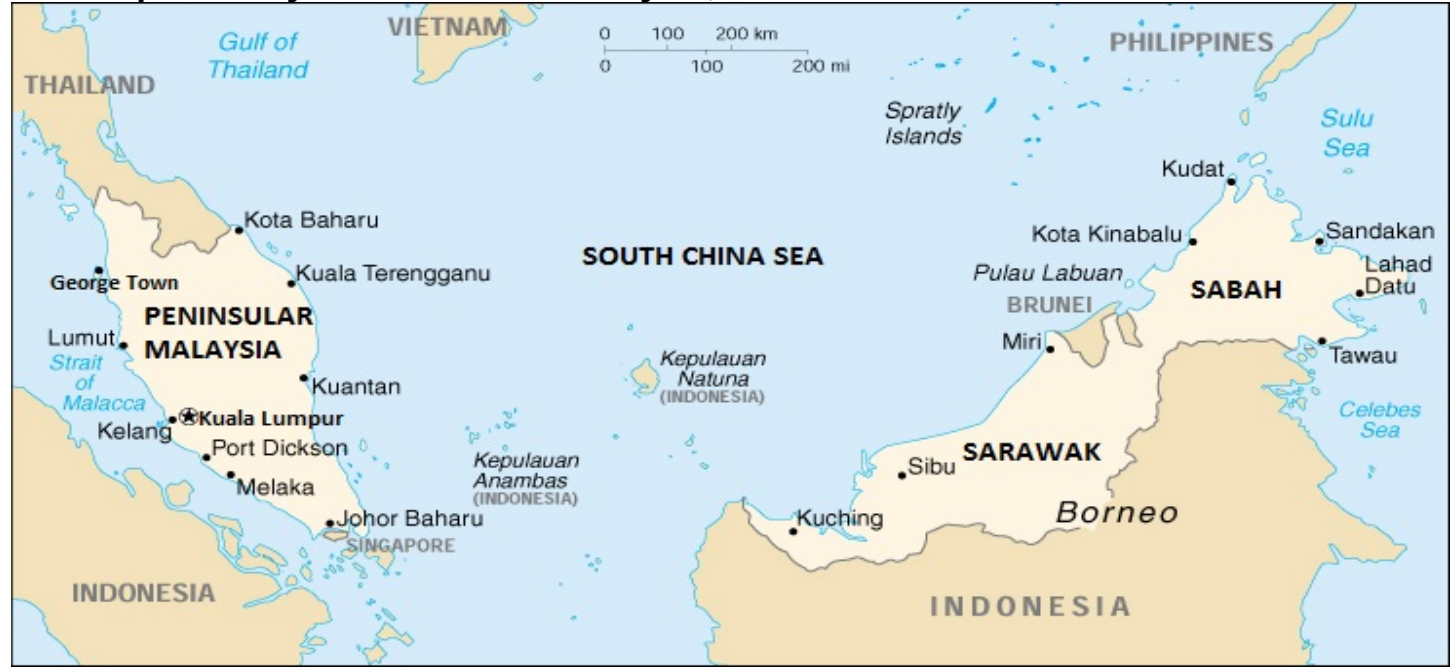

Source:https://www.worldatlas.com/webimage/countrys/printpage/printpage.php?l=/webimage/countrys/asia/ciam aps/my.jpg

Malaysia's total primary energy consumption stood at nearly 100 million tonnes oil equivalent (mtoe) in 2017, rising annually by an average rate of around 2.9 per cent from 2006-16 (BP 2019) to meet rising energy demand. By fuel, oil (37 per cent) and gas (36 per cent) were the main fuels consumed in the country, followed by coal (21.2 per cent), hydroelectric ( 5.5 per cent) and renewables ( 0.3 per cent). The transportation and industry sectors were the major consumers of oil, while gas was mainly used in the industry and power sectors (NEB 2016). Figure 23 summaries the economic activity, population distribution and electricity consumption of Peninsular Malaysia, Sabah and Sarawak in 2017. 
Figure 23: Summary of GDP, population and demand distributions

- Peninsular - Sabah - Sarawak

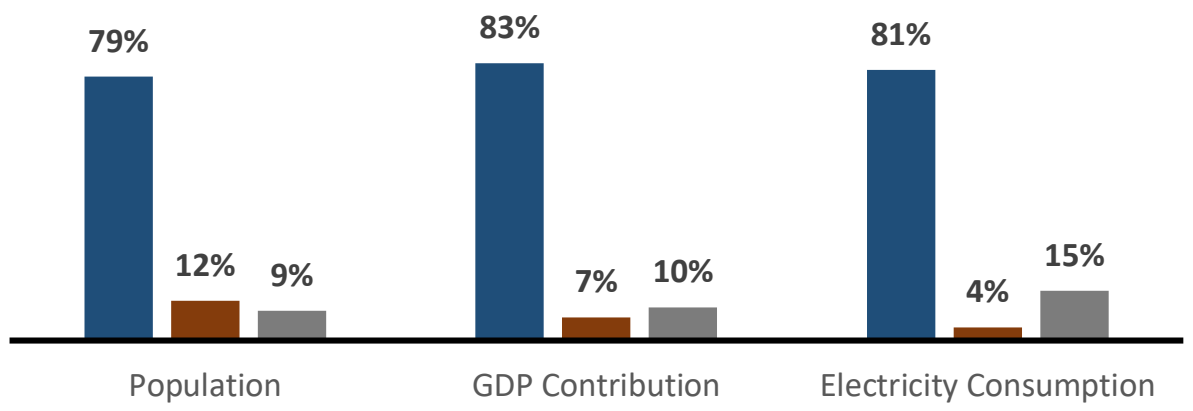

Total population: 32 million

GDP at 2010 prices: 1174.3 (RM billion)

Primary energy consumption: 99.6 (mtoe)

Electricity consumption: 147 (TWh)

Source: NEB 2016; DOSM 2017

The core national policies that underpin energy supply and demand are the National Energy Policy (1979), National Depletion Policy (1980), Four-Fuel Diversification Strategy policy (1981) and Five-Fuel Diversification Strategy policy (1990). In order to reduce reliance on fossil fuels and support the efficient use of natural resources, the Five-Fuel Diversification Strategy (natural gas, coal, oil, hydro and renewable energy) in 1990 was introduced to diversify and seek new alternatives in the energy sector, especially harvesting renewable resources (Rahman Mohamed and Lee 2006; Oh et al. 2010). For example, the country has targeted the achievement of $2080 \mathrm{MW}$ of renewable energy installed capacity by 2020 in the 11th Malaysia Plan (2016-2020).

Figure 24: Natural gas reserves in Peninsular Malaysia, Sabah and Sarawak

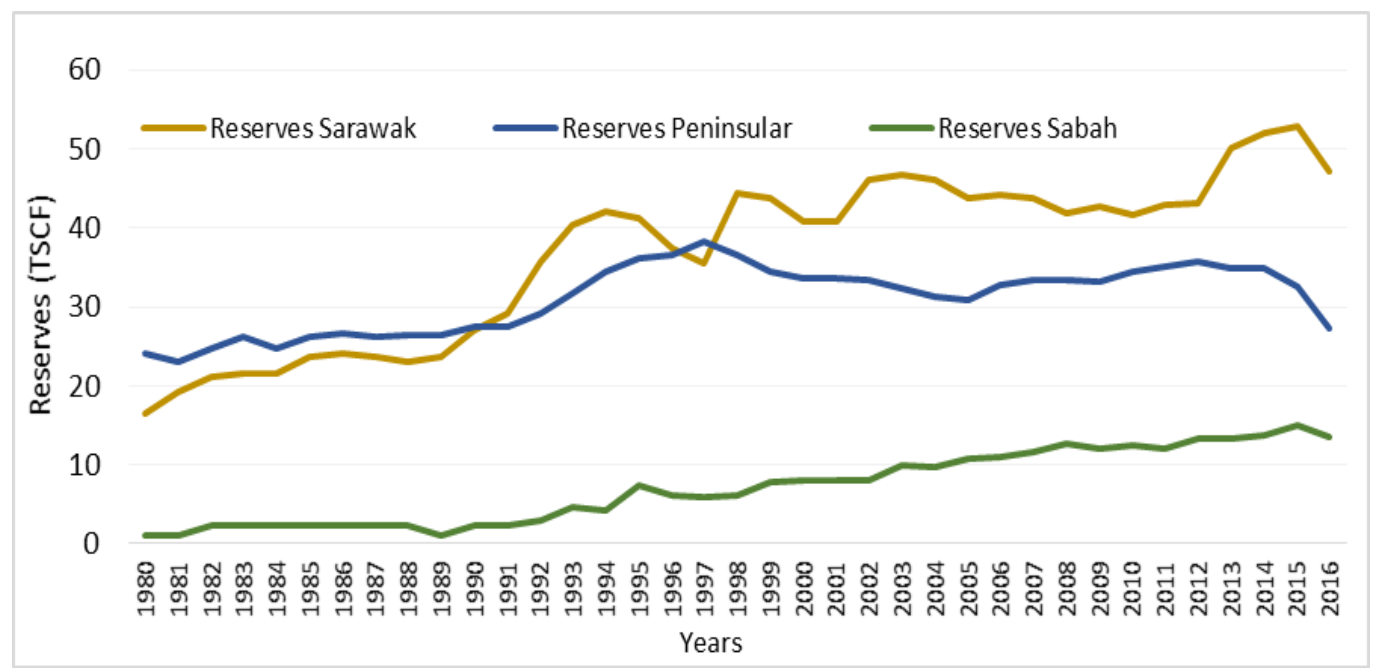

Source: NEB (2016) 
Figure 25: Total share of installed capacity in Malaysia

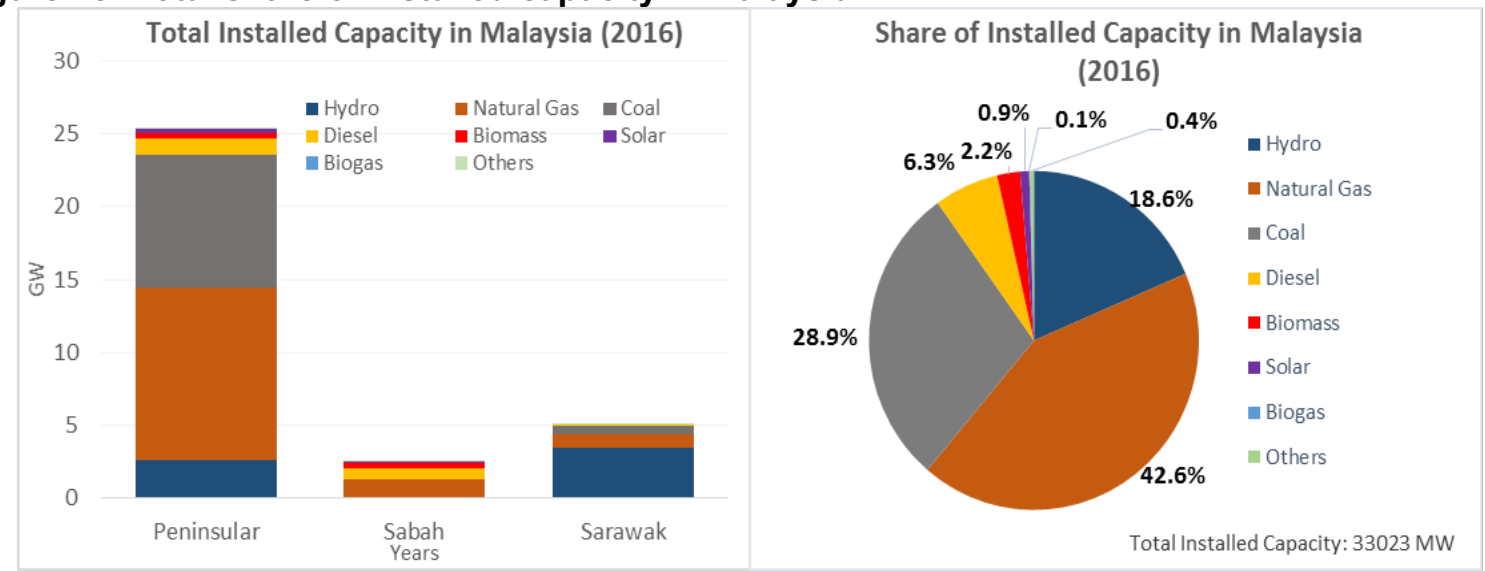

Source: NEB (2016)

Table 8: Share of TNB, SESB, SEB and IPP installed capacity (MW) in Malaysia

\begin{tabular}{|c|c|c|c|c|c|c|c|c|c|c|}
\hline & & Hydro & Gas & Coal & Diesel & Biomass & Solar & Biogas & Others & Total \\
\hline \multirow{6}{*}{$\begin{array}{l}\text { Peninsular } \\
\text { Malaysia }\end{array}$} & TNB & 2536 & 3577 & 0 & 0 & 0 & 0 & 0 & 0 & 6113 \\
\hline & IPP & 20 & 7402 & 9066 & 564 & 0 & 0 & 0 & 0 & 17052 \\
\hline & Co-generation & 0 & 897 & 0 & 79 & 12 & 0 & 0 & 25 & 1014 \\
\hline & Self-generation & 2 & 12 & 0 & 523 & 300 & 4 & 0 & 43 & 884 \\
\hline & FiT & 24 & 0 & 0 & 0 & 27 & 260 & 28 & 0 & 338 \\
\hline & Subtotal & 2582 & 11888 & 9066 & 1166 & 339 & 264 & 28 & 68 & 25401 \\
\hline \multirow{6}{*}{ Sabah } & SESB & 79 & 112 & 0 & 181 & 0 & 0 & 0 & 0 & 372 \\
\hline & IPP & 7 & 1013 & 0 & 102 & 0 & 0 & 0 & 0 & 1121 \\
\hline & Co-generation & 0 & 65 & 0 & 0 & 116 & 0 & 0 & 0 & 181 \\
\hline & Self-generation & 0 & 13 & 0 & 516 & 189 & 1 & 3 & 44 & 767 \\
\hline & FiT & 7 & 0 & 0 & 0 & 49 & 24 & 3 & 0 & 83 \\
\hline & Subtotal & 93 & 1203 & 0 & 799 & 354 & 25 & 6 & 44 & 2524 \\
\hline \multirow{6}{*}{ Sarawak } & SEB & 1054 & 595 & 480 & 114 & 0 & 0 & 0 & 0 & 2243 \\
\hline & IPP & 2400 & 0 & 0 & 0 & 0 & 0 & 0 & 0 & 2400 \\
\hline & Co-generation & 0 & 389 & 0 & 0 & 0 & 0 & 0 & 0 & 389 \\
\hline & Self-generation & 0 & 0 & 0 & 12 & 49 & 0 & 1 & 5 & 66 \\
\hline & Subtotal & 3454 & 984 & 480 & 125 & 49 & 0 & 1 & 5 & 5098 \\
\hline & Total & 6128 & 14075 & 9546 & 2090 & 742 & 290 & 35 & 117 & 33023 \\
\hline
\end{tabular}

Source: NEB (2016) 
Figure 26: Production and consumption of gas in Malaysia (1980-2018)

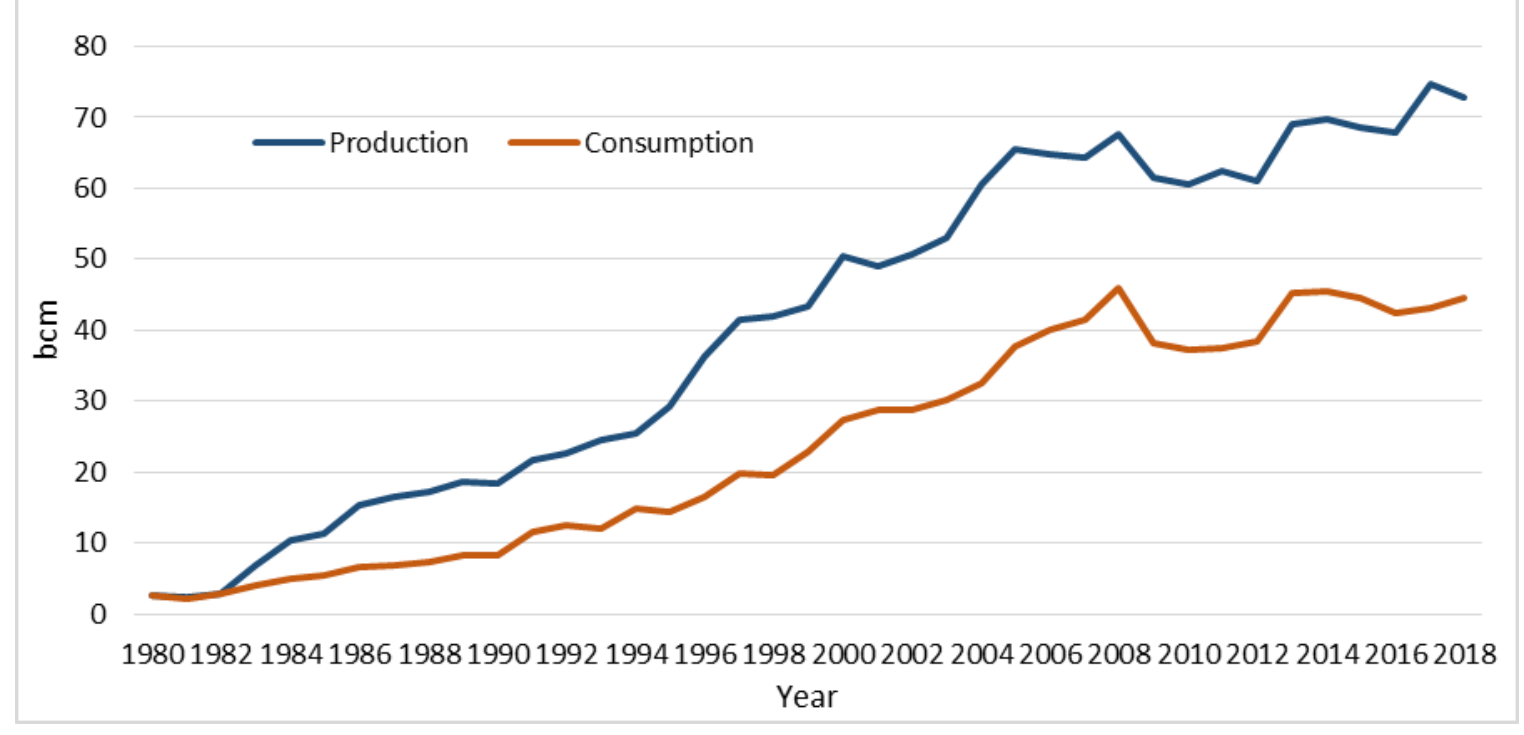

Source: OIES (2019)

Figure 27: Gas demand growth by sector (1971-2018) in Malaysia

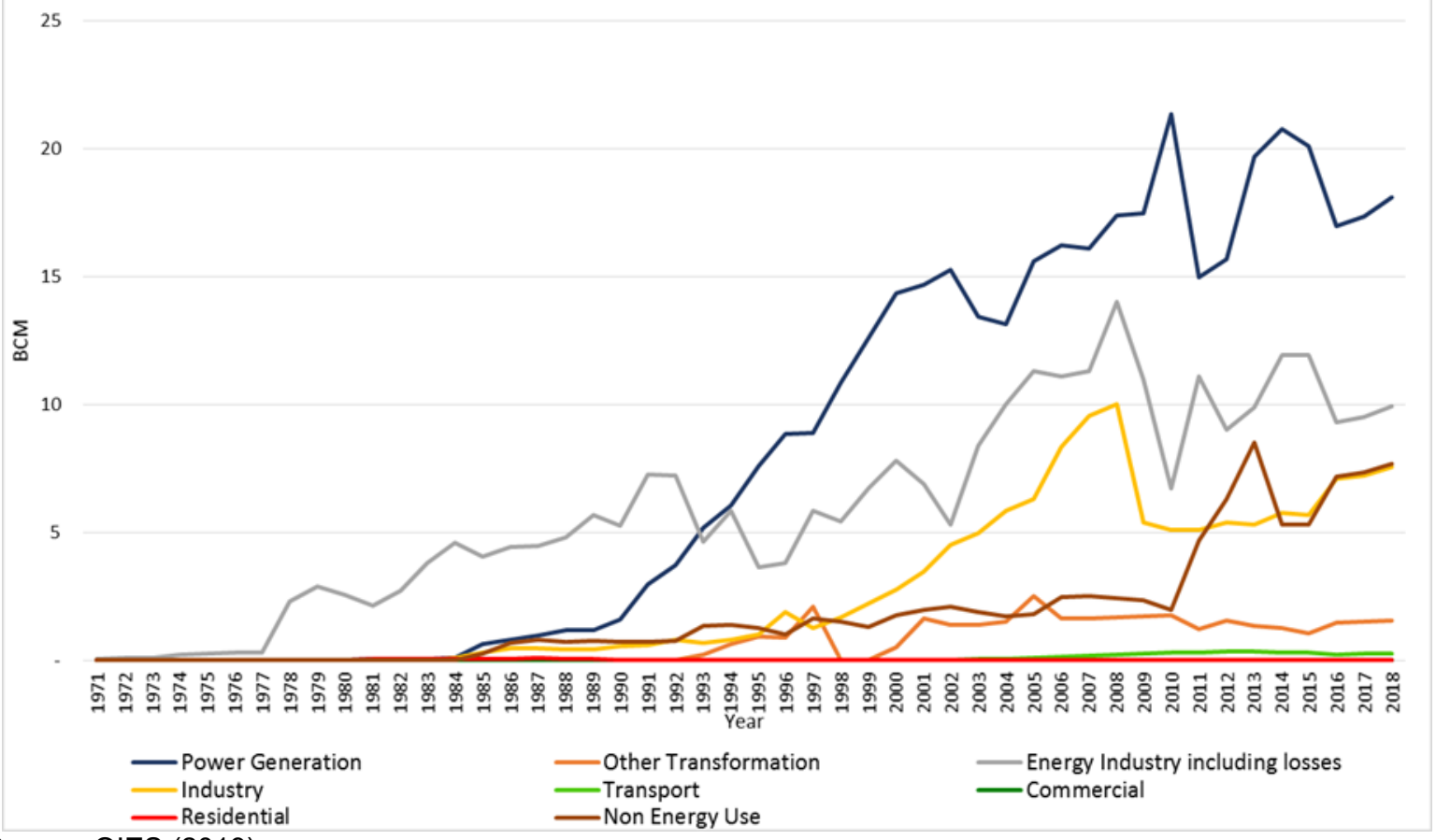

Source: OIES (2019) 
Table 9: Power sector gas supply agreement (GSA) on gas volume

Source: TNB (2012a)

\begin{tabular}{lcl}
\hline Plant & Volume $(\mathrm{mmscf} / \mathrm{d})$ & \multicolumn{1}{c}{ Signed } \\
\hline GSP & 113 & 22 Sept 1993 \\
\hline TNB & 500 & 21 Oct 1994 \\
\hline PD Power & 102 & 27 May 1994 \\
\hline YTL Paka & 118 & 15 March 1993 \\
\hline YTL PG & 59 & 15 March 1993 \\
\hline Powertek & 102 & 1 March 1994 \\
\hline Segari & 161 & 17 July 1993 \\
\hline Pahlawan & 44 & 30 July 1999 \\
\hline $\begin{array}{l}\text { TNB } \\
\text { (supp) }\end{array}$ & 150 & 28 Nov 2001 \\
\hline GB3 & 114 & 6 Sept 2001 \\
\hline Panglima & 118 & 11 Feb 2002 \\
\hline TTPC & 106 & 24 Jan 2002 \\
\hline PraiPower & 57 & 9 April 2002 \\
\hline
\end{tabular}

Table 10: Average sales volume (2014-18) in non-power by Gas Malaysia Berhad (GMB)

\begin{tabular}{|c|c|c|c|c|}
\hline Year & Volume (mmscf/d) & Volume (mmBtu) & $\begin{array}{l}\text { Regulated piped gas } \\
\text { prices } \\
\text { (RM/mmBtU) }\end{array}$ & $\begin{array}{l}\text { Unregulated piped } \\
\text { gas prices (LNG } \\
\text { indexed) } \\
(\mathrm{RM} / \mathrm{mmBtU})\end{array}$ \\
\hline \multirow[t]{3}{*}{2014} & 391 & 14760000 & Jan: 14.05 & Jan: 48.35 \\
\hline & & & May: 15.55 & May: 50.07 \\
\hline & & & Nov: 17.05 & Nov: 48.17 \\
\hline \multirow[t]{2}{*}{2015} & 421 & 15910000 & Jan: 17.05 & Jan: 48.91 \\
\hline & & & July: 18.55 & July: 38.34 \\
\hline \multirow[t]{2}{*}{2016} & 435 & 16426000 & Jan: 20.05 & Jan: 38.20 \\
\hline & & & July: 21.55 & July: 23.31 \\
\hline \multirow[t]{2}{*}{2017} & 487 & 18390000 & Jan: 23.05 & Jan: 30.23 \\
\hline & & & July: 24.55 & July: 33.71 \\
\hline \multirow[t]{2}{*}{2018} & 513 & 19380000 & Jan: 26.05 & Jan: 31.06 \\
\hline & & & July: 27.55 & July: 32.21 \\
\hline
\end{tabular}

Source: GMB (2018; pg. 14), EC (2019)

Note: For non-power sector, the gas price is capped at regulated gas prices for volumes up to $300 \mathrm{mmscf} / \mathrm{d}$. Any volume above this threshold is at unregulated gas price (LNG indexed). 
Table 11: Average daily gas consumption over a year in the power sector

\begin{tabular}{ll}
\hline Year & Volume (mmscf/d) \\
\hline $\mathbf{2 0 1 1}$ & 947 \\
\hline $\mathbf{2 0 1 2}$ & 959 \\
\hline $\mathbf{2 0 1 4}$ & 1331 \\
\hline $\mathbf{2 0 1 5}$ & 1213 \\
\hline $\mathbf{2 0 1 6}$ & 1128 \\
\hline $\mathbf{2 0 1 7}$ & 1042 \\
\hline $\mathbf{2 0 1 8}$ & 1014 (min: $561 ;$ max: 1385) \\
\hline $\mathbf{2 0 1 9}$ Q1 & 973 \\
\hline
\end{tabular}

Source: TNB (2012-19)

Note: PETRONAS had agreed to supply gas to the power sector with a limited volume of $1350 \mathrm{mmscf} / \mathrm{d}$ in 2003. This volume limit was reduced to $924 \mathrm{mmscf} / \mathrm{d}$ due to curtailments of gas supply to the power sector in 2011. In 2012, the amount of gas was limited to $1150 \mathrm{mmscf} / \mathrm{d}$ and reinstated again to $1350 \mathrm{mmscf} / \mathrm{d}$ by end 2013. In 2017, the guidelines for Gas Framework Agreement (GFA) were implemented, outlining the threshold quantity of 1000 mmscf/d at regulated gas price. (See Table 7 for regulated piped gas prices to power sector since 2000.) 
Table 12: Regulated piped gas prices to power sector (TNB) and non-power (GMB) (2000-2019)

\section{Year}

2000

2001

2002

2003

2004

2005

2006

2007

2008

2009

2010

2011

2012

2013

2014

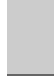

\section{5}

2016

2017

2017

2018

2019

2019

Source: EC (2017d) Gas price to power Sector (RM/mmBtu)

6.40

6.40

6.40

6.40

6.40

6.40 6.40 6.40 10.36 11.30 10.70 12.45

13.70

13.70

15.20

Jan-Jun 15.20 Jul-Dec 16.70 Jan-Jun 18.20 Jul-Dec 19.70 Jan-Jun 21.2 Jul-Dec 22.7 Jan-Jun 24.2 Jul-Dec 25.7 Jan-Jun 27.2 Jul-Dec 28.7
Gas Price to Non-Power Sector GMB (RM/mmBtu) 16.72 14.10

13.4

9.40

9.40

9.40

9.40

9.40

12.98

12.21

11.05

12.8

14.05

14.05

Jan-Apr 14.05

May-Oct 15.55

Nov-Dec 17.05

Jan-Jun 17.05

Jul-Dec 17.05

Jan-Jun 20.55

Jul-Dec 21.55

Jan-Jun 23.05

Jul-Dec 24.55

Jan-Jun 26.05

Jul-Dec 27.55

Jan-Jun 29.05

Jul-Dec 30.55 
Figure 28: Scope of Gas Supply Act 1993 and Gas Supply (Amendment) Act 2016
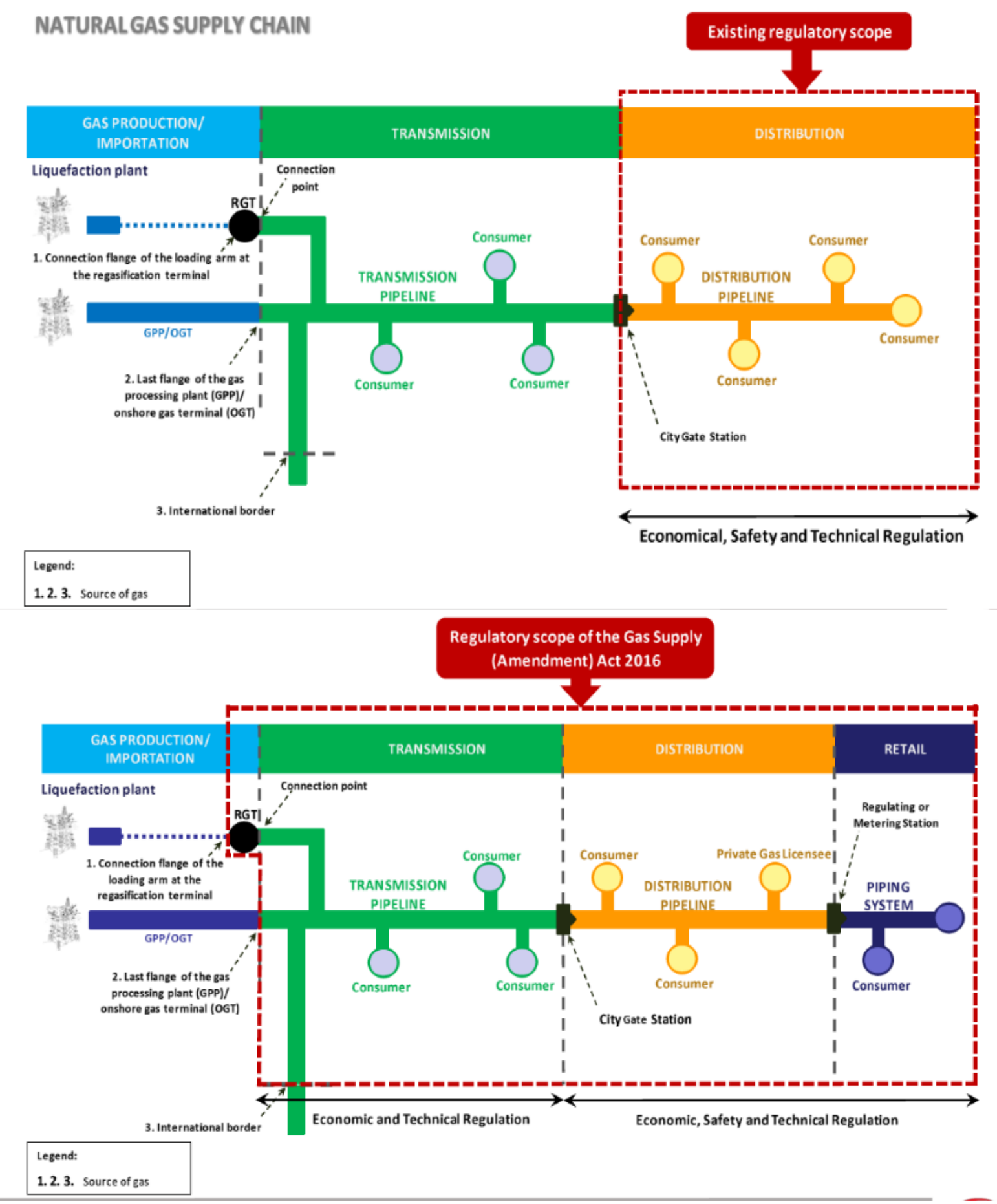

Source: EC (2017a) 


\subsection{Stakeholder interview questions}

\begin{tabular}{|c|c|}
\hline Subject matter & Questions \\
\hline $\begin{array}{l}\text { Government } \\
\text { objectives/policies }\end{array}$ & $\begin{array}{l}\text { 1. Do you think the liberalisation process will lead to major changes in } \\
\text { terms of competition and numbers of gas market participants? } \\
\text { 2. With the introduction of TPA, what are the next aims of the } \\
\text { government in relation to gas market competition and is the } \\
\text { government genuinely ready to see the role of PETRONAS reduced } \\
\text { throughout the value chain (for example upstream and downstream)? } \\
\text { 3. Does the government have any plan to further restructure the gas } \\
\text { industry (other initiatives besides TPA introduction)? For example, } \\
\text { separating the network(s) into different companies? } \\
\text { 4. How is security of gas supply defined if demand increases in future? } \\
\text { Are there any existing guidelines (e.g. Gas Supply Act } 1993 \text { (Act 501)) } \\
\text { that define long-term fuel security? }\end{array}$ \\
\hline $\begin{array}{l}\text { Legislation and } \\
\text { regulation }\end{array}$ & $\begin{array}{l}\text { 1. The role of the Energy Commission (EC) is to regulate the energy } \\
\text { sector, specifically the electricity and piped gas supply industries in } \\
\text { Peninsular Malaysia. How independent is the commission of the } \\
\text { government to take decisions? Is the EC solely responsible for setting } \\
\text { transportation tariffs, or does the government play a significant role? } \\
\text { 2. TPA system: } \\
\text { i. The TPA system has been established in law and by regulation, } \\
\text { but what is the current status of the system and participation of } \\
\text { new entrants under this system? If there has been no access to } \\
\text { the network by new players, what are the reasons and can we } \\
\text { expect that this will change soon? } \\
\text { ii. If no competition takes place under the TPA system, will the } \\
\text { regulator or government step in and change the rules? } \\
\text { iii. What charges are applied for new licence applications and are } \\
\text { these determined based on volume or fixed-price basis? }\end{array}$ \\
\hline Pricing and subsidy & $\begin{array}{l}\text { 1. How are the prices of gas to end-users determined (e.g. regulated, } \\
\text { subsidised or market determined depending on the type of end- } \\
\text { users)? What is the methodology for determining these prices, if } \\
\text { regulated? } \\
\text { 2. In your opinion, are companies other than PETRONAS allowed to } \\
\text { import gas or LNG and are there special terms for either activity? } \\
\text { 3. Who and how are gas imports and exports regulated? Are companies } \\
\text { other than PETRONAS allowed to import gas or LNG and are there } \\
\text { special terms for either activity? } \\
\text { 4. What is the methodology for determining the transmission tariffs } \\
\text { (offshore and onshore), processing charges and balancing charges? } \\
\text { 5. Is PETRONAS selling gas directly to you or are you buying via Gas } \\
\text { Malaysia Berhad? } \\
\text { 6. What do you think would happen if the government phased out gas } \\
\text { price subsidies for industry customers? } \\
\text { 7. With the introduction of TPA, are you planning to buy gas from new } \\
\text { players in the market? } \\
\text { 8. Do you think the liberalisation process will be successful in promoting } \\
\text { competition and new entrants? } \\
\text { 9. Are you ready to participate in the liberalised gas market in Malaysia? }\end{array}$ \\
\hline
\end{tabular}




\begin{tabular}{|c|c|}
\hline $\begin{array}{l}\text { Market entry and } \\
\text { dominance }\end{array}$ & $\begin{array}{l}\text { 1. Is there any evidence of short-term gas trading currently? What do you } \\
\text { think will happen in future? } \\
\text { 2. If yes, in which parts of the value chain of the gas market are new } \\
\text { companies allowed to participate? }\end{array}$ \\
\hline Infrastructure & $\begin{array}{l}\text { 1. Is there any gas processing capacity owned or operated } \\
\text { independently of PETRONAS (PETRONAS Gas Berhad's gas } \\
\text { processing plants)? } \\
\text { 2. Gas Supply (Amendment) } 2016 \text { Bill is expected to create equal } \\
\text { opportunities for gas importers and suppliers and issuance of } \\
\text { several activity-based licences that will allow holders to transport } \\
\text { gas through the Peninsular Gas Utilisation (PGU) pipeline. In future, } \\
\text { are there any plans to separate the networks into different } \\
\text { companies? } \\
\text { 3. Currently, the Natural Gas Distribution System (NGDS) is operated } \\
\text { by Gas Malaysia Berhad, where gas is piped to retail customers. Are } \\
\text { there any other system operators? If no, is there any plan to allow } \\
\text { separate operators in future? } \\
\text { 4. Have the network tariffs (connection and use of system charges) for } \\
\text { transmission and distribution networks begun to operate, for } \\
\text { example, is there actual third-party access, and what are the } \\
\text { volumes involved? Is the Network Code operating (as opposed to in } \\
\text { existence)? }\end{array}$ \\
\hline $\begin{array}{l}\text { Resources, exploration } \\
\text { and gas production }\end{array}$ & $\begin{array}{l}\text { 1. How are production and undeveloped reserves divided between } \\
\text { PETRONAS, IOCs and others? What is the share of PETRONAS } \\
\text { production compared with other producers? } \\
\text { 2. How long will gas and LNG exports continue and will this be } \\
\text { determined by domestic gas consumption, which has been growing } \\
\text { in recent years? } \\
\text { 3. What do you think will happen if liberalisation occurs and new players } \\
\text { participate in TPA? How long do you think the processes are going to } \\
\text { take to happen? }\end{array}$ \\
\hline New market players & $\begin{array}{l}\text { 1. Are you ready to participate in the liberalised gas market in } \\
\text { Malaysia? } \\
\text { 2. What you think will happen? Will competitive gas market happen } \\
\text { and who will be the new players? } \\
\text { 3. What is your opinion of the development of ASEAN LNG spot } \\
\text { market trade and are you likely to participate? }\end{array}$ \\
\hline $\begin{array}{l}\text { ASEAN LNG trading } \\
\text { and spot market }\end{array}$ & $\begin{array}{l}\text { 1. Will the anticipated 'glut' in the global LNG market happen and how } \\
\text { will it impact competition, spot LNG trade and the pricing market in } \\
\text { the region? } \\
\text { 2. How will the developments in the region (e.g. expansion of imports } \\
\text { and exports LNG trade, development of spot/hub prices in Asia, } \\
\text { especially JKM and Singapore sling price marker as alternatives to } \\
\text { JCC, Henry Hub/NBP pricing, development of LNG swaps) impact } \\
\text { the liberalisation process in Malaysia? } \\
\text { 3. How do you see the liberalisation process in Malaysia and the } \\
\text { potential impact of LNG spot trade on the Malaysian gas market? }\end{array}$ \\
\hline
\end{tabular}




\subsection{Definition of independent regulation in European Union ${ }^{46}$}

Directive 2003/55/EC introduced a requirement for the Member States in the EU to establish regulators with specific competences. However, experience shows that the effectiveness of regulation is frequently hampered through a lack of independence of regulator from government, and insufficient powers and discretion. Therefore, legislative proposals developed to provide for further harmonisation of the powers and strengthening of the independence of national energy regulators.

Member states shall guarantee the independence of the regulatory authority and shall ensure that it exercises its powers impartially and transparently. For this purpose, Member States shall ensure that, when carrying out the regulatory tasks conferred upon it:

'The energy regulators shall not seek or take direct instructions from any government or other public or private entity when carrying out the regulatory tasks. That requirement is without prejudice to close cooperation, as appropriate, with other relevant national authorities or to general policy guidelines issued by the government not related to the regulatory powers and duties.'

The regulatory authority can take autonomous decisions, independently from any political body, and has separate annual budget allocations, with autonomy in the implementation of the allocated budget, and adequate human and financial resources to carry out its duties:

- to issue penalties for discriminatory behaviour in favour of the vertically integrated undertaking

- to monitor communications between the transmission system operator and the vertically integrated undertaking so as ensure compliance of the transmission system operator with its obligations

- to act as dispute settlement authority between the vertically integrated undertaking and the transmission system operator in respect of any complaint.

Regulatory authorities shall have the authority to require transmission, storage, LNG and distribution system operators, if necessary, to modify the terms and conditions, including tariffs and methodologies to ensure that they are proportionate and applied in a non-discriminatory manner. Any party having a complaint against a transmission, storage, LNG or distribution system operator in relation to that operator's obligations may refer the complaint to the regulatory authority which, acting as dispute settlement authority, shall issue a decision within two months after the complaint.

\footnotetext{
${ }^{46}$ These are excerpts from, and a brief summary of, the regulatory provisions of the $3^{\text {rd }}$ EU Gas Directive. DIRECTIVE 2009/73/EC OF THE EUROPEAN PARLIAMENT AND OF THE COUNCIL of 13 July 2009 concerning common rules for the internal market in natural gas and repealing Directive 2003/55/EC, Official Journal of the European Union, L211/94, 14.8.2009, Articles 39-43.
} 
Table 13: Conversion - natural gas (NG) and liquefied natural gas (LNG) units

\begin{tabular}{|c|c|c|c|c|c|c|}
\hline From & $\Gamma$ & & & o & & 7 \\
\hline & $\begin{array}{l}\text { billion cubic } \\
\text { metres NG }\end{array}$ & $\begin{array}{l}\text { billion cubic } \\
\text { feet NG }\end{array}$ & $\begin{array}{l}\text { million tonnes } \\
\text { oil equivalent }\end{array}$ & $\begin{array}{c}\text { million } \\
\text { tonnes LNG }\end{array}$ & $\begin{array}{l}\text { trillion British } \\
\text { thermal units }\end{array}$ & $\begin{array}{l}\text { million barrels } \\
\text { oil equivalent }\end{array}$ \\
\hline & \multicolumn{2}{|l|}{$\Gamma$} & \multicolumn{2}{|c|}{ Multiply by } & & 7 \\
\hline 1 billion cubic metres NG & 1.000 & 35.315 & 0.860 & 0.735 & 34.121 & 5.883 \\
\hline 1 billion cubic feet NG & 0.028 & 1.000 & 0.024 & 0.021 & 0.966 & 0.167 \\
\hline 1 million tonnes oil equivalent & 1.163 & 41.071 & 1.000 & 0.855 & 39.683 & 6.842 \\
\hline 1 million tonnes LNG & 1.360 & 48.028 & 1.169 & 1.000 & 46.405 & 8.001 \\
\hline 1 trillion British thermal units & 0.029 & 1.035 & 0.025 & 0.022 & 1.000 & 0.172 \\
\hline 1 million barrels oil equivalent & 0.170 & 6.003 & 0.146 & 0.125 & 5.800 & 1.000 \\
\hline
\end{tabular}

Source: BP (2019) 